Prepared in cooperation with the U.S. Fish and Wildlife Service and the Bureau of Reclamation

Application of the Stream Salmonid Simulator (S3) to Klamath River Fall Chinook Salmon (Oncorhynchus tshawytscha), California-Parameterization and Calibration

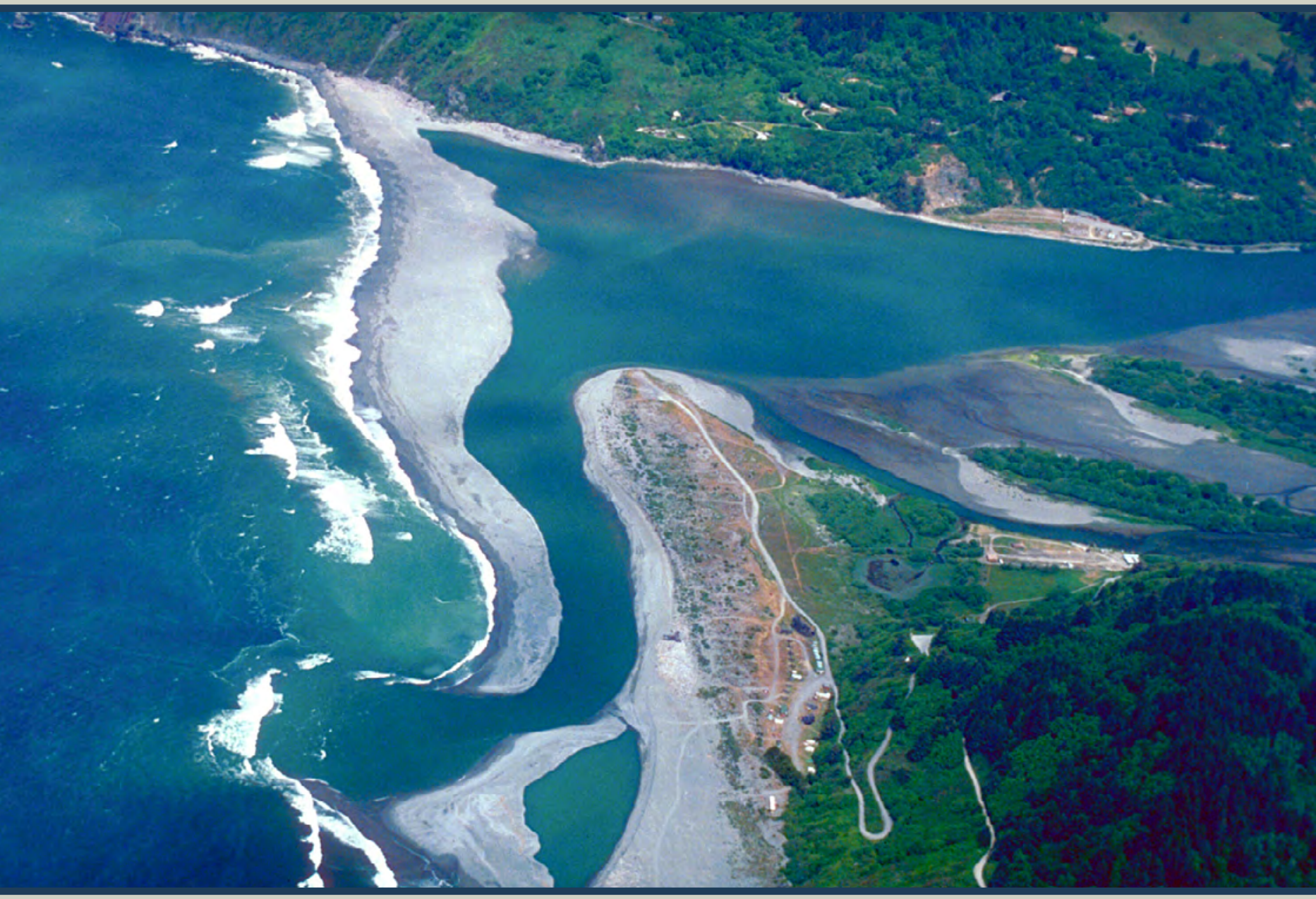

Open-File Report 2019-1107 
Cover: Mouth of the Klamath River at the Pacific Ocean, Del Norte County, California, looking north. Photograph by U.S. Army Corps of Engineers, 2007. 


\section{Application of the Stream Salmonid Simulator (S3) to Klamath River Fall Chinook Salmon (Oncorhynchus tshawytscha), California-Parameterization and Calibration}

By Russell W. Perry, John M. Plumb, Edward C. Jones, Nicholas A. Som, Thomas B. Hardy, and Nicholas J. Hetrick

Prepared in cooperation with the U.S. Fish and Wildlife Service and the Bureau of Reclamation

Open-File Report 2019-1107

U.S. Department of the Interior

U.S. Geological Survey 


\section{U.S. Department of the Interior \\ DAVID BERNHARDT, Secretary}

\section{U.S. Geological Survey \\ James F. Reilly II, Director}

U.S. Geological Survey, Reston, Virginia: 2019

For more information on the USGS-the Federal source for science about the Earth,

its natural and living resources, natural hazards, and the environment-visit

https://www.usgs.gov/ or call 1-888-ASK-USGS (1-888-275-8747).

For an overview of USGS information products, including maps, imagery, and publications, visit https://store.usgs.gov/.

The findings and conclusions in this report are those of the authors and do not necessarily represent the views of the U.S. Fish and Wildlife Service.

Any use of trade, firm, or product names is for descriptive purposes only and does not imply endorsement by the U.S. Government.

Although this information product, for the most part, is in the public domain, it also may contain copyrighted materials as noted in the text. Permission to reproduce copyrighted items must be secured from the copyright owner.

Suggested citation:

Perry, R.W., Plumb, J.M., Jones, E.C., Som, N.A., Hardy, T.B., and Hetrick, N.J., 2019, Application of the Stream Salmonid Simulator (S3) to Klamath River fall Chinook salmon (Oncorhynchus tshawytscha), CaliforniaParameterization and calibration: U.S. Geological Survey Open-File Report 2019-1107, 89 p., https://doi.org/10.3133/ofr20191107.

ISSN 2331-1258 (online) 


\section{Contents}

Executive Summary

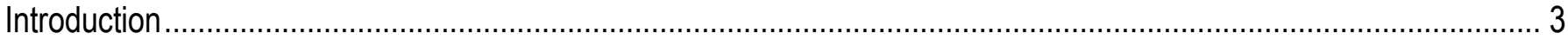

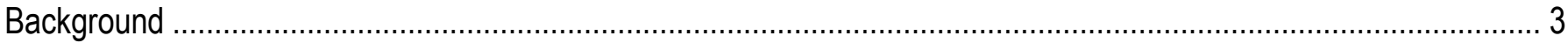

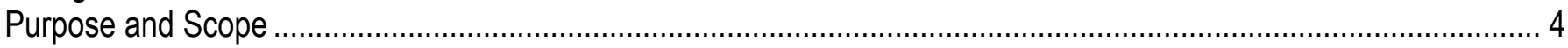

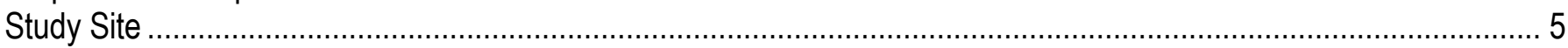

Methods

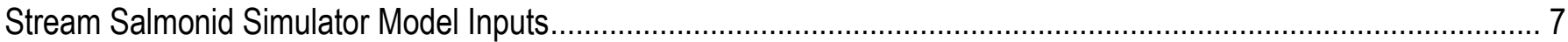

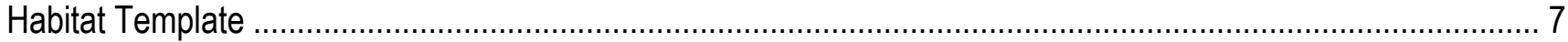

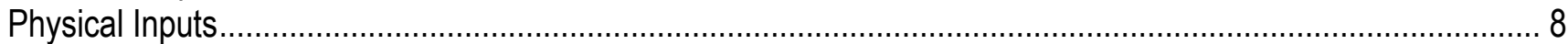

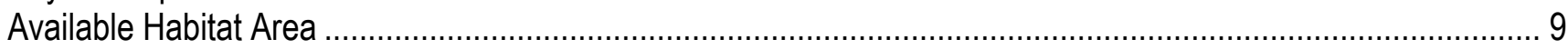

Habitat Modeling with Two-Dimensional Hydrodynamic Models ................................................................ 9

Extrapolating Weighted Usable Habitat Area from Two-Dimensional Models to Unmodeled Habitat Units.......19

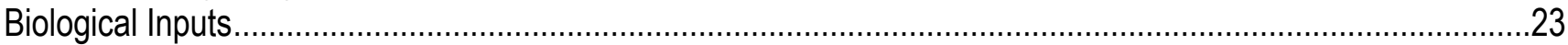

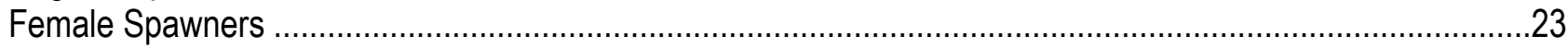

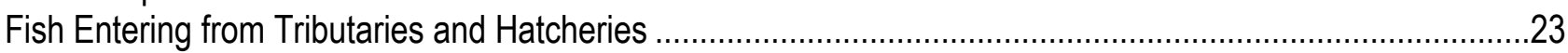

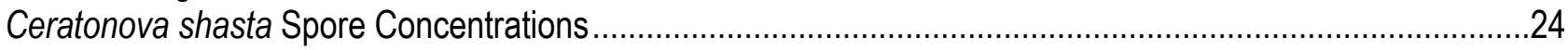

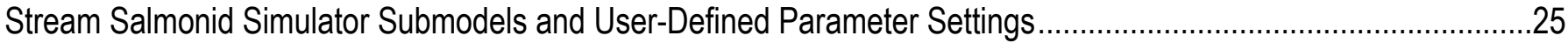

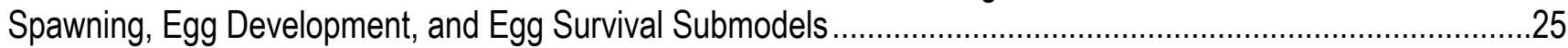

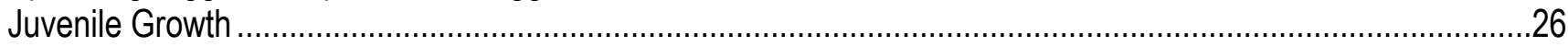

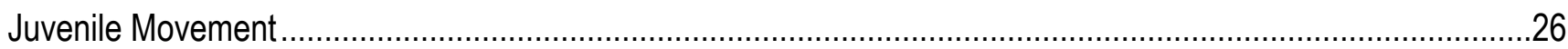

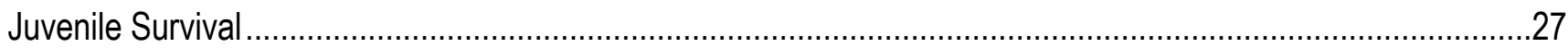

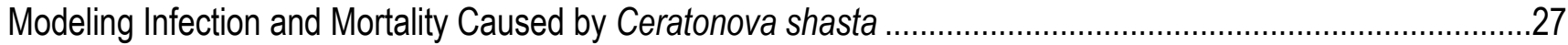

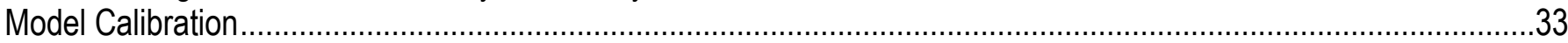

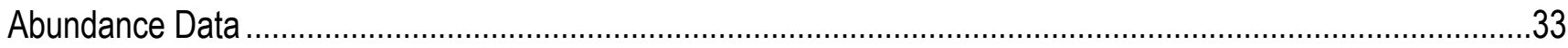

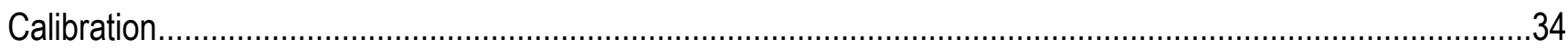

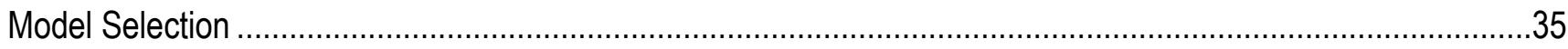

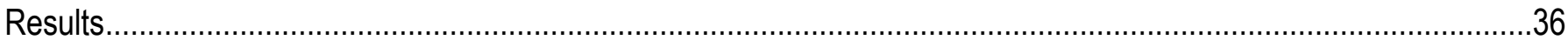

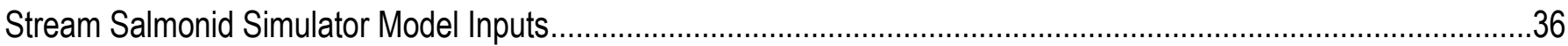

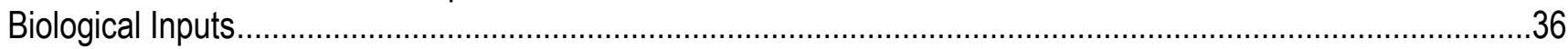

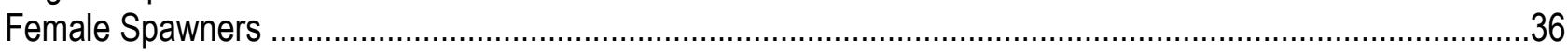

Juveniles from Tributary and Hatchery Sources ..............................................................................37

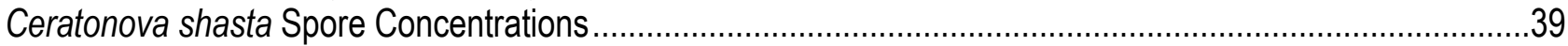

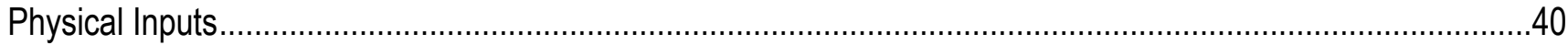

Egg-to-Fry Survival and Fry Emergence...............................................................................................4

Calibration, Model Selection, and Parameter Estimates...............................................................................46

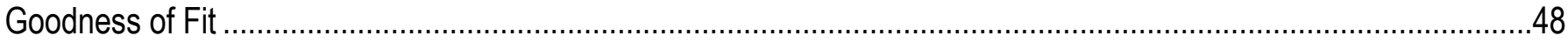

Simulated and Estimated Abundance ..................................................................................................

Simulated and Estimated Migration Timing..........................................................................................52

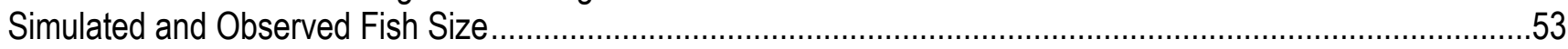

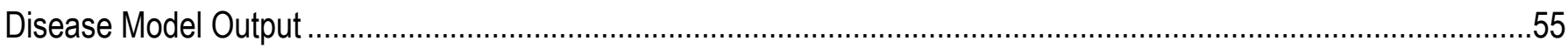

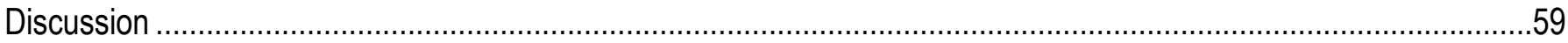

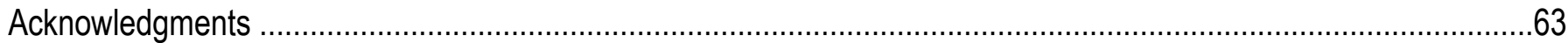

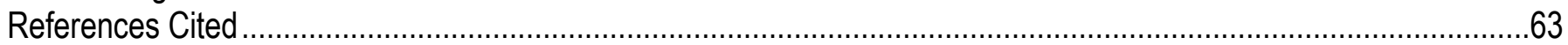

Appendix 1. Composite Two-Dimensional Weighted Usable Habitat Area Curves.....................................................67

Appendix 2. Fish Weight and Length Conversions ................................................................................68

Appendix 3. Estimating Mortality and Time to Death of Juvenile Chinook Salmon Exposed to Ceratonova shasta ....69 
Appendix 4. Comparison to I5 Trap with Parametric Bootstrap Confidence Limits ...................................................76

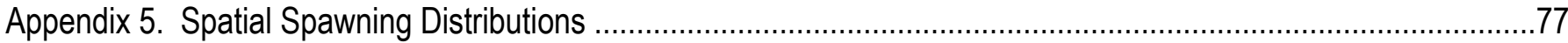

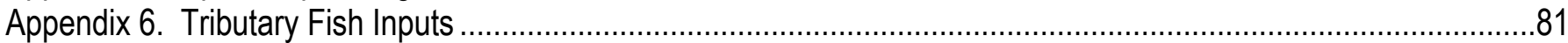

Appendix 7. Temporal Emergence Distributions .............................................................................................

\section{Figures}

Figure 1. Map showing locations of major tributaries, dams, the Kinsman fish trap, the Ceratonova shasta disease zone, and the eight locations used for two-dimensional hydrodynamic models, on the Klamath River, Oregon and California.

Figure 2. Schematic showing how two-dimensional (2D) hydrodynamic model was divided into discrete habitat units at the R Ranch 2D site, Klamath River, California.

Figure 3. Schematic showing how two-dimensional (2D) hydrodynamic model was divided into discrete habitat units, at the Trees of Heaven 2D site, Klamath River, California.

Figure 4. Schematic showing how two-dimensional (2D) hydrodynamic model was divided into discrete habitat units at the Brown Bear 2D site, Klamath River, California.

Figure 5. Schematic showing how two-dimensional (2D) hydrodynamic model was divided into discrete habitat units at the Seiad 2D site, Klamath River, California

Figure 6. Schematic showing how two-dimensional (2D) hydrodynamic model was divided into discrete habitat units, at the Rogers 2D site, Klamath River, California .

Figure 7. Schematic showing how two-dimensional (2D) hydrodynamic model was divided into discrete habitat units, at the Orleans 2D site, Klamath River, California

Figure 8. Schematic showing how two-dimensional (2D) hydrodynamic model was divided into discrete habitat units, at the Saints Bar 2D site, Klamath River, California....

Figure 9. Schematic showing how two-dimensional (2D) hydrodynamic model was divided into discrete habitat units, at the Pecwan 2D site, Klamath River, California.

Figure 10. Univariate habitat suitability curves for depth, velocity, and distance to cover fitted to presence-only observations of juvenile Chinook salmon fry and parr (and smolts) in the Klamath River, California, using methods of Som, Goodman, and others (2016).

Figure 11. Graphs showing the relation between discharge and channel width of habitat units at twodimensional (2D) sites for selected exceedance probabilities, on the Klamath River, California

Figure 12. Examples of scaling source weighted usable habitat area curves to target curves, for the Klamath River, California

Figure 13. Fitted regression model used to impute missing daily spore concentrations of Ceratonova shasta using water temperature for periods prior to 2009 for time periods when no spore data were collected, Klamath River, California, 2005-10.

Figure 14. Histogram showing mean annual fecundities for fall Chinook salmon returning to Iron Gate Dam, on the Klamath River, California, 1966-2014

Figure 15. Graphs showing cure component of the survival cure model for Chinook salmon fitted to sentinel trial data.

Figure 16. Survival cure model graphs showing probability of Chinook salmon surviving as a function of time since initial exposure over a range of water temperatures, exposure durations, and spore concentrations.......... 31

Figure 17. Graph showing spatial distribution of spawning female Chinook salmon used as inputs to the Stream Salmonid Simulator model for the Klamath River, California, brood year 2010

Figure 18. Graphs showing temporal distribution of weekly abundances of juvenile Chinook salmon entering the Klamath River by tributary source, California, migration year 2011

Figure 19. Daily time series of Ceratonova shasta spore concentration used in calibration of Stream Salmonid Simulator model for the Klamath River, California, 2005-13 
Figure 20. Time series of mean daily temperatures, by migration year, at the Kinsman fish trap, on the Klamath River, California, 2005 and 2007-13

Figure 21. Time series of mean daily river flows, by migration year, at the Kinsman fish trap, on the Klamath River, California, 2005 and 2007-13.

Figure 22. Graph showing spatial distribution of egg-to-fry survival for Chinook salmon in the Klamath River, California, brood year 2010

Figure 23. Graph showing spatial distribution of emerging Chinook salmon fry in the Klamath River, California, brood year 2010

Figure 24. Graph showing temporal distribution of Chinook salmon fry emergence in the Klamath River, California, brood year 2010

Figure 25. Graph showing effect of fish density on the daily probability of juvenile fall Chinook salmon moving downstream in the Klamath River, California

Figure 26. Graph showing annual abundance estimates for juvenile fall Chinook salmon that passed the Kinsman fish trap compared to those simulated by Stream Salmonid Simulator model, on the Klamath River, California, 2005 and 2007-13

Figure 27. Graphs showing weekly abundance estimates on the log and observed scales, for fall Chinook salmon that passed Kinsman fish trap compared to those simulated by the Stream Salmonid Simulator model, on the Klamath River, California, 2005 and 2007-13

Figure 28. Graph showing weekly abundance estimates (log-scale) for fall Chinook salmon that passed Kinsman fish trap and those simulated by the Stream Salmonid Simulator model, on the Klamath River, California, 2005-13.

Figure 29. Graphs showing estimated abundance of juvenile fall Chinook salmon passing the Kinsman fish trap, in the Klamath River, California, migration years 2005 and 2007-13

Figure 30. Graph showing 20th, 50th, and 80th percentiles in the migration dates for fall Chinook salmon that passed the Kinsman fish trap compared to those that were simulated by the Stream Salmonid Simulator model, in the Klamath River, California, 2005 and 2007-13.

Figure 32. Graphs showing simulated compared to observed fork length of fall Chinook salmon that passed the Kinsman fish trap, on the Klamath River, California, 2005 and 2007-13

Figure 33. Stacked bar charts showing simulated daily abundance of each source population of juvenile fall Chinook salmon passing the Kinsman trap and time series of daily spore concentrations, in the Klamath River, California, 2005 and 2007-13

Figure 34. Stacked bar charts showing simulated daily abundance of uninfected fish and juvenile fall Chinook salmon infected with Ceratonova shasta and time series of daily spore concentrations, in the Klamath River, California, 2005 and 2007-13.

Figure 35. Graphs showing spatial distribution of juvenile fall Chinook salmon mortality owing to Ceratonova shasta, in the Klamath River, California, 2005 and 2007-13 


\section{Tables}

Table 1. Summary of data sources used to quantify habitat units in the pre-dam Klamath River upstream of Iron Gate Dam, Oregon and California

Table 2. River reaches included in the RBM10 water temperature model that lie within the Klamath River, Oregon and California.

Table 3. Location of spawning survey reaches used as input for the number spawners that are allocated to each habitat unit in Stream Salmonid Simulator, for the Klamath River, California

Table 4. Parameter estimates of the survival cure model fitted to data from the extended sentinel experiment and selected low-spore trials analyzed by Ray and others (2014)

Table 5. Candidate Stream Salmonid Simulator models that were fit to weekly estimated abundances at the Kinsman fish trap on the Klamath River, California.

Table 6. Abundance and timing of female Chinook salmon spawning between Iron Gate Dam and Kinsman fish trap by migration year, Klamath River, California, 2004 and 2006-12 ...

Table 7. Total abundance estimates of juvenile Chinook salmon entering the main-stem Klamath River, California, and used as inputs to the Stream Salmonid Simulator model, 2005 and 2007-13.

Table 8. Summary statistics for mean daily temperatures at the Kinsman fish trap from November 1 of a brood year to August 31 of the following juvenile migration year, on the Klamath River, California, 2005 and 2007-13.

Table 9. Summary statistics for mean daily river flows at the Kinsman fish trap from November 1 of a brood year to August 31 of the following juvenile migration year, on the Klamath River, California, 2005 and 2007-13 ...... 42 Table 10. Percentile dates of emergence timing for simulated juvenile Chinook salmon, by migration year, from Iron Gate Dam to Kinsman fish trap, on the Klamath River, California, 2005 and 2007-13

Table 11. Model-selection results based on Akaike's Information Criterion for small samples, showing number of parameters, negative log-likelihood, and the relative difference of candidate Stream Salmonid Simulator models fit to weekly abundance estimates at the Kinsman fish trap, for the Klamath River, California

Table 12. Parameter estimates for the four Stream Salmonid Simulator candidate models that expressed survival and movement parameters as constant between fry and parr life stages, for the Klamath River,California. .. 47 Table 13. Parameter values for the four Stream Salmonid Simulator candidate models that expressed survival and movement parameters separately between fry and parr life stages, for the Klamath River, California 


\section{Conversion Factors}

U.S. customary units to International System of Units

\begin{tabular}{lcl}
\hline \multicolumn{1}{c}{ Multiply } & \multicolumn{1}{c}{ By } & \multicolumn{1}{c}{ To obtain } \\
\hline & \multicolumn{1}{c}{ Length } & \\
\hline inch (in.) & 2.54 & $\begin{array}{l}\text { centimeter }(\mathrm{cm}) \\
\text { millimeter }(\mathrm{mm})\end{array}$ \\
inch (in.) & 25.4 & \\
\hline \multicolumn{2}{c}{ Area } & hectare (ha) \\
\hline square mile $\left(\mathrm{mi}^{2}\right)$ & 259.0 & square kilometer $\left(\mathrm{km}^{2}\right)$ \\
square mile $\left(\mathrm{mi}^{2}\right)$ & 2.590 & \\
\hline & Flow rate & meter per second $(\mathrm{m} / \mathrm{s})$ \\
foot per second $(\mathrm{ft} / \mathrm{s})$ & 0.3048 & cubic meter per second $\left(\mathrm{m}^{3} / \mathrm{s}\right)$ \\
cubic foot per second $(\mathrm{ft} / \mathrm{s})$ & 0.02832 &
\end{tabular}

International System of Units to U.S. customary units

\begin{tabular}{|c|c|c|}
\hline Multiply & By & To obtain \\
\hline \multicolumn{3}{|c|}{ Length } \\
\hline meter $(\mathrm{m})$ & 3.281 & foot $(\mathrm{ft})$ \\
\hline millimeter (mm) & 0.03937 & inch (in.) \\
\hline kilometer $(\mathrm{km})$ & 0.6214 & mile (mi) \\
\hline \multicolumn{3}{|c|}{ Area } \\
\hline square meter $\left(\mathrm{m}^{2}\right)$ & 10.76 & square foot $\left(\mathrm{ft}^{2}\right)$ \\
\hline \multicolumn{3}{|c|}{ Volume } \\
\hline liter $(\mathrm{L})$ & 0.2642 & gallon (gal) \\
\hline \multicolumn{3}{|c|}{ Travel rate/spread } \\
\hline meter per second $(\mathrm{m} / \mathrm{s})$ & 3.281 & foot per second (ft/s) \\
\hline kilometer per day (km/d) & 0.6214 & mile per day (mi/d) \\
\hline square kilometer per day $\mathrm{km}^{2} / \mathrm{d}$ & 0.3861 & square mile per day $\left(\mathrm{mi}^{2} / \mathrm{d}\right)$ \\
\hline \multicolumn{3}{|c|}{ Mass } \\
\hline $\operatorname{gram}(\mathrm{g})$ & 0.03527 & ounce, avoirdupois (oz) \\
\hline
\end{tabular}

Temperature in degrees Celsius $\left({ }^{\circ} \mathrm{C}\right)$ may be converted to degrees Fahrenheit $\left({ }^{\circ} \mathrm{F}\right)$ as follows:

$$
{ }^{\circ} \mathrm{F}=\left(1.8 \mathrm{x}^{\circ} \mathrm{C}\right)+32
$$




\author{
Abbreviations \\ AIC Akaike's Information Criterion \\ $\mathrm{AIC}_{\mathrm{c}} \quad$ Akaike's Information Criterion corrected for small sample size \\ DNA deoxyribonucleic acid \\ FL fork length \\ GLM generalized linear model \\ HSC Habitat suitability criteria \\ KBRA Klamath Basin Restoration Agreement \\ KHSA Klamath Hydroelectric Settlement Agreement \\ LS low slope \\ MS moderate slope \\ PIT Passive Integrated Transponder \\ qPCR quantitative polymerase chain reaction \\ rkm river kilometer \\ $\mathrm{R}^{2} \quad$ coefficient of determination \\ SS steep slope \\ S3 Stream Salmonid Simulator \\ 2D two dimensional \\ WUA weighted usable habitat area
}




\section{Application of the Stream Salmonid Simulator (S3) to Klamath River Fall Chinook Salmon (Oncorhynchus tshawytscha), California-Parameterization and Calibration}

By Russell W. Perry ${ }^{1}$, John M. Plumb르, Edward C. Jones ${ }^{1}$, Nicholas A. Som², Thomas B. Hardy ${ }^{3}$, and Nicholas J. Hetrick²

\section{Executive Summary}

In this report, we describe application of the Stream Salmonid Simulator (S3) to Chinook salmon (Oncorhynchus tshawytscha) in the Klamath River between Keno Dam in southern Oregon and the ocean in northern California. S3 is a deterministic life-stage-structured population model that tracks daily growth, movement, and survival of juvenile salmon. It can track different source populations or species, such as major tributary populations that enter a river like the Klamath River. A key theme of the model is that river flow affects habitat availability and capacity, which in turn drives density-dependent population dynamics. To explicitly link population dynamics to habitat quality and quantity, the river environment is constructed as a one-dimensional series of linked habitat units, each of which has an associated daily time series of discharge, water temperature, and useable habitat area or carrying capacity. In turn, the physical characteristics of each habitat unit and the number of fish occupying each unit affect survival and growth within each habitat unit and movement of fish among habitat units.

The physical template of the Klamath River was formed by classifying the river into 2,635 mesohabitat units composed of runs, riffles, and pools. This template enabled modeling of the unimpounded Klamath River between the Keno Dam (the uppermost of four dams) and Iron Gate Dam (the lowermost dam) to address dam-removal scenarios. However, in this report, our focus was on parameterizing and calibrating the model under existing conditions, which included 1,706 discrete habitat units over the 312-kilometer $(\mathrm{km})$ section of river between Iron Gate Dam and the ocean. For each habitat unit, we developed a time series of daily flow, water temperature, and amount of available habitat (weighted usable habitat area [WUA]) for spawners, fry, and parr. WUA time series were constructed using habitat suitability criteria for Chinook salmon applied to eight two-dimensional (2-D) hydrodynamic models that represented the geomorphic variability in habitat across the Klamath River. Results from the 2-D models were then extrapolated to unmodeled habitat units by scaling WUA curves for changes in habitat unit length and width. These variables were then used to drive population dynamics such as egg development and survival and juvenile movement, growth, and survival.

\footnotetext{
${ }^{1}$ U.S. Geological Survey

${ }^{2}$ U.S. Fish and Wildlife Service

${ }^{3}$ Texas State University
} 
Over the past 15 years, management has focused on the effects of the myxozoan parasite Ceratonova shasta on juvenile pacific salmon (Oncorhynchus spp.). C. shasta has a complex life cycle with two obligate hosts - the polychaete worm (Manayunkia speciosa) and pacific salmon - and a freeliving spore stage (actinospores) that infects and can cause disease in juvenile salmon. To model the effects of $C$. shasta on juvenile salmon, we developed a disease submodel that simulated (1) the probability of becoming infected and eventually dying from C. shasta, and (2) the time between initial exposure and death of infected fish. This disease model was driven by (1) a time series of actinospore concentrations measured from water samples collected in the Klamath River since 2005, (2) duration of exposure to actinospores, and (3) water temperature. We noted that different source populations of salmon had different exposure profiles to $C$. shasta resulting from population-level differences in migration timing and proximity of tributaries to the area known as the highly infectious zone.

Additionally, by simulating the lag time between exposure and time of death, we reported that most of the mortality due to $C$. shasta occurred in the lower Klamath River well downstream of the infectious zone.

We estimated key movement and survival parameters by calibrating the model to 8 years of weekly juvenile abundance estimates from juvenile salmon trapping efforts in the Klamath River at Kinsman Creek, $78 \mathrm{~km}$ downstream of Iron Gate Dam. The calibration consisted of replicating historical conditions as closely as possible (for example, flow, temperature, spawner abundance, spawning location and timing, hatchery releases, and juveniles entering from tributaries), and then running the model to predict weekly abundance passing the trap location. We also evaluated alternative model structures that included either density-independent movement and survival, density-dependent survival, or density-dependent movement. Akaike's Information Criterion model-selection criterion was used to evaluate the strength of evidence for alternative model structures to match the observed abundance estimates.

Model selection indicated that the model with density-dependent movement was better supported by the data than density-dependent survival or density-independent movement and survival. Parameter estimates indicated that fry and parr increased their probability of movement as the number of fish per WUA approached an estimated capacity of 52.8 fish per WUA. Given that the model was initialized with only the spatiotemporal distribution of spawners and juveniles entering from tributaries, it performed well at capturing the essential outmigration features that are ultimately governed by rates of growth, movement, and mortality. Although the fit to the data was not perfect, the model generally matched observed weekly abundance, migration timing, and size of juvenile outmigrants. The model closely predicted annual abundance in six of eight calibration years, but considerably underpredicted juvenile abundance for the 2012 brood (during 2013, the year of highest abundance).

The S3 model integrates biological and physical characteristics over the entire temporal and spatial freshwater residency of juvenile salmonid populations. By doing so, it can provide valuable insights into how fish production may change in response to management actions in the Klamath River such as dam removal, flow management, disease management, or optimization of hatchery releases. Combinations of system attributes (for example, physical habitat, hydrographs) subject to manipulation by managers can be translated into scenarios that form the inputs to S3 model runs. The S3 model can provide expected outcomes for these scenarios and information about the relative effects of management actions on the abundance, size, and run timing of juvenile Chinook salmon. These predictions, in turn, will inform management decisions to maximize joint benefits to Klamath River water users and salmon populations. 


\section{Introduction}

\section{Background}

Many anadromous salmonid populations along the West Coast of North America have declined substantially over the past century owing partly to construction of dams for flood control, hydroelectricity, and domestic and agricultural water development. In river systems that support anadromous salmonid populations, flow regulation can influence water quality; water temperature; and the magnitude, timing, and variability of daily discharge. These alterations to the river environment, in turn, influence the productivity of anadromous salmonid habitat and populations. Water management in regulated river systems, therefore, often seeks to balance human uses of water with maintenance and recovery of anadromous salmonid populations.

The Klamath Basin of northern California and southern Oregon has been the source of considerable controversy over the past century owing to competition for water resources. Effects of this competition on Chinook salmon (Oncorhynchus tshawytscha), Coho salmon (Oncorhynchus kisutch), and steelhead (Oncorhynchus mykiss) in the basin have been substantial and include truncated fish distributions below impassable dams. Resource managers have for decades relied on detailed habitat and population models to aid in understanding effects of water management decisions on salmon populations in the part of the Klamath River Basin below these dams (Williamson and others, 1993; Bartholow, 1996; Hardy and others, 2006).

Recent substantial changes in Klamath River management options and improved understanding of salmon ecology within the basin have created a need for better quantitative models to help inform decision-makers. For example, the lower four hydroelectric dams on the river have been considered for removal. In 2010, the Klamath Basin stakeholders came together to sign the Klamath Hydroelectric Settlement Agreement (KHSA) (Klamath Hydroelectric Settlement Agreement, 2016) and the Klamath Basin Restoration Agreement (KBRA) (Klamath Basin Restoration Agreement, 2010). In the agreements, the Basin stakeholders agreed to move toward removal of the lower four hydroelectric dams (J.C. Boyle, Copco 1, Copco 2, and Iron Gate Dams) on the Klamath River owned by PacifiCorp, with removal of the dams scheduled for 2020. Because of the KBRA and KHSA agreements, the U.S. Secretary of the Interior, in cooperation with the U.S. Secretary of Commerce and other Federal agencies, was tasked with deciding on alternative management actions about whether dams should remain in place or be removed (U.S. Department of the Interior, 2013).

More recently, research and management have focused on the effects of the myxozoan parasite Ceratonova shasta on juvenile pacific salmon (Oncorhynchus spp.). C. shasta has a complex life cycle with two obligate hosts - the polychaete worm (Manayunkia speciosa) and pacific salmon. Conceptual models have been developed to outline how water management and environmental factors affect $C$. shasta and its hosts (Foott and others, 2011) To understand how to manage water to reduce disease, research has focused on habitat requirements of polychaetes (Alexander and others, 2016), spatial and temporal trends in C. shasta spore concentrations (Hallett and others, 2012), the prevalence of infection of juvenile salmonids with $C$. shasta (Som, Hetrick, and others, 2016), and mortality caused by $C$. shasta (Ray and others, 2014). Results of this research have helped refine quantitative models useful in estimating the effects of river discharge and other environmental conditions on the incidence of $C$. shasta infection in juvenile salmon and on resultant fish mortality. 
following:

Key questions related to ongoing water and fish management in the Klamath River include the

- How does management of daily river flows affect production of juvenile salmon in reaches downstream of the dam?

- How do daily dam operations influence habitat quantity and quality, and, in turn, affect juvenile salmon movement, growth, and survival?

- How does disease caused by C. shasta, a myxozoan parasite, influence infection and mortality of juvenile salmon?

- How do past, present, and future habitat restoration alternatives (for example, dam removal) influence juvenile salmon production?

- How can water temperatures best be managed to minimize mortality and maximize growth of juvenile salmon?

To provide resource managers with a tool for understanding how various management actions affect juvenile salmon populations, we developed the Stream Salmonid Simulator (S3), a dynamic simulation model that mimics growth, movement, and survival of juvenile salmonid populations in streams and rivers (Perry and others, 2018a). The S3 model is based in concept on SALMOD, a fish production model with a long history in the Klamath Basin (Bartholow and others, 1993; Williamson and others, 1993; Bartholow, 1996; Bartholow and others, 2002). The underlying basis of SALMOD is that daily flows influence the amount of habitat available to different salmonid life stages, and that the amount of habitat influences density-dependent processes that affect fish production. In developing S3, our goal was to retain the essential ideas behind SALMOD (for example, linking fish habitat to production), but to reinvent the modeling framework to:

- Develop a more rigorous mathematical basis for spatially explicit population dynamics in a riverine environment,

- Update movement models to incorporate recent advances in modeling juvenile salmon migration,

- Implement more mechanistic growth models parameterized for anadromous salmonids of interest, and

- Implement the model in an open-source modeling platform.

The S3 model was first applied to the restoration reach of the Trinity River downstream of Lewiston Dam (Perry and others, 2018b).

\section{Purpose and Scope}

The purpose of this report is to describe application of the S3 model to the Klamath River between Keno Dam and the ocean. Because future analyses will involve simulating the response of salmon populations to dam removal, we constructed this version of the S3 model to include the unimpounded reaches of the river upstream of Iron Gate Dam. However, this report emphasizes model calibration to observed juvenile abundance data, and, therefore, focuses most heavily on model simulations downstream of Iron Gate Dam. The report details model construction, parameterization, and 
calibration. In it, we evaluate how well the production of juvenile Chinook salmon predicted by S3 compares to observed data. The report is presented as a companion to Perry and others (2018a), which describes the general model structure and submodels common to applications of S3 to Chinook salmon in the Klamath and Trinity Rivers.

\section{Study Site}

The Klamath River originates in and to the east of the Cascade Mountains of southern Oregon and flows through northern California to the Pacific Ocean. Its headwaters are fed by underground springs; the Williamson, Wood, and Sprague Rivers; and Lake Ewauna (fig. 1). Historically, water flowed from Upper Klamath Lake into Lower Klamath Lake by way of the Link River and Lake Ewauna before making its descent to the Pacific Ocean (Weddell, 2000). Lower Klamath Lake was drained in the early part of the 20th century for conversion to agricultural uses, and a part of that land is now managed as a refuge for waterfowl and other wetland-dependent species. Discharge from Upper Klamath Lake is controlled by the Link River Dam.

The Klamath River Basin covers more than $12,000 \mathrm{mi}^{2}$ and is divided into two subbasins (upper and lower) at Iron Gate Dam. The upper basin area includes parts of Klamath County in Oregon, and Siskiyou and Modoc Counties in California. The lower basin area includes parts of the Siskiyou, Modoc, Trinity, Humboldt, and Del Norte Counties in California. The Klamath River Basin is unlike most watersheds and has a unique geomorphology opposite of that present in most other drainage basins. It has been called "a river upside down" by the National Geographic Society (Rymer, 2008). Much of the upper Oregon section of the basin is flat and open, in comparison to the narrow canyons and mountainous terrain present in the lower California section of the basin.

The upper Klamath River Basin lies in the rain shadow of the Cascade Range on the west, the Deschutes River Basin on the north, the Great Basin on the east, and the Pit River Basin on the south. The upper basin consists of mostly agriculture and rangeland with areas of pine forest and semi-arid high desert plateaus, and is characterized by low relief, volcanic geology with an average annual precipitation of 34.89 in. (California Rivers Assessment, 2011). The lower Klamath River Basin is mostly forested except for areas of agriculture and rangeland in the drainages of the Scott and Shasta Rivers. The basin is dominated by a steep, rugged, complex terrain, and alluvial reaches. Average annual precipitation for the lower basin is 79.62 in. (California Rivers Assessment, 2011).

In this report, we describe construction of the $\mathrm{S} 3$ for the Klamath River between Keno Dam and the ocean. This section of the Klamath River is impounded by four large dams that are being considered for removal in 2020 (U.S. Department of Interior, 2013). The farthest dam upstream is Keno Dam (river kilometer [rkm] 378.2) and the farthest dam downstream, Iron Gate Dam (rkm 312; fig. 1), blocks the migration of anadromous salmon to the upper basin. The river downstream of Iron Gate Dam is critical habitat used by several anadromous salmonids, including spring and fall run Chinook salmon (Oncorhynchus tshawytscha), Coho Salmon (Oncorhynchus kisutch), and Steelhead Trout (Oncorhynchus mykiss). Additionally, multiple tributaries contribute water and juvenile Chinook salmon to the main-stem Klamath River. The largest of these tributaries are Bogus Creek (rkm 311.6), the Shasta River (rkm 289.6), the Scott River (rkm 232.8), the Salmon River (rkm 107.5), and the Trinity River (rkm 70.6). 


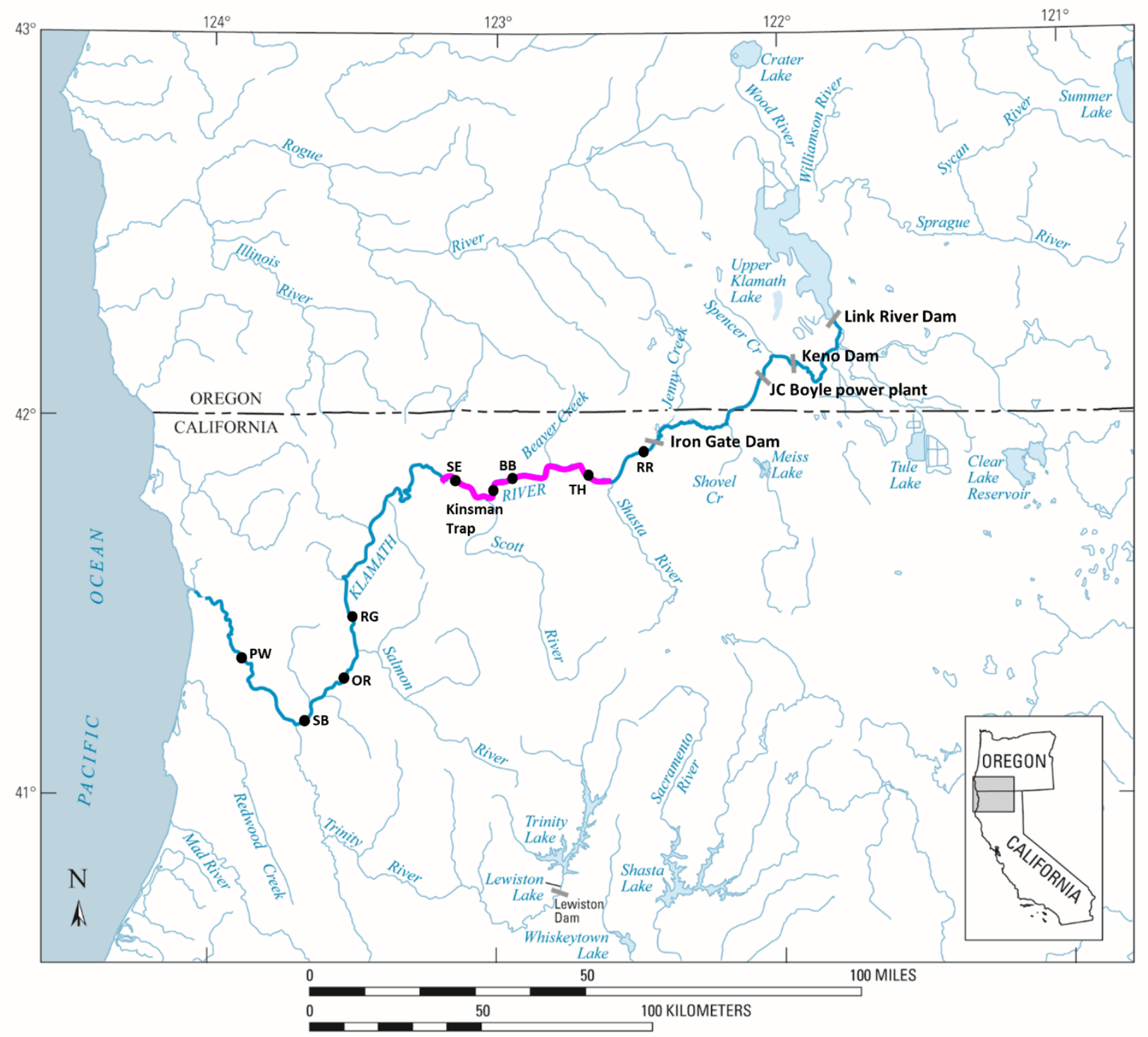

Figure 1. Map showing locations of major tributaries, dams, the Kinsman fish trap, the Ceratonova shasta disease zone (thick pink line), and the eight locations used for two-dimensional hydrodynamic models (RR, R Ranch; $\mathrm{TH}$, Trees of Heaven; BB, Brown Bear; SE, Seiad; RG, Rogers; OR, Orleans; SB, Saints Bar; PW, Pecwan), on the Klamath River, Oregon and California.

\section{Methods}

We apply herein the S3 simulation model to juvenile Chinook salmon in the Klamath River. First, we present methods for construction of the habitat template, estimation of the usable habitat area, and development of the physical and biological inputs used by S3. Second, we briefly describe growth, movement, survival, and disease submodels, detailing values we used for user-defined parameter 
settings. Third, we define a set of candidate models to test hypotheses about the mechanism by which density dependence affects population dynamics. Finally, we describe methods for model calibration and parameter estimation, along with the model-selection criteria we use to identify which candidate model best fits observed abundance estimates.

\section{Stream Salmonid Simulator Model Inputs}

\section{Habitat Template}

The spatial domain of the S3 model is defined by a one-dimensional series of discrete habitat units. Habitat units are spatially referenced by their upstream and downstream boundaries measured as the distance in river kilometers from the ocean. The length of a habitat unit is simply the difference between its upstream and downstream boundaries.

In total, the Klamath S3 model comprises 2,635 habitat units between Keno Dam and the ocean. Habitat unit boundaries were defined either by field surveys for reaches downstream of Iron Gate Dam (Hardy and others, 2006; Hardy and Shaw, 2011) or by historical aerial imagery or river maps of the unimpounded pre-dam riverbed upstream of Iron Gate Dam (Hardy and Shaw, 2011). Both habitat assessment efforts were done for the purposes of parameterizing SALMOD (Bartholow and others, 2002), and we took advantage of this existing dataset for constructing the S3 habitat template.

Within the 312-km section of river between Iron Gate Dam and the ocean, 1,706 discrete habitat units were identified, and each were classified as a specific mesohabitat type (MHT). Habitat units for the Lower Klamath River between Iron Gate Dam and the ocean were demarcated and classified during field surveys in 1997 and 2000 (Hardy and others, 2006; Hardy and Shaw, 2011). Habitat surveys consisted of two catarafts, each carrying a rower and observer, with units classified from an upstreamto-downstream direction with three channel configurations defined: main channel, split channel, and side-channels. Visual features of the river were used to classify individual MHTs and included gradient, active-channel confinement, surface disturbance, width-to-depth ratio, substrate composition, and the presence or absence of backwaters associated with hydraulic controls. The survey team identified three dominant gradient types for classifying MHTs: low-slope, moderate-slope, and steep-slope habitat units. Furthermore, habitat units also were classified into the habitat type of pools, split channels, and side channels.

When a habitat unit had a mixture of mesohabitat types (for example, a pool with a section of low slope along one bank), then both dominant and subdominant MHTs were recorded, with the dominant MHT classification being used for all data analyses. However, side channels and split channels were further divided into sub-units, with sub-units assigned to either the main channel, side channel, or split channel. Further detail is available in Hardy and Shaw (2011).

In the 55-km section of river between Keno Dam and Iron Gate Dam, the pre-dam unimpounded riverbed was divided into 929 habitat units. Hardy and Shaw (2011) used a variety of data sources to demarcate and classify habitat units in the pre-dam river upstream of Iron Gate Dam, including Google Earth $^{\mathrm{TM}}$ imagery, existing habitat surveys, historical pre-dam aerial photography, and survey maps of the riverbed. These data sources were used to measure and classify habitat units using the same classification scheme as for the field surveys conducted downstream of Iron Gate Dam. Data sources used for each river section are listed in table 1; further details are available in Hardy and Shaw (2011). 
Table 1. Summary of data sources used to quantify habitat units in the pre-dam Klamath River upstream of Iron Gate Dam (river kilometer 312), Oregon and California.

[Further detail is available in Hardy and Shaw (2011). Upstream boundary: Distance from mouth of Klamath River at Pacific Ocean, in river kilometers]

\begin{tabular}{|c|c|c|}
\hline Reach description & Data source & $\begin{array}{c}\text { Upstream boundary } \\
\text { (river kilometer) }\end{array}$ \\
\hline $\begin{array}{l}\text { Unimpounded reach downstream of Keno } \\
\text { Dam }\end{array}$ & Google Earth $^{\mathrm{TM}}$. & 378.2 \\
\hline J.C. Boyle Reservoir & Pre-dam historical photography. & 370.2 \\
\hline $\begin{array}{l}\text { Unimpounded reach downstream of J.C. } \\
\text { Boyle Dam }\end{array}$ & $\begin{array}{l}\text { Existing habitat survey conducted by } \\
\text { PacifiCorp. }\end{array}$ & 360.6 \\
\hline Copco Reservoir & 1912 engineering survey & 334.3 \\
\hline $\begin{array}{l}\text { Unimpounded reach downstream of } \\
\text { Copco Number } 2 \text { Dam }\end{array}$ & Existing habitat survey conducted by PacifiCorp & 325.1 \\
\hline Iron Gate Reservoir & Pre-dam historical photography. & 322.8 \\
\hline
\end{tabular}

\section{Physical Inputs}

The S3 model requires two physical inputs that drive population dynamics either directly or indirectly: (1) water temperature, and (2) stream flow. Daily temperatures dictate biological rates of development such as maturation of eggs in the gravel, growth of juveniles after emergence, and disease susceptibility and mortality owing to C. shasta. River discharge affects available habitat, and in turn, density dependent dynamics. The S3 model requires flow and temperature inputs as a time series of daily mean water temperature (in degrees Celsius and daily mean discharge (in cubic feet per second) for discrete reaches of the modeled spatial extent. For water temperature, we used the RBM10 water temperature model (Perry and others, 2011) and output water temperatures at 20 locations (table 2). River flows were constructed from gaged tributary inputs, and accretions for ungagged tributaries were estimated by apportioning unassigned gaged flows of the Klamath River in proportion to the watershed area of ungaged tributaries. Daily flow and temperature were assumed constant between output locations and then mapped to each habitat unit in S3 to create a daily time series for each habitat unit.

Table 2. River reaches included in the RBM10 water temperature model that lie within the Klamath River, Oregon and California.

[Distance to dam: Distance in river kilometers from upstream boundary of the river reach to the Iron Gate Dam]

\begin{tabular}{lcc}
\hline \multicolumn{1}{c}{ River reach } & $\begin{array}{c}\text { Length } \\
\text { (kilometers) }\end{array}$ & $\begin{array}{c}\text { Distance to dam } \\
\text { (river kilometer) }\end{array}$ \\
\hline Iron Gate Dam to Bogus Creek & 0.6 & 0.6 \\
Bogus Creek to Willow Creek & 7.3 & 7.3 \\
Willow Creek to Cottonwood Creek & 5.6 & 12.9 \\
Cottonwood Creek to Shasta River & 8.9 & 21.8 \\
Shasta River to Humbug Creek & 9.1 & 30.9 \\
Humbug Creek to Beaver Creek & 17.1 & 47.9 \\
Beaver Creek to Dona Creek & 13.0 & 60.9 \\
Dona Creek to Horse Creek & 9.3 & 70.2 \\
Horse Creek to Scott River & 8.4 & 78.6 \\
Scott River to Seiad Valley & 23.6 & 102.1 \\
$\quad$ streamgage & &
\end{tabular}




\begin{tabular}{lcc}
\hline \multicolumn{1}{c}{ River reach } & $\begin{array}{c}\text { Length } \\
\text { (kilometers) }\end{array}$ & $\begin{array}{c}\text { Distance to dam } \\
\text { (river kilometer) }\end{array}$ \\
\hline Seiad Valley streamgage to Indian & 33.9 & 136.0 \\
$\quad$ Creek & 1.9 & 137.9 \\
Indian Creek to Elk Creek & 11.7 & 149.5 \\
Elk Creek to Clear Creek & 54.3 & 203.9 \\
Clear Creek to Salmon River & 11.0 & 214.8 \\
Salmon River to Orleans & 12.4 & 227.2 \\
Orleans to Red Cap Creek & 3.9 & 231.1 \\
Red Cap Creek to Bluff Creek & 9.8 & 240.9 \\
Bluff Creek to Trinity River & 45.3 & 286.2 \\
Trinity River to Blue Creek & 11.6 & 297.8 \\
Blue Creek to Klamath & 13.7 & 311.4 \\
Klamath to Estuary & & \\
\hline
\end{tabular}

\section{Available Habitat Area}

Inputs required for the S3 model include relations between discharge and the amount of suitable habitat for each habitat unit in the model domain. To quantify available habitat area for each habitat unit, we use an extrapolation procedure that scaled weighted usable habitat area (WUA) curves constructed from two-dimensional (2D) hydrodynamic models for eight distinct geomorphic reaches of the Klamath River to each habitat unit of the S3 model domain. The eight hydrodynamic models were located throughout the lower Klamath River to represent the range of available habitats and channel types (fig. 1). The habitat units from the habitat survey described in the previous section were crossreferenced to the 2D hydrodynamic model sites, and 82 unique habitat units intersected the domain of the 2D hydrodynamic models (figs. 2-9). Unique habitat types for each 2D model site were assigned a unique code, and these habitat type codes were then assigned to each of the 2,635 habitat units that composed the S3 model domain. The habitat codes from the 2D hydrodynamic models formed a library of modeled WUA relations that could be assigned to unmodeled habitat units on the basis of geomorphic similarity between modeled and unmodeled habitat units. These assignments were made by consensus by a team of fish habitat experts from the U.S. Fish and Wildlife Service, U.S. Geological Survey, and Texas State University. See Hardy and Shaw (2011) for more detail on assignment of 2D habitat types to unmodeled units and Hardy and others (2006) for more detail on the hydrodynamic models.

\section{Habitat Modeling with Two-Dimensional Hydrodynamic Models}

Given the few-to-many mapping of 2D habitat units to all habitat units in S3, the first step was to develop WUA curves for each of the 82 unique habitat units in the 2D hydraulic models. WUA curves were generated as follows:

1. Run 2D hydraulic models over a range of river flows.

2. For each computational cell in the model, calculate univariate habitat suitability criteria (HSC) for different life stages:

a. For spawning habitat, HSC was based on water velocity and depth using methods of Hardy and others (2006).

b. For fry and parr habitat, HSC was based on distance to nearest cover, water velocity, and depth using the methods of Som, Goodman, and others (2016; fig. 10). 
3. Compute the geometric mean of the univariate HSCs.

4. Estimate the WUA for each habitat unit as the product of the computational cell surface area and geometric mean HSC, summed over all cells within each habitat unit.

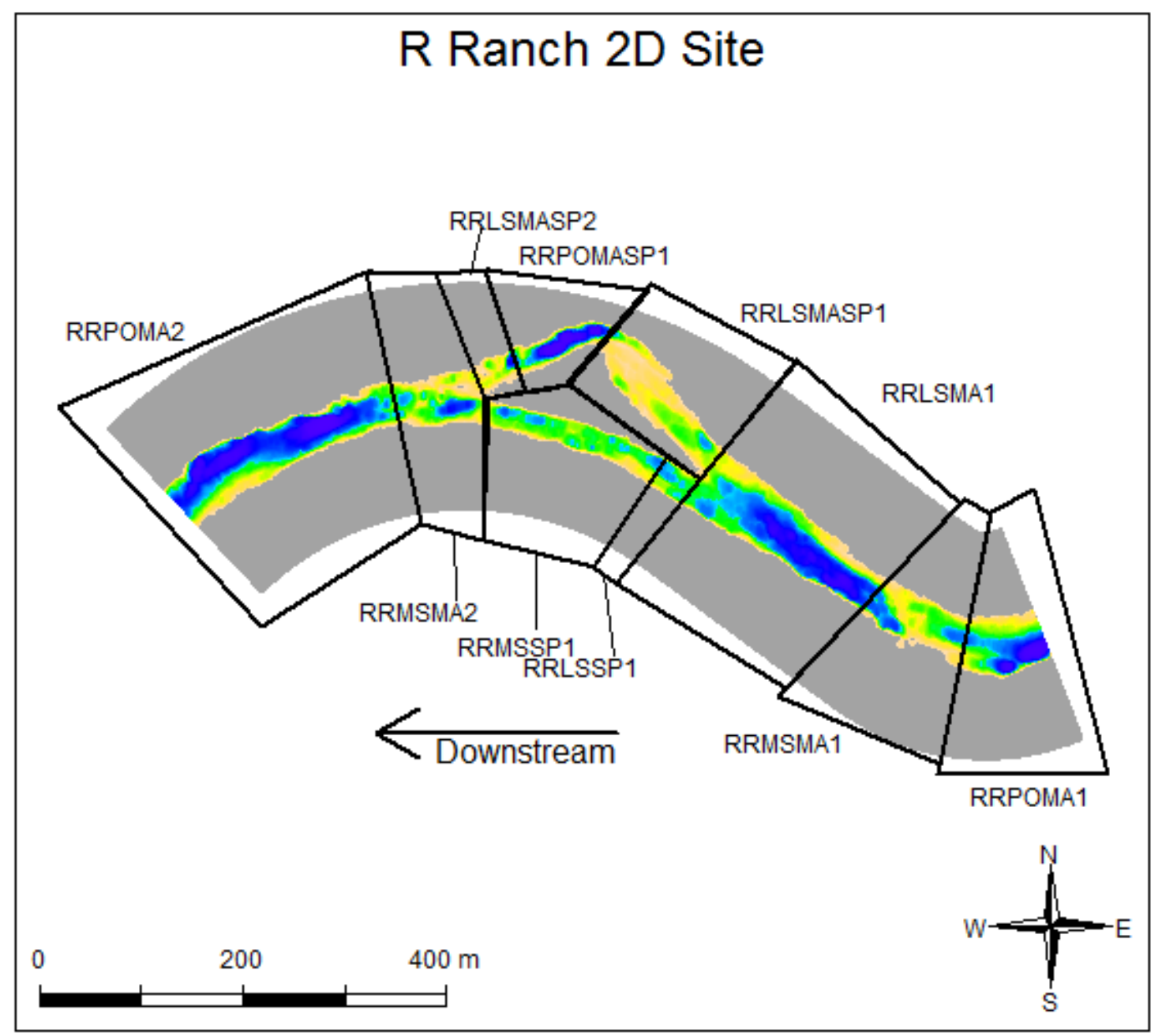

Figure 2. Schematic showing how two-dimensional (2D) hydrodynamic model was divided into discrete habitat units at the R Ranch 2D site, Klamath River, California. Shaded contours show water depth, with blue representing deeper regions and yellow representing shallower regions. Habitat types were coded as follows: RR, R Ranch 2D site; PO, pool; LS, low slope; MS, moderate slope; MA, main channel; SP, split channel. Numbers after habitat types indicate replicate habitat types within the same 2D model site. m, meter. 


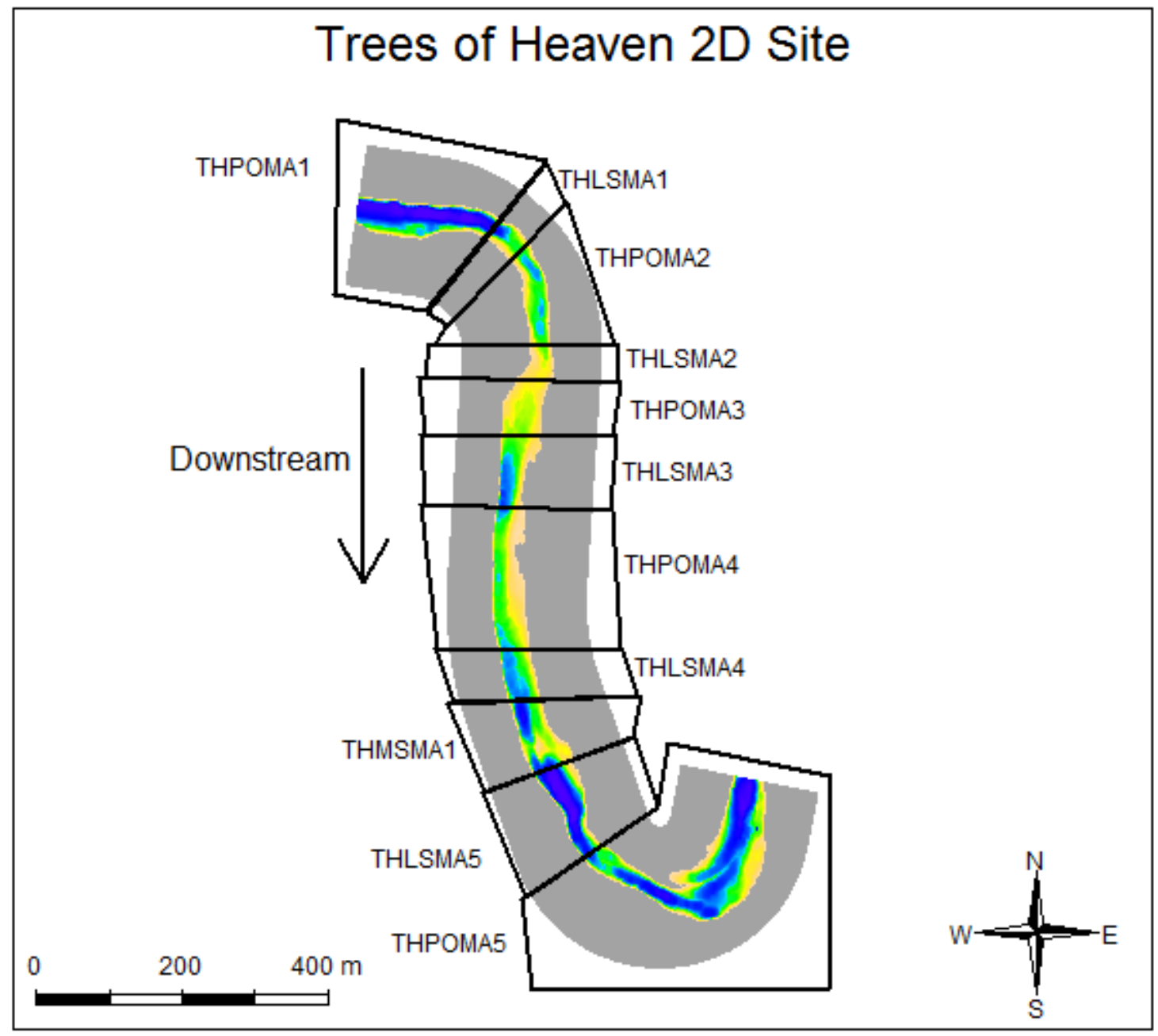

Figure 3. Schematic showing how two-dimensional (2D) hydrodynamic model was divided into discrete habitat units, at the Trees of Heaven 2D site, Klamath River, California. Shaded contours show water depth, with blue representing deeper regions and yellow representing shallower regions. Habitat types were coded as follows: TH, Trees of Heaven 2D site; PO, pool; LS, low slope; MS, moderate slope; MA, main channel. Numbers after habitat types indicate replicate habitat types within the same $2 \mathrm{D}$ model site. $\mathrm{m}$, meter. 


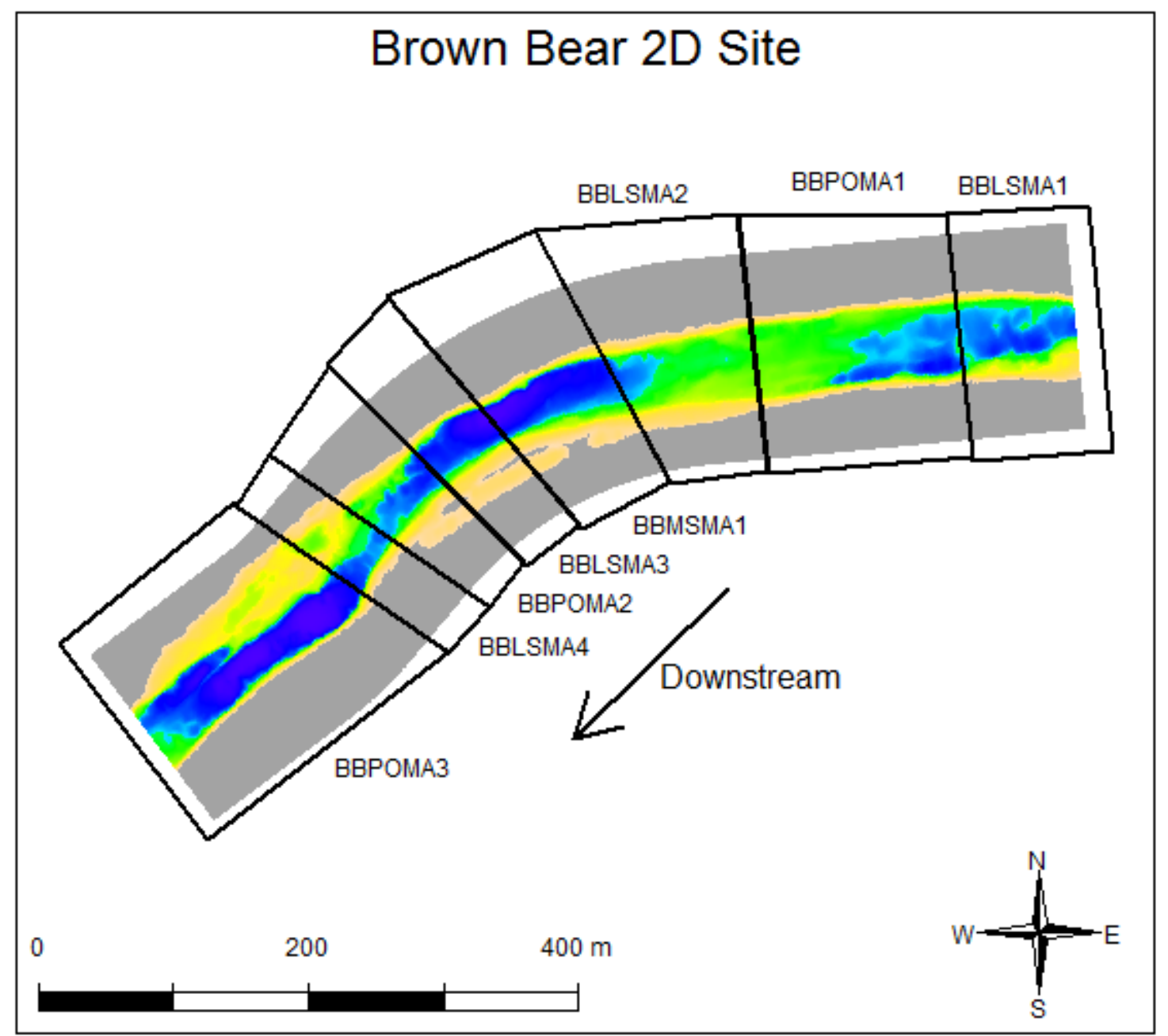

Figure 4. Schematic showing how two-dimensional (2D) hydrodynamic model was divided into discrete habitat units at the Brown Bear 2D site, Klamath River, California. Shaded contours show water depth, with blue representing deeper regions and yellow representing shallower regions. Habitat types were coded as follows: BB, Brown Bear 2D site; PO, pool; LS, low slope; MS, moderate slope; MA, main channel. Numbers after habitat types indicate replicate habitat types within the same $2 \mathrm{D}$ model site. $\mathrm{m}$, meter. 


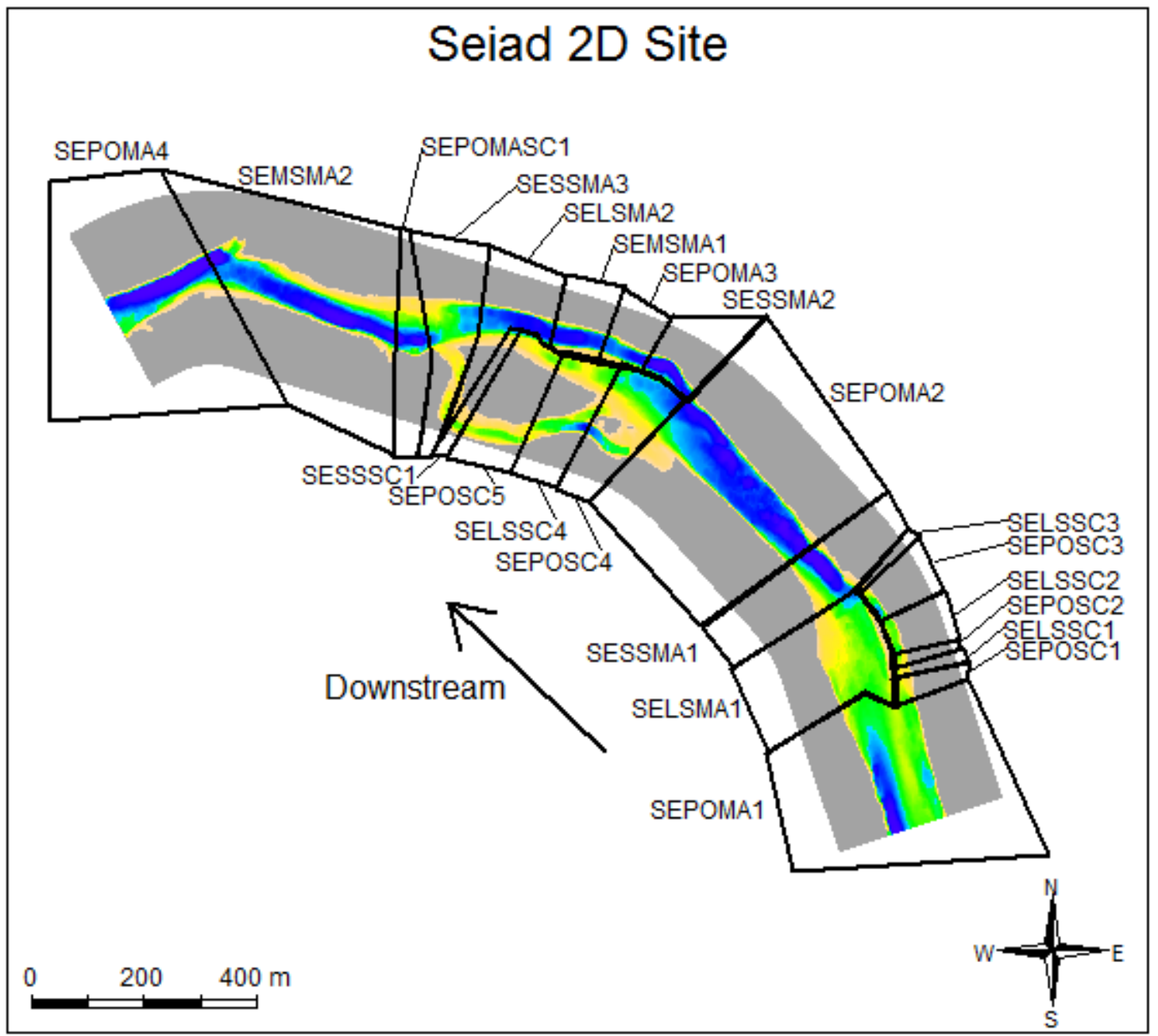

Figure 5. Schematic showing how two-dimensional (2D) hydrodynamic model was divided into discrete habitat units at the Seiad 2D site, Klamath River, California. Shaded contours show water depth, with blue representing deeper regions and yellow representing shallower regions. Habitat types were coded as follows: SE, Seiad 2D site; PO, pool; LS, low slope; MS, moderate slope; SS, steep slope, MA, main channel; SC, side channel. Numbers after habitat types indicate replicate habitat types within the same 2D model site. $\mathrm{m}$, meter. 


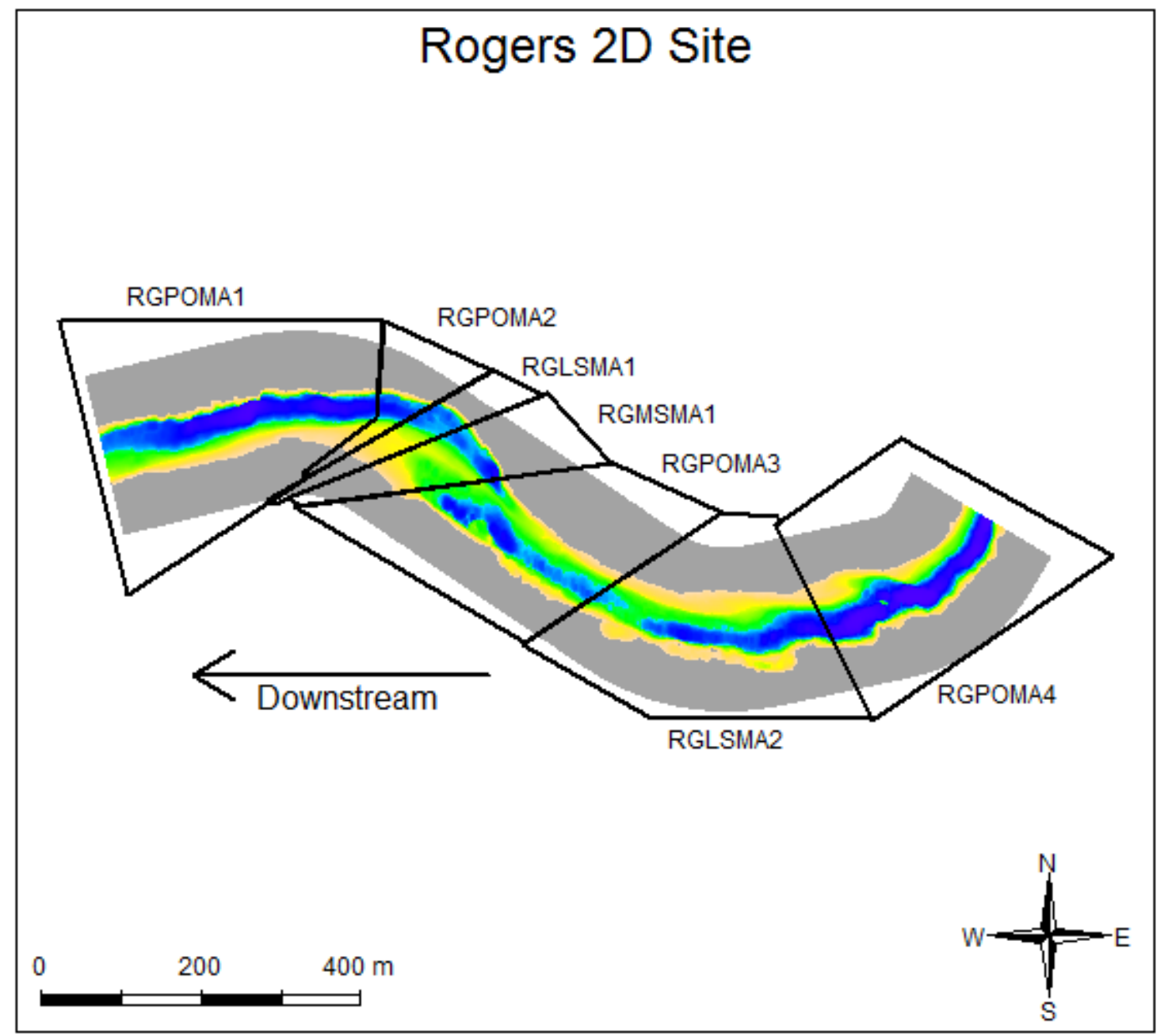

Figure 6. Schematic showing how two-dimensional (2D) hydrodynamic model was divided into discrete habitat units, at the Rogers 2D site, Klamath River, California. Shaded contours show water depth, with blue representing deeper regions and yellow representing shallower regions. Habitat types were coded as follows: RG, Rogers 2D site; PO, pool; LS, low slope; MS, moderate slope; MA, main channel. Numbers after habitat types indicate replicate habitat types within the same $2 \mathrm{D}$ model site. $\mathrm{m}$, meter. 


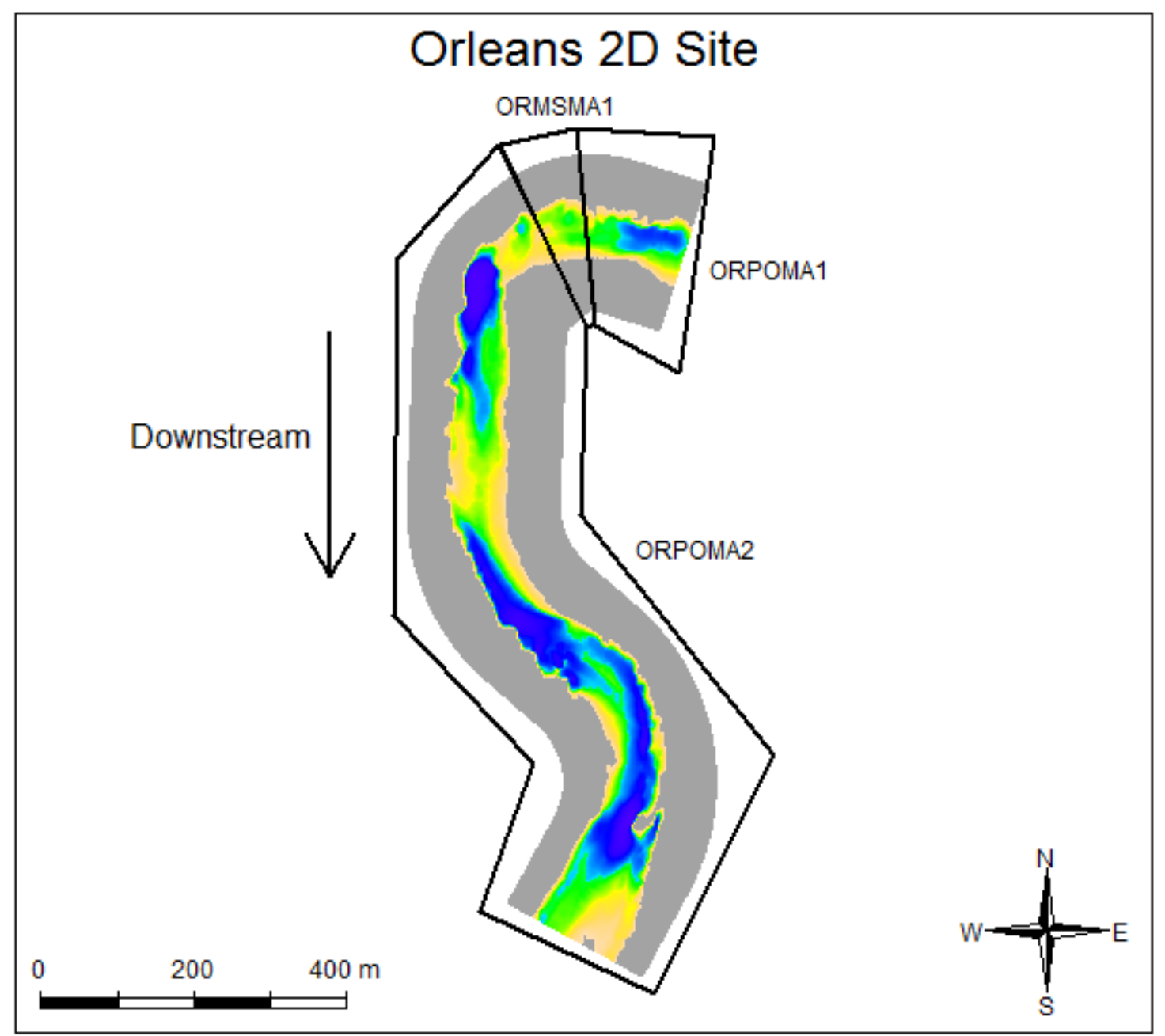

Figure 7. Schematic showing how two-dimensional (2D) hydrodynamic model was divided into discrete habitat units, at the Orleans 2D site, Klamath River, California. Shaded contours show water depth with blue representing deeper regions and yellow representing shallower regions. Habitat types were coded as follows: OR, Orleans 2D site; PO, pool; MS, moderate slope; MA, main channel. Numbers after habitat types indicate replicate habitat types within the same $2 \mathrm{D}$ model site. $\mathrm{m}$, meter. 


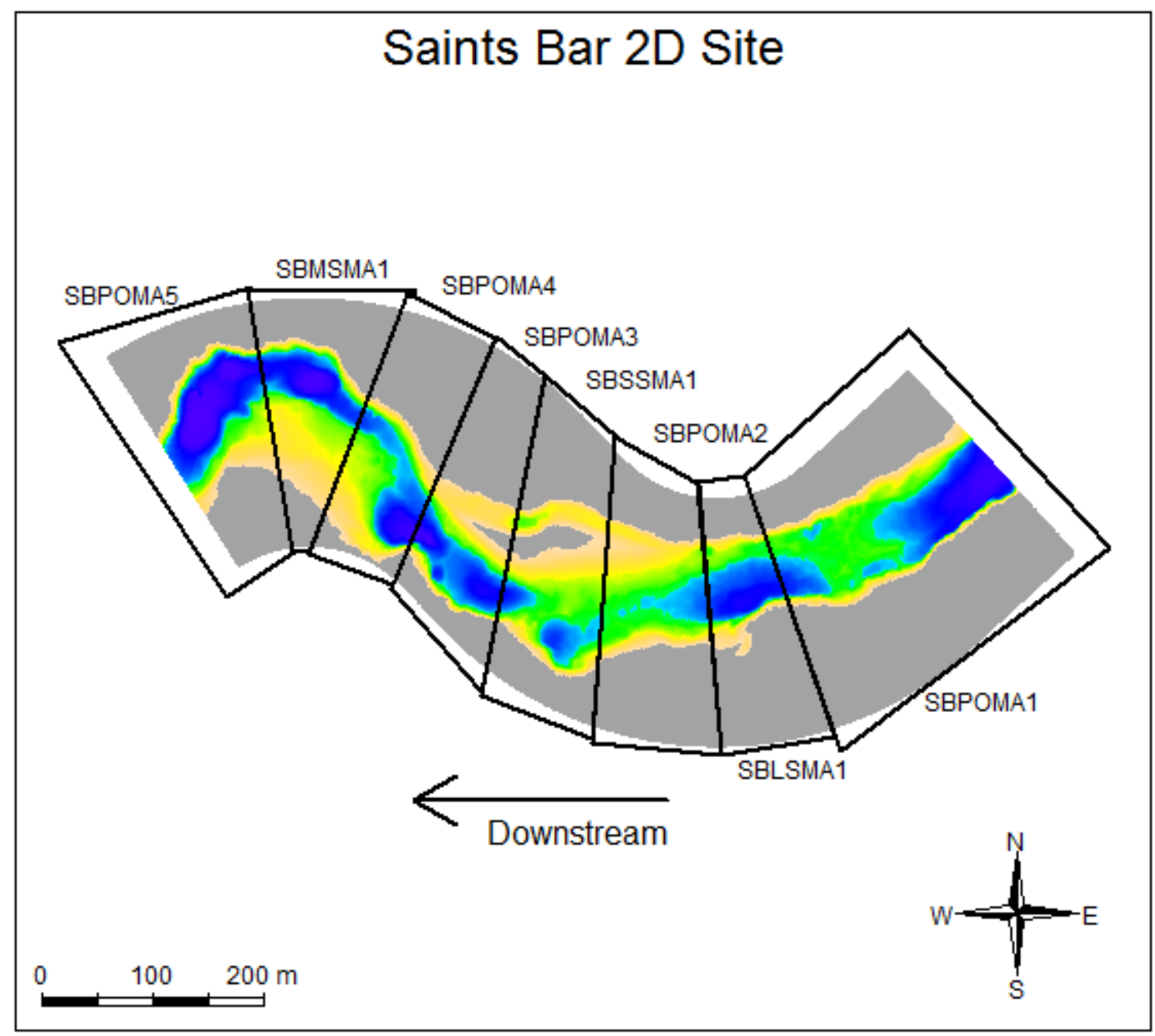

Figure 8. Schematic showing how two-dimensional (2D) hydrodynamic model was divided into discrete habitat units, at the Saints Bar 2D site, Klamath River, California. Shaded contours show water depth with blue representing deeper regions and yellow representing shallower regions. Habitat types were coded as follows: SB, Saints Bar 2D site; PO, pool; LS, low slope; MS, moderate slope; SS, steep slope; MA, main channel. Numbers after habitat types indicate replicate habitat types within the same 2D model site. $\mathrm{m}$, meter. 


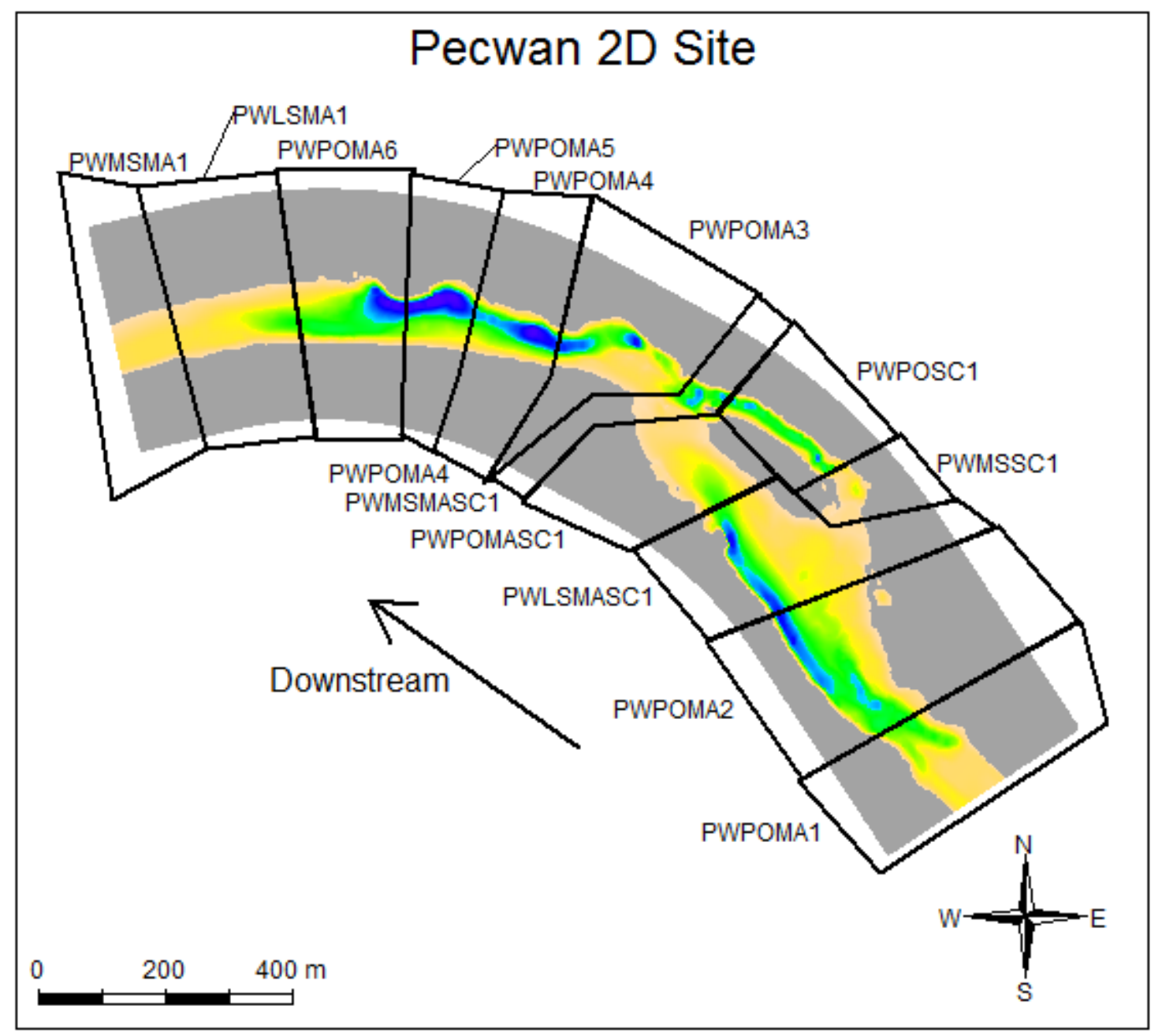

Figure 9. Schematic showing how two-dimensional (2D) hydrodynamic model was divided into discrete habitat units, at the Pecwan 2D site, Klamath River, California. Shaded contours show water depth with blue representing deeper regions and yellow representing shallower regions. Habitat types were coded as follows: PW, Pecwan 2D site; PO, pool; LS, low slope; MS, moderate slope; SS, steep slope; MA, main channel; SC, side channel. Numbers after habitat types indicate replicate habitat types within the same 2D model site. $\mathrm{m}$, meter. 


\section{Fry}
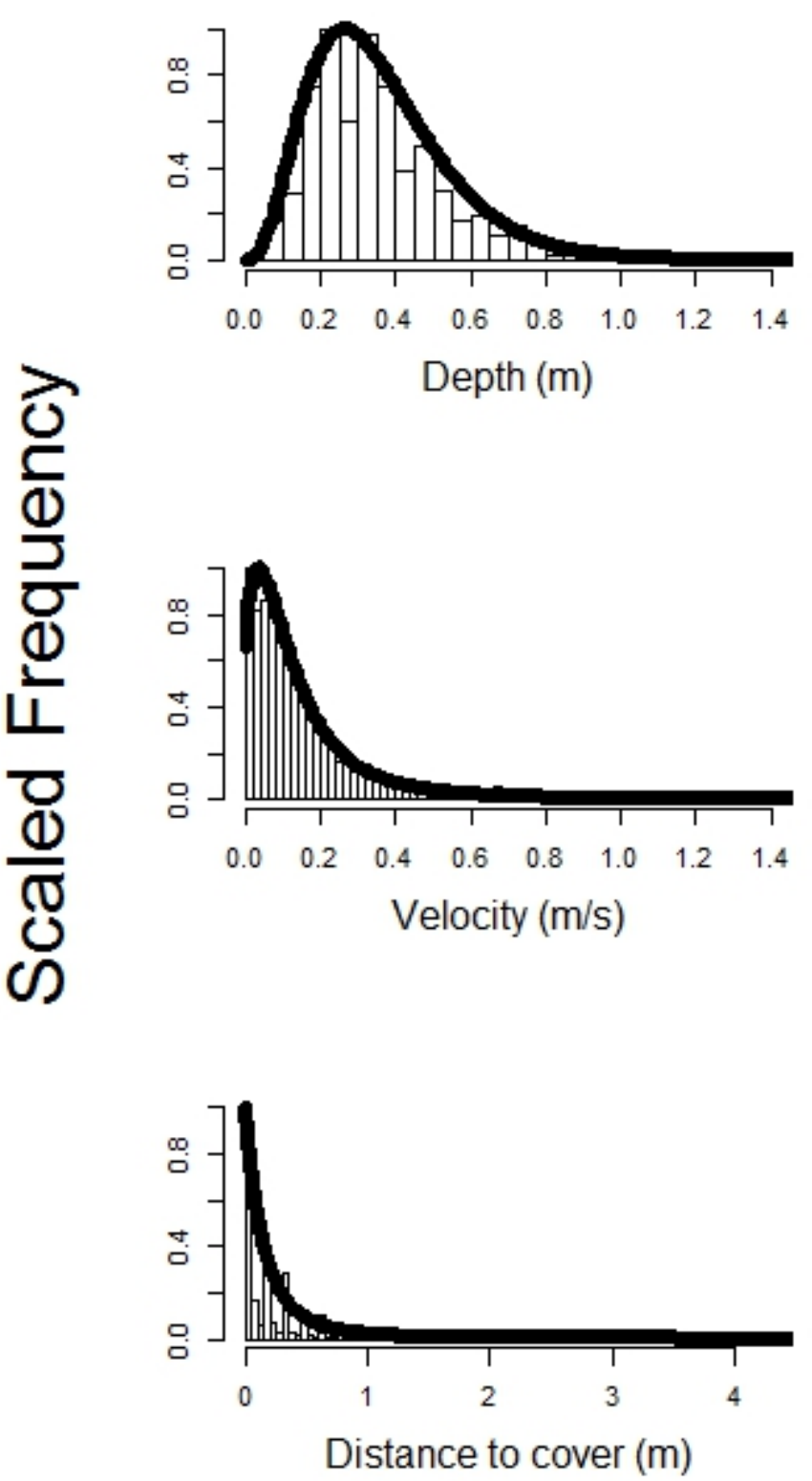

Parr

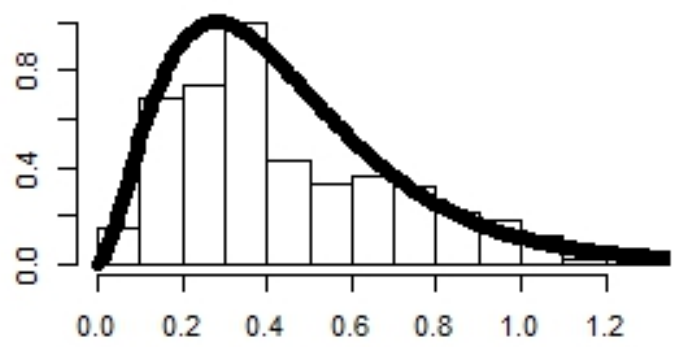

Depth $(m)$
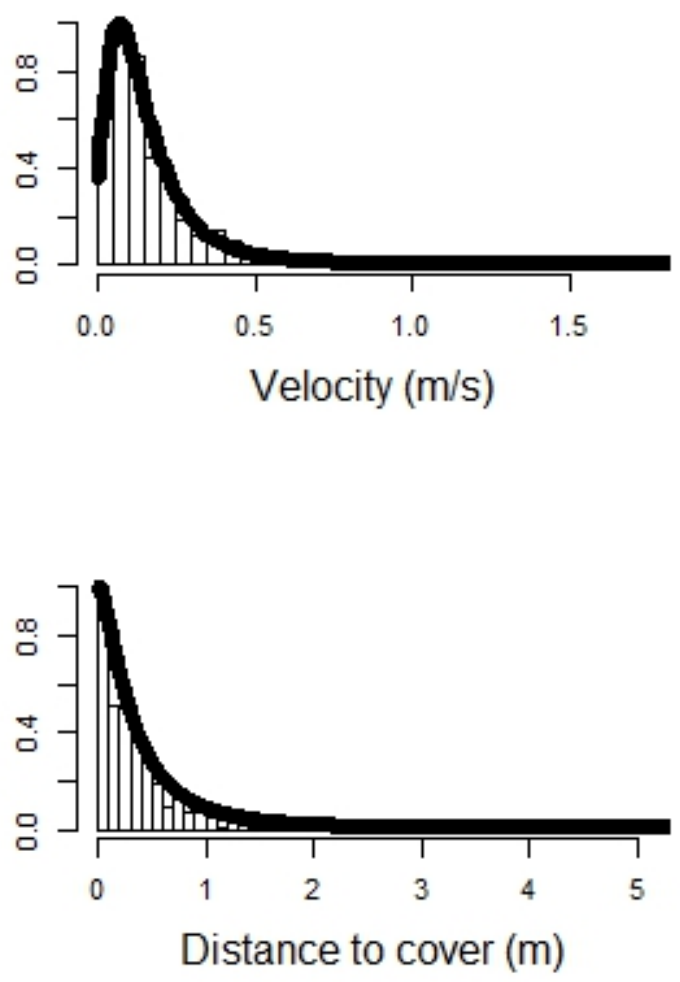

Figure 10. Univariate habitat suitability curves for depth (in meters [m]), velocity (in meters per second [m/s]), and distance to cover (in $\mathrm{m}$ ) fitted to presence-only observations of juvenile Chinook salmon fry and parr (and smolts) in the Klamath River, California, using methods of Som, Goodman, and others (2016). 


\section{Extrapolating Weighted Usable Habitat Area from Two-Dimensional Models to Unmodeled Habitat Units}

To extrapolate to unmodeled habitat units, WUA curves of replicate habitat types at a 2D site were averaged to develop a composite WUA representative of a given habitat type within a given geomorphic reach. Prior to averaging over replicate habitat units, we standardized each WUA curve by dividing WUA by the length of the habitat unit, which yielded units of square meters of usable habitat per linear meter of stream (square meters per meter). Standardized WUA also may be thought of as "weighted usable width" (WUW), since dividing surface area by stream length yields the average channel width, a property that we use in the extrapolation procedure. This process yielded a library of 34 unique habitat types that were then assigned to each of the 2,635 habitat units. Each of the composite WUA curves that form the basis for the flow-habitat relations are shown in appendix 1.

Composite WUA curves from the 2D models (hereinafter, "source" units) could not be applied directly to the unmodeled habitat units in S3 (hereinafter, "target" units) because geomorphically similar target units have a different length, width, and range of flows than the source habitat units, especially if tributaries enter between source and target units. Thus, the WUA curves had to be scaled appropriately from source to target units. Our procedure for scaling WUA curves used a conceptually simple process that scaled WUA according to expected length and width differences between source and target unit. We used the following steps to extrapolate WUA from source to target units:

1. Standardize each source WUA by dividing by the length of the habitat unit, which expresses available habitat as WUW.

2. For each target habitat unit, calculate the exceedance probability associated with a given daily river flow.

3. Using output for the habitat units from the 2D hydrodynamic models, quantify the relation between channel width and river flow, where flows for each habitat unit are determined based on a common exceedance probability. Calculate this relation for a range of exceedance probabilities.

4. Use the flow-to-width relation for each exceedance probability from step 3 to estimate mean channel width of each target unit at a given daily river flow.

5. Use the flow-to-width relation to estimate the mean channel width of the source unit associated with the same exceedance probability of the target habitat unit in step 4.

6. Scale the weighted usable width of the source unit to the target unit by multiplying it by ratio of source to target channel widths:

$$
\mathrm{WUW}_{\text {target }}=\mathrm{WUW}_{\text {source }} \times \frac{\text { width }_{\text {target }}}{\text { width }_{\text {source }}} .
$$

7. Convert WUW of the target unit to weighted usable area by multiplying WUW by the length of the target habitat unit. 
Our procedure for scaling WUA curves is based on the well-founded continuity equations that define hydraulic channel geometry as a power function of discharge (Leopold and Maddock, 1953). Leopold and Maddock (1953) showed that geometric channel properties (such as channel width) along the longitudinal profile of a river follow a power function at common exceedance flows:

$$
w_{h}=a_{p} Q_{h, p}^{b_{p}}
$$

where $w_{h} \quad$ is the width of habitat unit $h$, is the discharge of the habitat unit associated with exceedance probability $p$, and $a_{p}$ and $b_{p} \quad$ are parameters that vary with exceedance probability.

For example, at 50-percent exceedance flows, channel widths at different locations will follow a power function of discharge across sites. At 25-percent exceedance flows, channel widths also will follow a power function of discharge, but with different exponent $\left(b_{p}\right)$ and intercept $\left(a_{p}\right)$ values than at 50percent exceedance flows.

To develop the width continuity equations for S3, we first quantified exceedance flows in 1percent increments for all 2,635 habitat units using a 50-year historical flow record provided by Perry and others (2011). Second, for all 2D habitat units, we (1) estimated mean channel width as the wetted surface area divided by the length of the habitat unit, and (2) averaged the width of replicate habitat units at a given 2D site to develop composite widths associated with each source WUA curve. Third, we estimated the parameters of equation 2 by fitting log-log linear regressions to the widths of all habitat units at flows associated with each 1-percent increment of exceedance (fig. 11).

These equations served two functions: (1) they allowed us to scale discharge between source and target habitat units by relating flows at different locations to common exceedance probabilities, and (2) they provided an estimate of channel width of both source and target units at a common exceedance probability, which allowed us to scale the WUA by the relative change in channel width between source and target units (fig. 12). 

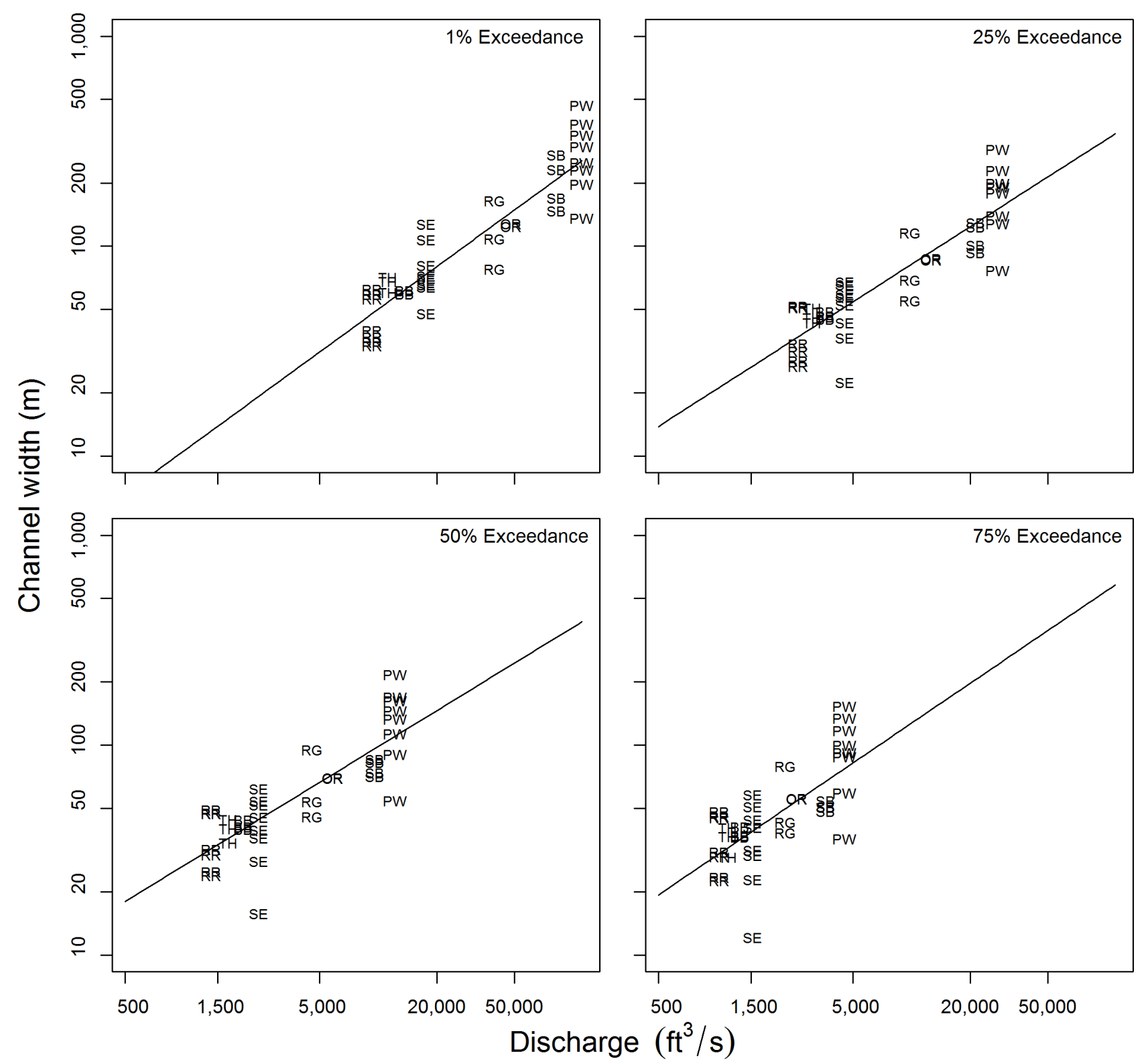

Figure 11. Graphs showing the relation between discharge (in cubic feet per second $\left[\mathrm{ft}^{3} / \mathrm{s}\right]$ ) and channel width (in meters [m]) of habitat units at two-dimensional (2D) sites for selected exceedance probabilities, on the Klamath River, California. Symbols represent the eight 2D hydrodynamic model sites: RR, R Ranch; TH, Trees of Heaven; BB, Brown Bear; SE, Seiad; RG, Rogers; OR, Orleans; SB, Saints Bar; PW, Pecwan. \%, percent. 

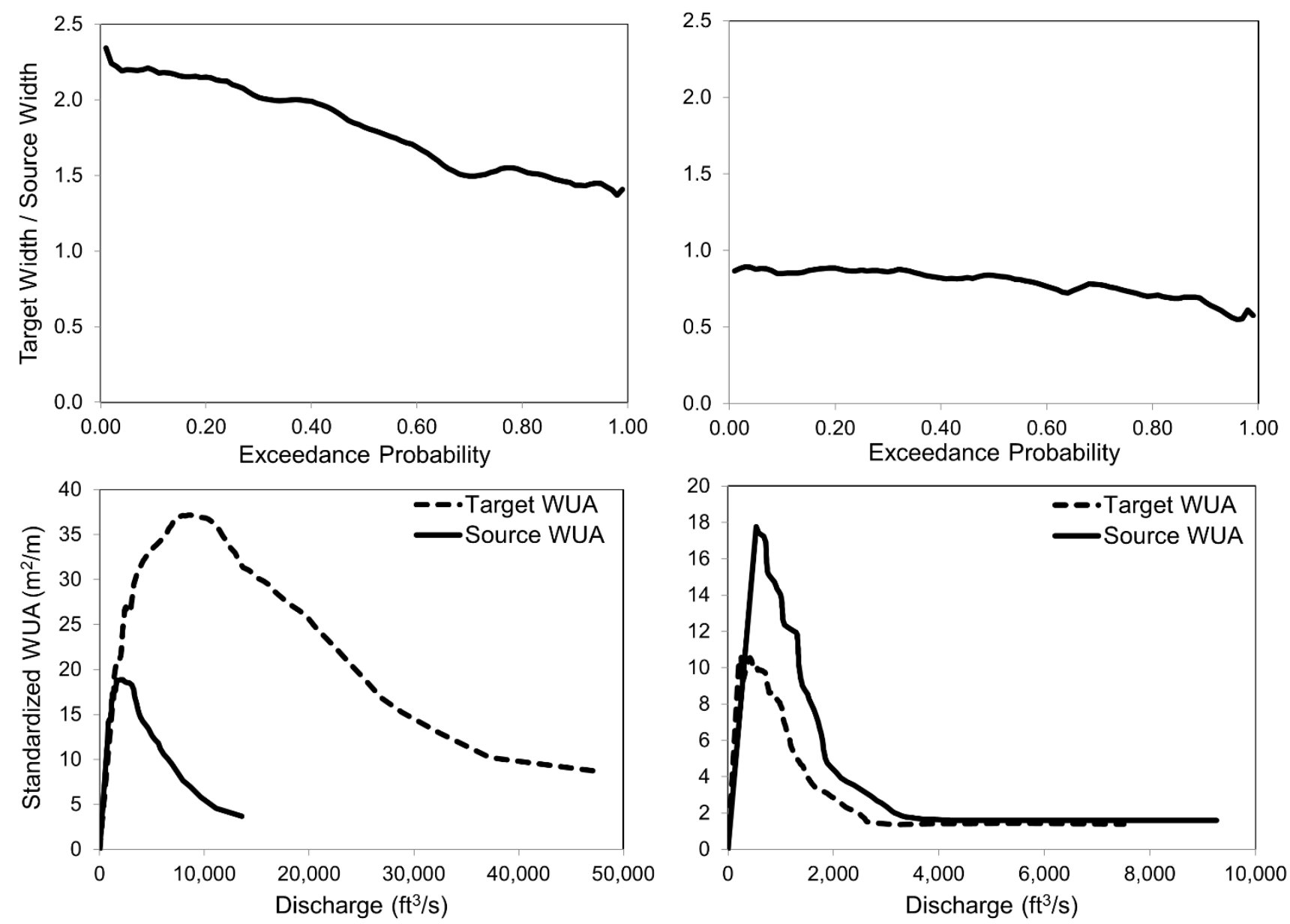

Figure 12. Examples of scaling source weighted usable habitat area (WUA) curves to target curves, for the Klamath River, California. Graphs on left show examples of scaling up a source WUA to a target WUA based on channel-width ratio at difference exceedance probabilities (width ratio greater than 1). Graphs on right show examples of scaling down a source WUA to a target WUA (width ratio less than 1 ). $\mathrm{m}^{2} / \mathrm{m}$, square meters per meter; $\mathrm{ft}^{3} / \mathrm{s}$, cubic feet per second. 


\section{Biological Inputs}

The S3 model relies on the three primary forms of biological inputs to simulate population dynamics: (1) female spawners, (2) juvenile hatchery fish releases, and (3) juveniles entering from tributaries. Additionally, a daily time series of spore concentrations is needed to drive the C. shasta disease submodel. Methods detailing these inputs are described in sections that follow.

\section{Female Spawners}

To develop inputs for the number of female spawners, spawner survey data were summarized as a weekly time series of redd counts or female abundance estimates by survey reach (Gough and Som, 2015; table 3). Weekly reach-level redd counts were then distributed uniformly across days within each week and then assigned to each habitat unit in proportion to available spawning area. Surveys were not conducted downstream of rkm 178 owing to low historical use of the lower Klamath for spawning. Therefore, we assumed that no spawning occurred downstream of rkm 178.

Table 3. Location of spawning survey reaches used as input for the number spawners that are allocated to each habitat unit in Stream Salmonid Simulator, for the Klamath River, California.

[No spawning was assumed in the section of river downstream of river kilometer 178.4. Start location/End location: Distance from mouth of Klamath River at Pacific Ocean, in river kilometers]

\begin{tabular}{cccc}
\hline Redd survey reach & $\begin{array}{c}\text { Start location } \\
\text { (river kilometer) }\end{array}$ & $\begin{array}{c}\text { End location } \\
\text { (river kilometer) }\end{array}$ & $\begin{array}{c}\text { Reach length } \\
\text { (kilometers) }\end{array}$ \\
\hline 1 & 312.0 & 311.4 & 0.6 \\
2 & 311.4 & 308.6 & 2.8 \\
3 & 309.6 & 307.4 & 1.2 \\
4 & 307.4 & 305.2 & 2.2 \\
5 & 305.2 & 302.4 & 2.8 \\
6 & 302.4 & 297.4 & 5.0 \\
7 & 297.4 & 294.6 & 2.8 \\
8 & 294.6 & 289.4 & 5.2 \\
9 & 289.4 & 266.7 & 22.8 \\
10 & 266.7 & 237.2 & 29.5 \\
11 & 237.2 & 218.4 & 18.8 \\
12 & 218.4 & 196.4 & 22.0 \\
13 & 196.4 & 178.4 & 18.0 \\
\hline
\end{tabular}

\section{Fish Entering from Tributaries and Hatcheries}

In addition to natural production within the Klamath River, three major sources contribute juveniles to the Klamath River upstream of the Kinsman fish trap: (1) Iron Gate Hatchery, (2) Bogus Creek, and (3) the Shasta River. Since the model was calibrated to weekly abundance estimates from the Kinsman fish trap (see section, "Model Calibration"), we do not include tributaries downstream of the Kinsman trap (Scott River, Salmon River, and Trinity River) in this report because these tributaries do not contribute juveniles to the trap abundance estimates used to calibrate S3. Release numbers by date were obtained from Iron Gate Hatchery. Weekly abundance estimates of juveniles entering the Klamath River were obtained from agencies that operated juvenile fish traps on tributary streams. The U.S. Fish 
and Wildlife Service provided abundance estimates for Bogus Creek and the Trinity River (for example, Gough and others, 2015). California Department of Fish and Wildlife provided abundance estimates for the Shasta River and Scott River (for example, Chesney and others, 2009). To construct model inputs, weekly abundance estimates were distributed uniformly across days within each reach.

\section{Ceratonova shasta Spore Concentrations}

To simulate infection and mortality of juvenile salmon caused by $C$. shasta, S3 requires inputs of daily $C$. shasta spore concentrations. Therefore, we developed a daily time series of spore concentrations using measurements of the quantity of $C$. shasta deoxyribonucleic acid (DNA) in water samples collected in the Klamath River near Beaver Creek (rkm 263.5) from 2005 to 2013 (Hallett and others, 2012). Water samples were analyzed by the Aquatic Animal Health Laboratory at Oregon State University using quantitative polymerase chain reaction (qPCR) techniques. DNA quantity was measured as cycle threshold values, which were converted to spore concentration (in spores per liter) by the Aquatic Animal Health Laboratory. Although qPCR techniques cannot distinguish between actinospore and myxospore parasite stages (of which the latter stage infects polychaetes, not salmon), we assume that most DNA content collected during the juvenile salmon rearing period is composed of actinospores. Prior to 2009, water samples were collected about every 2 weeks during a part of the juvenile salmon outmigration season. After 2009, water samples were collected continuously throughout the year at weekly or finer intervals. For periods when regularly spaced water samples were collected, we assumed that daily spore concentrations remained constant between the mid-points of sampling dates. Prior to 2009 when there were long time periods with no data collection, we imputed missing daily spore concentration data using a regression model that estimated the natural logarithm of spore concentration as a quadratic function of water temperature with a year-specific intercept during 2005-10 (fig. 13).

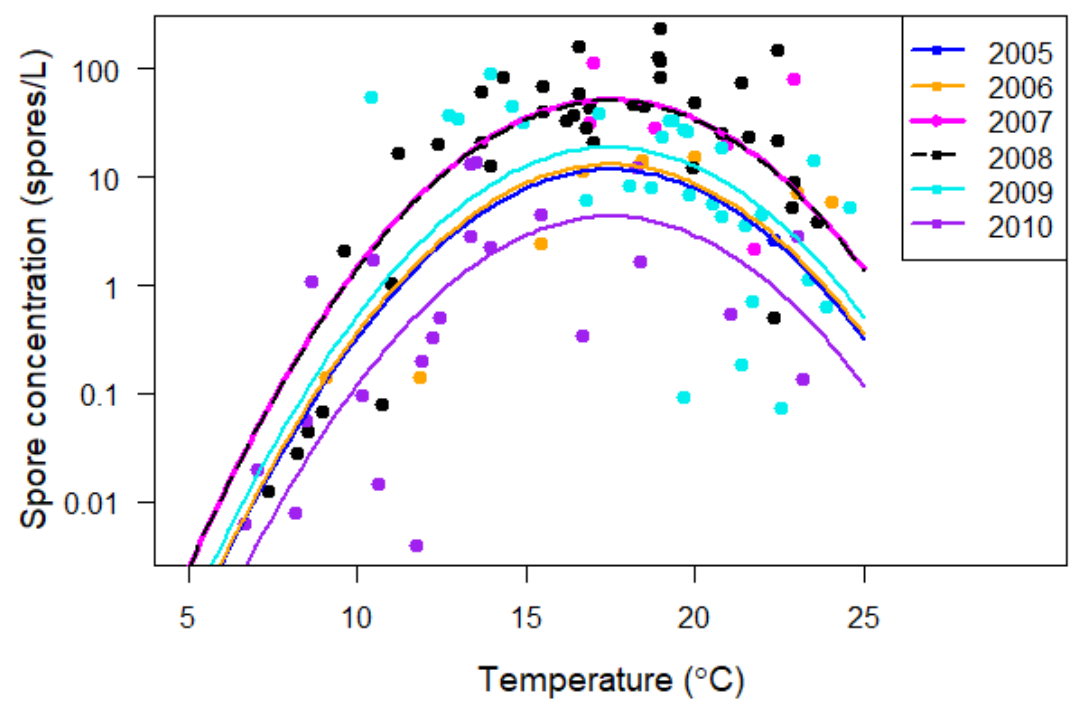

Figure 13. Fitted regression model used to impute missing daily spore concentrations of Ceratonova shasta using water temperature for periods prior to 2009 for time periods when no spore data were collected, Klamath River, California, 2005-10. ${ }^{\circ} \mathrm{C}$, degrees Celsius; spores/L, spores per liter. 


\section{Stream Salmonid Simulator Submodels and User-Defined Parameter Settings}

When simulating juvenile salmon populations with S3, some population dynamics are dictated by user defined options and parameter inputs. Juvenile fish populations in the S3 model are affected by three dynamic processes: (1) survival, (2) growth, and (3) movement. In the sections that follow, we describe how the submodels were parameterized for the Klamath River and specify values of userdefined parameters. For details on the mathematical structure of individual submodels, we encourage readers to consult Perry and others (2018a).

\section{Spawning, Egg Development, and Egg Survival Submodels}

The number of eggs that survive to emerge as fry is affected by several user-defined parameters and submodels. We set the fecundity of female spawners to 3,135 eggs per redd based on the mean number of eggs observed for Chinook salmon returning to Iron Gate Hatchery from 1996 to 2014 (fig. 14).

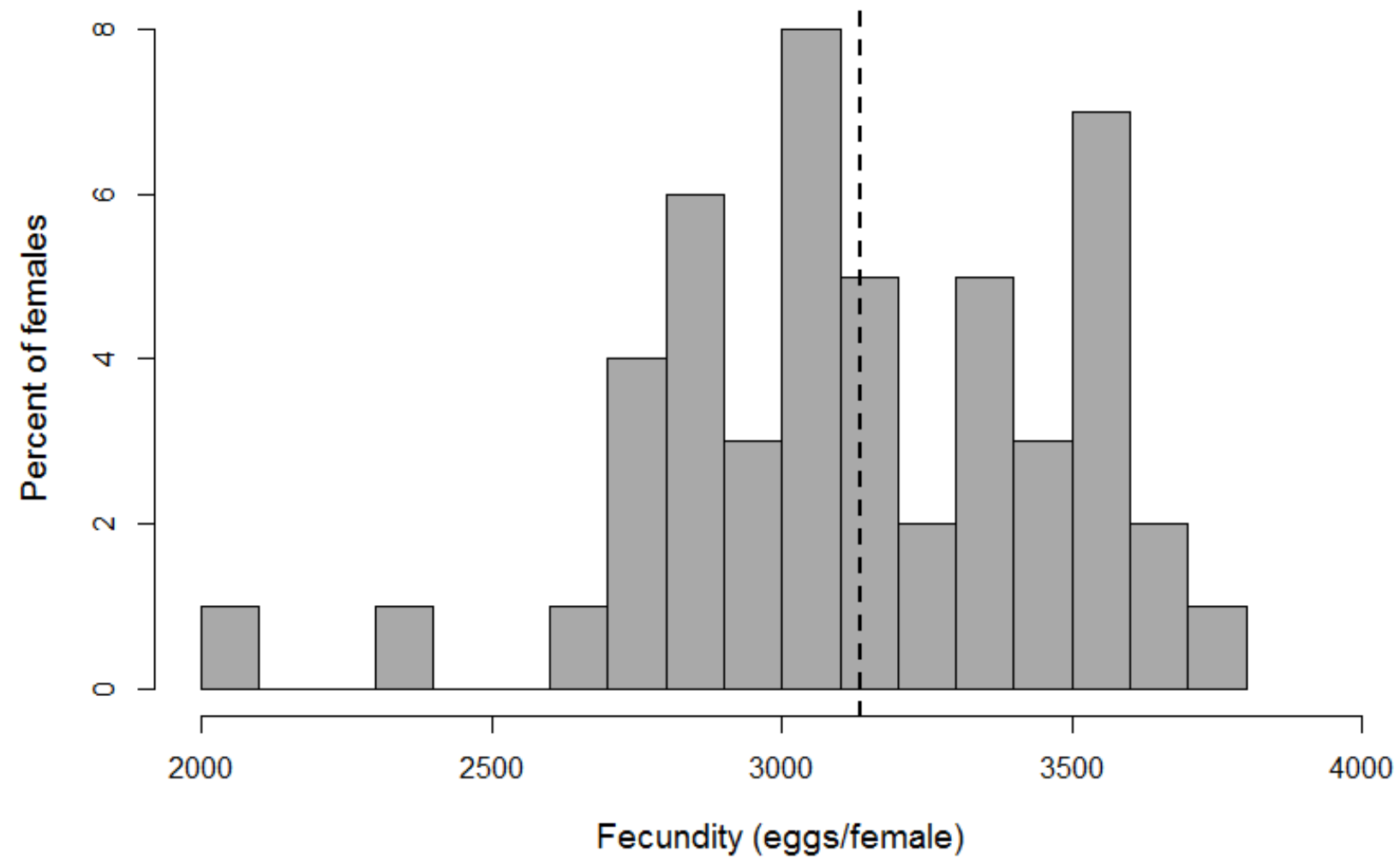

Figure 14. Histogram showing mean annual fecundities for fall Chinook salmon returning to Iron Gate Dam, on the Klamath River, California, 1966-2014. Dashed line denotes the mean fecundity of 3,135 eggs per female.

The mean time from spawning to fry emergence is modeled as a function of daily water temperature and accumulation of degree days (see Perry and others, 2018a). Variation in emergence timing is assumed to follow a normal distribution about the mean emergence date and is controlled by the standard deviation in degree days required to hatch, which we set to 26.6 degree days (Celsius) based on Geist and others (2006).

During the incubation period, S3 includes three mechanisms that affect egg-to-fry survival: (1) baseline "natural" mortality, (2) temperature-related mortality, and (3) redd superimposition (Perry and others, 2018a). The natural mortality rate was set at 0.25 percent per day, which equates to a baseline 
survival rate of about 92.8 percent per month. Thermal tolerance parameters were set so that water temperatures less than or equal to $(\leq) 17^{\circ} \mathrm{C}$ had no effect on egg survival, but temperatures greater than $(>) 17^{\circ} \mathrm{C}$ imposed a daily survival rate of 25 percent (Geist and others, 2006).

Redd superimposition is the process whereby a later arriving spawner builds a redd on top of an existing redd and dislodges or entombs the eggs laid by the earlier spawner. Superimposition is modeled in S3 as a function of redd capacity and spawner abundance. The probability that an existing redd is superimposed is defined by redd density (redd abundance $\div$ redd capacity), which is calculated and applied daily for each habitat unit. The amount of redd mortality attributed to superimposition on day $t$ is simply the number of redds to be recruited that day multiplied by the existing pre-recruitment redd density. However, given the propensity of Chinook salmon to guard their redds until death, the S3 model allows the user to set a "guarding period" parameter. We set the guarding period to 10 days, assuming that semelparous Chinook salmon live to guard their nests for 1-2 weeks after spawning.

\section{Juvenile Growth}

S3 provides two options for temperature-driven growth models: the Ratkowsky Model and the Wisconsin Bioenergetics Model (Perry and others, 2018a). Mean fish size for each source population and life stage in each habitat unit was incremented daily as a function of water temperature using the Wisconsin Bioenergetics Model with a revised consumption function (Plumb and Moffitt, 2015). For application to the Klamath River, we fixed the proportion of maximum consumption parameter to 0.66 and set all other parameter values to those listed in Perry and others (2018a). Under this parameterization, the Wisconsin and Ratkowsky growth models have similar growth rates over a range of water temperatures (Perry and others, 2018a).

The growth model governs life-stage transitions by moving fish to the next life stage when their mean size exceeds user-defined size thresholds for each life stage. For our simulations, the juvenile lifestage classifications were as follows: fry, fork length (FL) $\leq 55 \mathrm{~mm}$; parr, 55 less than $(<) \mathrm{FL} \leq 90 \mathrm{~mm}$; and smolt, FL $>90 \mathrm{~mm}$. Fish lengths were calculated from weight based on the estimated relation between fork length and fish weight (see appendix 2). For natural-origin fish, we set the weight of emergent fry to $0.3 \mathrm{~g}$, which back-calculates to a fork-length of $34 \mathrm{~mm}$. We assumed that the growth model applied uniformly to all juvenile life-stages and natural and hatchery origin fish. To provide a reference of the performance of the S3 growth model, we graphically compared the observed fork lengths of fish at the Kinsman fish trap (Gough and others, 2015) to those generated by the S3 model simulations.

\section{Juvenile Movement}

S3 has two submodels for simulating fish movement: (1) the "mover-stayer" model, and (2) the "advection-diffusion" model (Perry and others, 2018a). In both models, movement from one habitat unit to another is simulated in the downstream direction only. In our simulations, we used the "moverstayer" model for rearing fry and parr, and the "advection-diffusion" model for actively migrating smolts. The mover-stayer model can be implemented with density-independent or density-dependent movement, which is a user-specified option. With density-independent movement, abundance and capacity have no effect on movement probability. Density-independent movement is the only option available with the advection-diffusion model.

Two parameters drive movement in the mover-stayer model: (1) the probability of remaining in the currently occupied habitat unit ( $\left.P_{\text {stay }}\right)$ from time $t$ to $t+1$ (resulting in "stayers"), and (2) the mean distance moved downstream (that is, resulting in "movers"; $\mu$ mov, kilometers per day). For the densitydependent form of the model, $P$ stay is expressed as a Beverton-Holt function such that $P$ stay decreases as 
the ratio of abundance to capacity increases. That is, the probability of moving (1- $\left.P_{\text {stay }}\right)$ increases as abundance approaches capacity. The mean distance moved, $\mu_{\text {mov }}$, was calculated based on the average length-migration rate relation obtained from Zabel (2002) and Plumb (2012) for juvenile Snake River fall Chinook salmon (Perry and others, 2018a). We estimated $P_{\text {stay }}$ separately for density-dependent and density-independent forms of the mover-stayer model through model calibration.

The S3 density-independent "advection-diffusion" model was used to simulate the movement of actively migrating smolts, but not smaller fish that are less likely to move downstream (Zabel and Anderson, 1997; Zabel, 2002). The advection-diffusion model assumes that the spatial distribution of a population at a given point in space after $t$ time units is described by a normal distribution requiring two parameters: (1) a mean travel rate ( $\hat{r}$, in kilometers per day) and (2) a standard deviation in travel rate ( $\sigma$; that is, rate of population spread) that was set to $21.1 \mathrm{~km}^{2} / \mathrm{d}$ (Perry and others, 2018a). We allow the movement rate of smolts to depend on size, with the rate of movement increasing as a cubic function of the fork length of the fish. The parameters of this model were based on size relations developed by Zabel (2002) and Plumb (2012) for juvenile Snake River fall Chinook salmon (Perry and others, 2018a).

\section{Juvenile Survival}

Daily survival probability, like movement probability, can be specified either as densityindependent or density-dependent. In the density-dependent form, survival probability is expressed as a Beverton-Holt function that decreases as the ratio of abundance to capacity increases (Perry and others, 2018a). In this form, we estimate $S_{0}$, the expected survival as abundance approaches zero, and the capacity in terms of maximum habitat density (that is., fish per square meter of weighted usable habitat area). In the density-independent form, daily survival probability is estimated as a constant value that does not depend on abundance or habitat capacity. Under both forms of the survival model, parameters may be allowed to differ among life-stages and source-populations. Parameters of the survival model were estimated through calibration. We compare alternative models that use either the densityindependent or density-dependent form of the survival model. Additionally, we allow the parameters to vary among life stages.

\section{Modeling Infection and Mortality Caused by Ceratonova shasta}

We incorporated mortality due to $C$. shasta into $\mathrm{S} 3$ by first simulating the infection of juvenile fish with $C$. shasta within the infectious zone and then modeling the time to mortality of infected fish. Although the extent of the infectious zone can vary somewhat among years (Bartholomew and others 2015), we consider the infectious zone to occur between the Interstate 5 bridge (rkm 289.6) and Seiad (rkm 213.0, fig. 1). Outside this infectious zone, the model assumes juvenile salmon have a zero probability of becoming infected with $C$. shasta. Within the infectious zone, the probability of infection and eventual death is modeled as a function of daily water temperature and C. shasta spore concentration, both of which are provided as model inputs. We used time series of $C$. shasta spore concentrations within this zone since 2005 as inputs to drive the disease model in S3 (Som, Hetrick, and others, 2016; Hallett and others, 2012).

We used a survival cure model like that of Ray and others (2014) to simulate disease-caused mortality of infected juvenile Chinook salmon. The survival cure model is composed of two components: (1) a "cure" probability, which is the proportion of the population expected to survive the disease; and (2) a time-to-death function for individuals expected to die from disease:

$$
S(t)=(1-\pi)+\pi S(t \mid \text { death })
$$


where $S(t) \quad$ is the overall probability of surviving $t$ days after initial exposure,

$\pi \quad$ is the proportion of fish that become infected and eventually die from ceratomyxosis,

$1-\pi \quad$ is the proportion of infected fish that survive exposure to $C$. shasta, and

$S(t \mid$ death $) \quad$ is the proportion of fish that survive to time $t$ of those expected to die from $C$. shasta.

To develop a disease model for S3, we fit the survival cure model to sentinel trial data from a study known as the extended sentinel experiment. In this section, we briefly describe the results from the analysis of the sentinel experiments and how the model was adapted for use in S3. See appendix 3 for a more detailed summary of the analysis of the extended sentinel experiment. The goal of the extended sentinel experiment was to quantify how mortality owing to $C$. shasta is influenced by exposure duration, spore concentration during exposure, water temperature during exposure, and water temperature during the post-exposure period. Twenty-one sentinel trials were conducted in 2014 and 2015; each trial was conducted by:

1. Exposing 27-30 juvenile Chinook salmon held in cages in the infectious zone for 1-7 days;

2. Recording daily spore concentration and water temperature during the exposure period (water samples were collected hourly and pooled for the day, while water temperature was collected hourly and averaged for the day);

3. Transporting fish to the Aquatic Animal Health Laboratory at Oregon State University where fish were held at either $13{ }^{\circ} \mathrm{C}, 15^{\circ} \mathrm{C}$, or $18{ }^{\circ} \mathrm{C}$; and

4. Recording the time to death of each fish for up to 90 days, at which point the number of survivors was recorded.

Because sentinel trials were conducted during a period of high spore concentrations (all trials occurred when spore concentration was greater than 10 spores per liter [spores/L]), we combined this dataset with data from 12 sentinel trials reported by Ray and others (2014) that were conducted when spore concentrations were low $(<10$ spores/L). This ensured that our model parameters were estimated across a wide range of spore concentrations observed in the Klamath River.

The cure analysis modeled both the probability of infection and eventual death, $\pi$, and the timeto-death, $S(t \mid$ death) as a function of (1) exposure duration (d), 2) logarithm of mean total spore concentration (in spores per liter) during the exposure duration, (3) mean water temperature (in degrees Celsius) during the exposure duration, and (4) mean water temperature during the post-exposure period. The probability of infection and death was modeled using a logit link function, and $S(t \mid$ death $)$ was modeled using the log-logistic distribution. For $\pi$, the parameter estimates indicate that infection and mortality were positively related to spore concentration and exposure duration (table 4, fig. 15). We also noted a negative interaction between exposure temperature and holding temperature for $\pi$. For $S(t \mid$ death), we identified negative relations with spore concentration, holding temperature, and exposure temperature, indicating that increases in these variables reduced time to death (table 4, fig. 16). We also estimated a negative interaction between exposure duration and spore concentration, indicating that the effect of exposure duration on time to death varied with spore concentration (table 4). 
Table 4. Parameter estimates of the survival cure model fitted to data from the extended sentinel experiment and selected low-spore trials analyzed by Ray and others (2014).

[Model for $\pi$ is a model for the proportion of fish that become infected and eventually die from ceratomyxosis. Model for $S(t \mid$ death $)$ is a model for the proportion of fish that survive to time $t$ of those expected to die from Ceratonova shasta. Model terms: $E$, exposure duration; $C$, natural logarithm of total Ceratonova shasta spore concentration; $T_{\mathrm{E}}$, water temperature during exposure period; $T_{\mathrm{H}}$, water temperature during holding period]

\begin{tabular}{|c|c|c|c|}
\hline Model term & Parameter estimate & Standard error & $\begin{array}{c}95-p e r c e n t \\
\text { confidence interval }\end{array}$ \\
\hline \multicolumn{4}{|c|}{ Model for $\pi$} \\
\hline Intercept & -1.680 & 0.130 & $-1.935,-1.425$ \\
\hline$C$ & 1.944 & 0.178 & $1.596,2.292$ \\
\hline$T_{\mathrm{E}}$ & -0.324 & 0.110 & $-0.540,-0.107$ \\
\hline$T_{\mathrm{H}}$ & 0.700 & 0.125 & $0.455,0.944$ \\
\hline$E$ & 0.880 & 0.092 & $0.699,1.061$ \\
\hline$T_{\mathrm{E}} \times T_{\mathrm{H}}$ & -0.822 & 0.125 & $-1.068,0.576$ \\
\hline \multicolumn{4}{|c|}{ Model for $S(t \mid$ death $)$} \\
\hline $\log$ (scale parameter) & -2.052 & 0.051 & $-2.151,-1.952$ \\
\hline Intercept & 3.478 & 0.026 & $3.427,3.529$ \\
\hline$C$ & -0.128 & 0.025 & $-0.178,-0.078$ \\
\hline$T_{\mathrm{E}}$ & -0.059 & 0.022 & $-0.102,-0.016$ \\
\hline$T_{\mathrm{H}}$ & -0.235 & 0.025 & $-0.284,-0.187$ \\
\hline$E$ & 0.064 & 0.039 & $-0.013,0.141$ \\
\hline$C \times E$ & -0.181 & 0.036 & $-0.251,-0.111$ \\
\hline
\end{tabular}



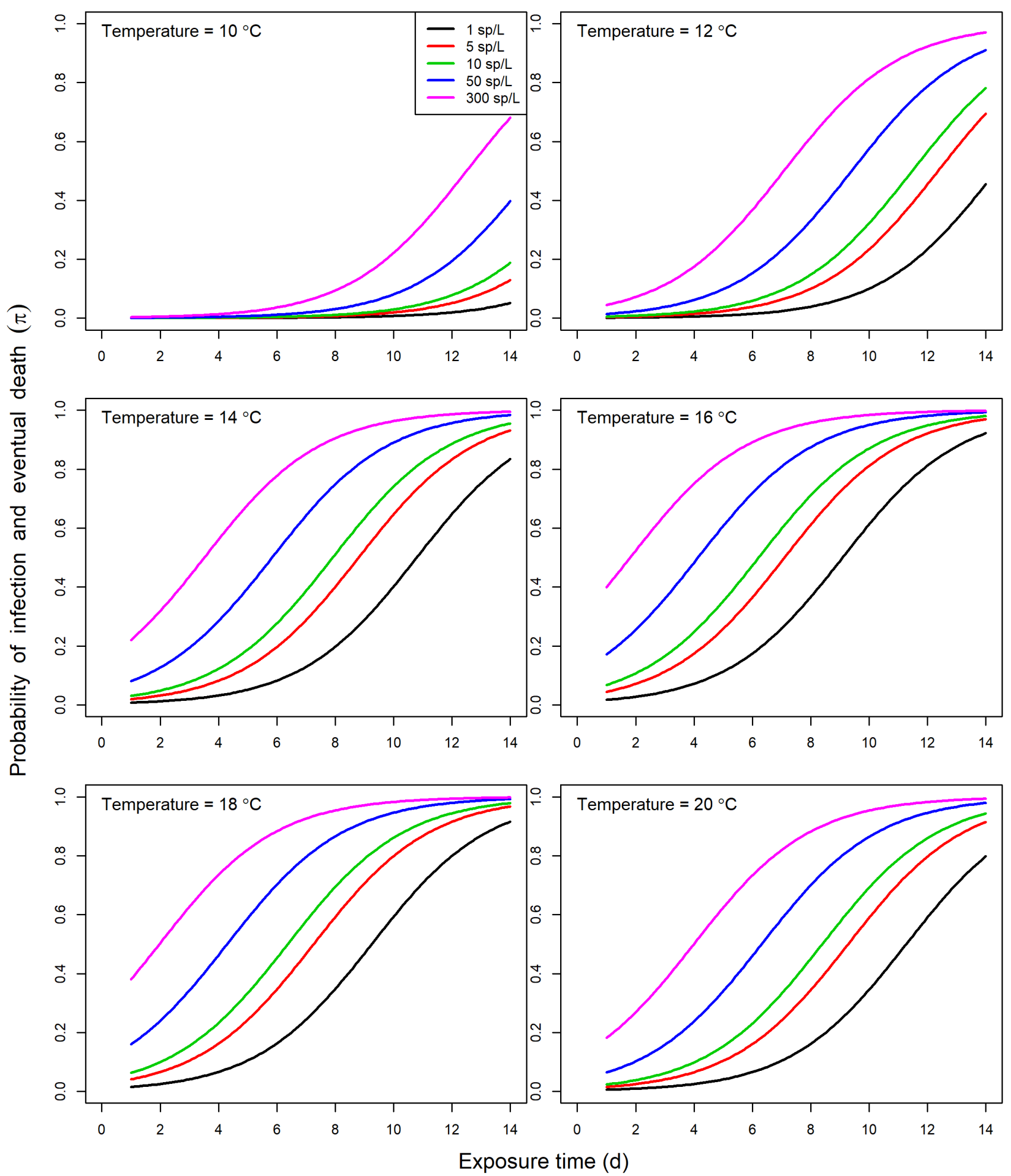

Figure 15. Graphs showing cure component of the survival cure model for Chinook salmon fitted to sentinel trial data. Each graph shows the joint probability of being infected and eventually dying from ceratomyxosis for a given water temperature as a function of exposure duration. ${ }^{\circ} \mathrm{C}$, degrees Celsius; $d$, days; sp/L, spores per liter. 

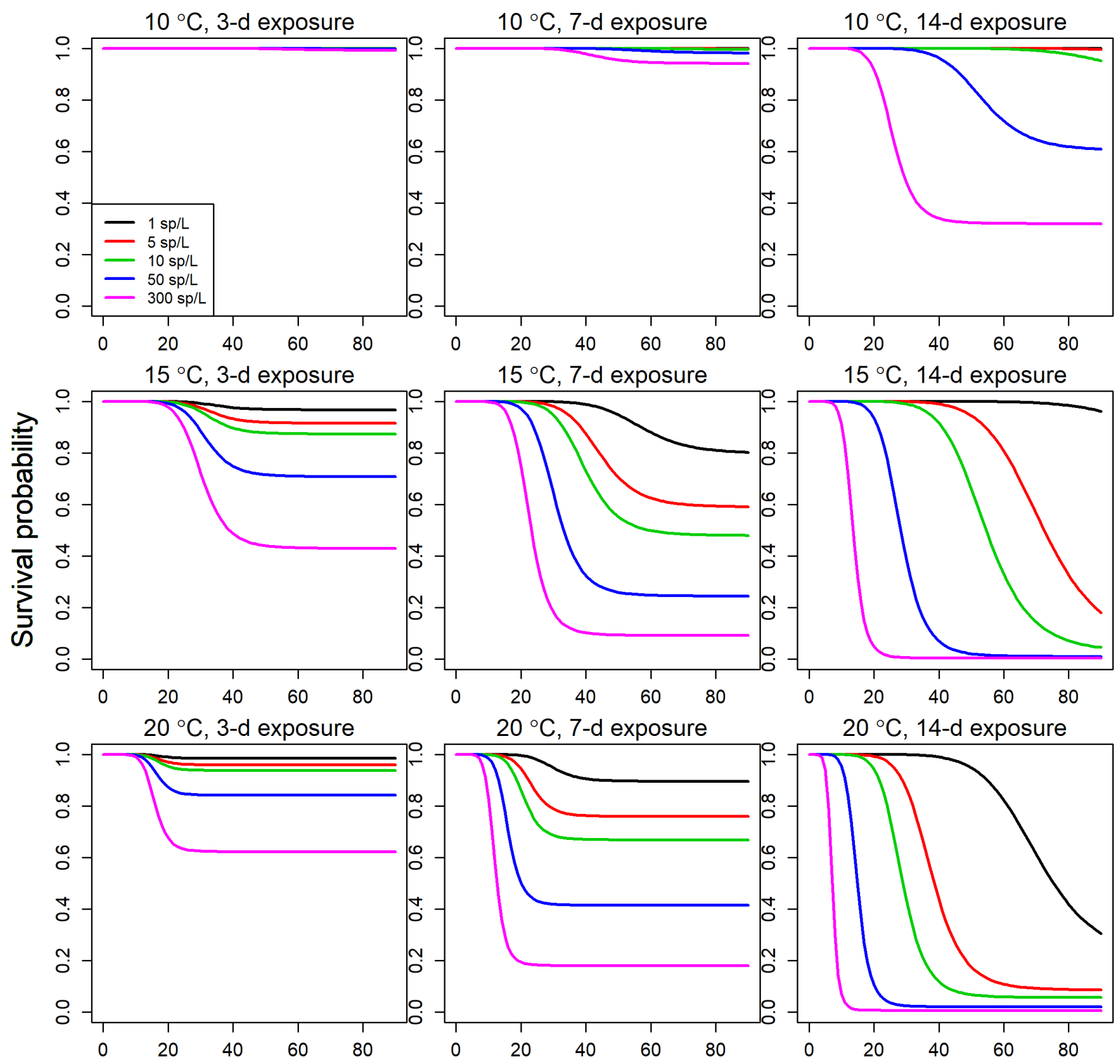

Time since initial exposure (d)

Figure 16. Survival cure model graphs showing probability of Chinook salmon surviving as a function of time since initial exposure over a range of water temperatures, exposure durations, and spore concentrations. ${ }^{\circ} \mathrm{C}$, degrees Celsius; d, day; sp/L, spores per liter. 
The S3 model tracks the total number of juveniles and the number of juveniles infected with $C$. shasta:

$$
n_{p, s}(h, t)=I_{p, s}(h, t)+U_{p, s}(h, t)
$$

where $I_{p, s}(h, t), U_{p, s}(h, t)$, and $n_{p, s}(h, t)$ are the infected, uninfected, and total number of juvenile salmon in source population $p$ and life stage $s$ in habitat unit $h$ at time $t$, respectively. Transitions from uninfected to infected groups are modeled by applying a daily probability that uninfected fish become infected with C. shasta:

$$
\begin{gathered}
I_{p, s}^{\mathrm{D}}(h, t)=I_{p, s}(h, t)+P_{\text {inf }}(h, t) U_{p, s}(h, t), \text { and } \\
U_{p, s}^{\mathrm{D}}(h, t)=U_{p, s}(h, t)-I_{p, s}^{\mathrm{D}}(h, t),
\end{gathered}
$$

where $P_{\text {inf }}(h, t) \quad$ is the daily probability of becoming infected with $C$. shasta in habitat unit $h$ on day $t$, and

superscript " $\mathrm{D}$ " $\quad$ refers to the number of infected and uninfected fish in habitat unit $h$ on day $t$ after infection has occurred but prior to movement (See Perry and others, 2018a).

We omit the $p$ and $s$ subscripts on $P_{\text {inf }}(h, t)$ because we assume that different source populations and juvenile life stages respond to $C$. shasta similarly. Note that $P_{\text {inf }}(h, t)=0$ if unit $h$ falls outside the userdefined infectious zone.

We used the cure part of the survival model $(\pi)$ for infection probability, $P_{\text {inf }}(h, t)$. Because $\pi$ is a function of cumulative exposure time in the infectious zone whereas $P_{\text {inf }}(h, t)$ is a daily probability of transitioning from uninfected to infected, we converted $\pi$ into a daily probability:

$$
P_{\text {inf }}(h, t)=\frac{\pi_{E_{t}}-\pi_{E_{t}-1}}{1-\pi_{E_{t}-1}},
$$

where $E_{t} \quad$ is the exposure duration at time $t$, and

$\pi_{E_{t}} \quad$ is the probability of becoming infected and eventually dying given an exposure of $E_{t}$ days.

In essence, equation 7 calculates the probability of becoming infected between time $t$ - 1 and $t$, conditional on not being infected by time $t-1$. 
Because $\pi$ estimates the proportion of fish that eventually die from ceratomyxosis, all infected fish, $I_{p, s}(h, t)$, eventually die according to the time-to-death component of the cure model $[S(t \mid$ death $)]$ unless they arrive at the ocean prior to death. Like $\pi$, because $S(t \mid$ death) is the cumulative proportion remaining alive since the initial exposure, we converted $S(t \mid$ death $)$ to a daily mortality:

$$
M_{\text {inf }}(h, t)=\frac{F(t \mid \text { death })-F(t-1 \mid \text { death })}{1-F(t-1 \mid \text { death })},
$$

where $F(t \mid$ death $)$ is $1-S(t \mid$ death $)$, and $M_{\text {inf }}(h, t)$ is the proportion of infected fish dying between time $t-1$ and $t$ conditional on infected fish surviving to time $t-1$.

Covariates for $\pi_{E_{t}}$ were calculated as follows: $E_{t}$ was the cumulative time that fish spent in the infectious zone, $T_{\mathrm{E}}$ was the mean water temperature over the exposure time, and $C$ was the mean of the natural logarithm of spore concentration over the exposure time in the infectious zone. For $\pi$, we set $T_{\mathrm{H}}$ $=T_{\mathrm{E}}$, but for $S(t \mid$ death $), T_{\mathrm{H}}$ was mean water temperature during the period after fish passed through the infectious zone. We also imposed constraints on the covariates so as not to apply the model too far outside the conditions under which the sentinel exposure experiment was conducted. For both $\pi$ and $S\left(t \mid\right.$ death), we set a maximum exposure time of 14 days (that is, $E_{t}>14 \mathrm{~d}$ was set to $14 \mathrm{~d}$ ) because we determined that the interaction terms in the model caused unrealistic model behavior at longer exposure times. Additionally, we set $\pi=0$ for spore concentrations $\leq 1$ spore/L.

\section{Model Calibration}

\section{Abundance Data}

We calibrated S3 to 8 years of weekly juvenile fall Chinook abundance estimates from the Kinsman fish trap. The Kinsman fish trap is located just upstream of the Scott River (fig. 1) and consists of a combination of frame traps and screw traps (Gough and others, 2015). Specifically, we calibrated to abundance estimates from brood years 2005-13, excluding 2006. These years were selected based on the completeness and robustness of the juvenile abundance estimates among available years. We did not fit S3 to juvenile data collected in 2006 because weekly abundance estimates were unavailable owing to extremely high river discharge and debris loading that prevented trap operation. Across all years, we fit S3 to 138 point estimates that represented the total weekly abundance of juvenile Chinook salmon passing the Kinsman fish trap. Weekly abundance estimates were separated into hatchery and natural origin but were not otherwise broken down by life stage or tributary source. We did not use data from a trap located just upstream of the Interstate 5 bridge because it was located relatively close to Iron Gate Dam. However, we used the calibrated model to simulate abundance of fish passing this trap and then compared simulated to observed weekly abundance (appendix 4).

We did not fit S3 to the weekly abundances of hatchery fish that passed the Kinsman fish trap. We decided not to use hatchery fish in calibration because the number of weeks with estimable abundances were relatively few. Hatchery fish often were released late in the year, and the capture of hatchery fish often caused trap capacity to be exceeded, rendering the trap inoperable. For example, there were only 6 weekly estimates of hatchery fish in 2005, 6 weekly estimates in 2007, 3 weekly 
estimates in 2010, 5 weekly estimates in 2011, and 6 weekly estimates in 2012. Although hatchery fish were not included in S3 calibration, hatchery fish were included as part of the S3 simulations, and so hatchery fish do affect the model dynamics and output. Therefore, we set the daily survival probability of hatchery fish equal to the daily survival probability of natural-origin smolts, which was estimated through calibration.

\section{Calibration}

The goal of calibration is to estimate survival and movement parameters of the S3 model by fitting the model to estimates of weekly abundance of juveniles passing the Kinsman trap. To fit the model to abundance estimates, we used a likelihood function where deviations between simulated and estimated weekly abundances followed a normal distribution:

$$
\hat{N}_{w, y}=\tilde{N}_{w, y}(\boldsymbol{\theta})+\varepsilon_{w, y},
$$

where $\hat{N}_{w, y} \quad$ is the number of juveniles estimated to have passed the trap in week $w$ of year $y$,

$\tilde{N}_{w, y}(\boldsymbol{\theta}) \quad$ is the simulated number of juvenile salmon passing the trap in week $w$ of year $y$ for a given vector of parameters $\theta$, and

$\varepsilon_{w, y} \quad$ is a normally distributed error term with mean zero and standard deviation $\sigma$.

We use the " " notation here to indicate quantities simulated by S3, and the "hat" notation to indicate that true abundances are unknown and estimated with uncertainty. We account for the uncertainty in estimated abundances by using a weighted likelihood for the errors (Deriso and others, 2007):

$$
-\ln L\left(\boldsymbol{\theta} \mid \hat{N}_{w, y}\right) \propto \sum_{y} \sum_{w}\left[\ln \left(w_{w, y} \sigma\right)+\frac{\left[\hat{N}_{w, y}-\tilde{N}_{w, y}(\boldsymbol{\theta})\right]^{2}}{2 w_{w, y}^{2} \sigma^{2}}\right],
$$

where $-\ln L\left(\boldsymbol{\theta} \mid \hat{N}_{w, y}\right)$ is the negative log-likelihood of the parameters given the observed data, and $w_{w, y} \quad$ are weights that are proportional to the uncertainty in each $\hat{N}_{w, y}$.

For weights, we used the coefficient of variation, $w_{w, y}=\mathrm{CV}\left(\hat{N}_{w, y}\right)$, since the standard errors of $\hat{N}_{w, y}$ are proportional to $\hat{N}_{w, y}$. The residual standard deviation, $\sigma$, was estimated analytically using:

$$
\hat{\sigma}=\sqrt{\frac{1}{n} \sum_{w} \sum_{y} \frac{\left[\hat{N}_{w, y}-\tilde{N}_{w, y}(\boldsymbol{\theta})\right]^{2}}{w_{w, y}^{2}}},
$$

where $n \quad$ is the total number of abundance estimates across weeks and years. 
We used standard optimization routines in $\mathrm{R}$ ( $\mathrm{R}$ Core Team, 2017) to maximize the likelihood with respect to the parameters.

Although the S3 model simulates daily abundance by life stage and source population, weekly abundance estimates $\left(\hat{N}_{w, y}\right)$ were aggregated over all life stages but were separated for natural- and hatchery-origin fish. Therefore, for fitting the model to observed data, $\tilde{N}_{w, y}(\boldsymbol{\theta})$ represents the total simulated weekly abundance passing the Kinsman trap, summed over life stages and source populations separately for natural- and hatchery-origin juveniles.

Given a fitted model, we used a parametric bootstrap routine to generate confidence intervals in simulated weekly abundance of fish passing the Kinsman Trap. First, we generated 100 parameter sets by drawing each parameter set from a multivariate normal distribution with the mean parameter vector and variance-covariance matrix estimated through model calibration. Next, we ran S3 for each of the parameter sets and summarized the weekly abundance passing the Kinsman Trap. Finally, bootstrap confidence intervals for each simulated weekly abundance were generated using the 2.5th and 97.5th percentiles of the output from the 100 model runs.

\section{Model Selection}

S3 allows considerable flexibility in how the survival, movement, and growth submodels are a parameterized. Each submodel may be expressed using either a density-dependent or densityindependent function. Furthermore, each submodel allows different parameter values to be set for each life stage and source population. For example, the most complex model structure allows each life stage and source population to have different parameter values for survival, movement, and growth. In contrast, the simplest model structure assumes that parameter values are the same across life stages and source populations.

To determine which model structure best fit the observed weekly abundance estimates, we fit a candidate set of eight models (table 5). We then compared the relative plausibility of each candidate model using Akaike's Information Criterion corrected for small sample size $\left(\mathrm{AIC}_{\mathrm{c}}\right.$ ), where the lowest $\mathrm{AIC}_{\mathrm{c}}$ value indicates the model with the most support given its fit to the data and the number of parameters (Burnham and Anderson, 2002).

Table 5. Candidate Stream Salmonid Simulator models that were fit to weekly estimated abundances at the Kinsman fish trap on the Klamath River, California.

[Model nomenclature is as follows: S represents the survival submodel and M represents the movement submodel. Entries within parentheses represent the structure for each submodel: "." represents density-independent parameters that are constant among life stages, "BH" represents a density-dependent Beverton-Holt function with parameters constant across life stages, "s" represents a density-independent model with different parameter values for each life stage, and "s, BH" represents a density-dependent function with parameters estimated separately for each life stage]

\begin{tabular}{|c|c|c|}
\hline Model number & Model structure & Number of parameters \\
\hline 1 null & $\mathrm{S}(.) \mathrm{M}()$. & 2 \\
\hline 2 & $\mathrm{~S}(\mathrm{BH}) \mathrm{M}()$. & 4 \\
\hline 3 & $\mathrm{~S}(.) \mathrm{M}(\mathrm{BH})$ & 3 \\
\hline 4 & $\mathrm{~S}(\mathrm{BH}) \mathrm{M}(\mathrm{BH})$ & 5 \\
\hline 5 & $\mathrm{~S}(\mathrm{~s}) \mathrm{M}(\mathrm{s})$ & 5 \\
\hline 6 & $\mathrm{~S}(\mathrm{~s}, \mathrm{BH}) \mathrm{M}(\mathrm{s})$ & 7 \\
\hline 7 & $\mathrm{~S}(\mathrm{~s}) \mathrm{M}(\mathrm{s}, \mathrm{BH})$ & 7 \\
\hline 8 full & $\mathrm{S}(\mathrm{s}, \mathrm{BH}) \mathrm{M}(\mathrm{s}, \mathrm{BH})$ & 9 \\
\hline
\end{tabular}


The simplest model (that is, the null model) that was fit to the weekly abundance estimates expressed both survival and movement probabilities as density-independent (table 5). Under this null model, daily survival probability was set constant across the fry, parr, and smolt life stages. For movement, the daily probability of remaining in a habitat unit $\left(P_{\text {stay }}\right)$ was set equal across the fry and parr life stages, but smolt movement probabilities were modeled as a function of fork length using the advection-diffusion model described in Perry and others (2018a). We modeled smolt movement using a density-independent advection-diffusion process because this approach likely was more applicable to actively migrating smolts compared to the move-or-stay behavior associated with the fry and parr life stages (Zabel and Anderson, 1997; Zabel, 2002). Thus, our null model of survival and movement for juvenile Chinook salmon in the Klamath River required the estimation of 2 parameters: one parameter for survival across all life stages, and one parameter for the mover-stayer process model across the life stages.

Our most complex candidate model (that is, the full model) expressed both survival and movement probabilities as density-dependent and life-stage specific (table 5). Smolt survival, however, always was modeled as density-independent owing to the tendency of this life stage to actively migrate. Under this full model, the fry and parr life stages each have their own set of Beverton-Holt parameters for survival and movement, resulting in nine total parameters: four parameters to estimate densitydependence survival of fry and parr, one parameter to estimate density-independent survival for smolts, and four parameters to estimate density-dependent movement probabilities for fry and parr under the mover-stayer model. All other candidate models in the set were expressed as simpler combinations of this full model.

When fitting the S3 model to the trap abundance estimates, we imposed constraints on some parameters to prevent the estimation of biologically unrealistic values. We set a lower bound on the daily survival probability of 0.8 . When estimating maximum fish density under the Beverton-Holt model, we set the lower bound to 1 fish per square meter (fish $/ \mathrm{m}^{2}$ ) with no upper bound.

\section{Results}

\section{Stream Salmonid Simulator Model Inputs}

\section{Biological Inputs}

\section{Female Spawners}

The number of female Chinook salmon spawning in the main-stem Klamath River between Iron Gate Dam and the Kinsman fish trap varied widely among brood years (table 6). For example, in 2010 there were 1,925 female spawners, but in 2012 there were 10,697 female spawners. The spatial distribution of spawners was consistent among years with most redds located just downstream of Iron Gate Dam (fig. 17; appendix 5). The within-year temporal distribution of spawning also was fairly consistent across years, with quantiles of spawning dates falling within a 2-week period among years (table 6). For example, the 20th percentile dates of the spawning period ranged from October 16 to 25 , the 50th percentile dates ranged from October 19 to November 8 and the 80th percentile dates ranged from October 26 to November 16. 
Table 6. Abundance and timing of female Chinook salmon spawning between Iron Gate Dam (river kilometer [rkm] 312) and Kinsman fish trap (rkm 236) by migration year, Klamath River, California, 2004 and 2006-12.

\begin{tabular}{ccllc}
\hline Brood year & 20th percentile & 50th percentile & 80th percentile & Female spawners \\
\hline 2004 & October 16 & October 24 & October 31 & 2,948 \\
2006 & October 12 & October 19 & October 26 & 2,196 \\
2007 & November 1 & November 8 & November 16 & 4,522 \\
2008 & October 22 & October 29 & November 6 & 3,324 \\
2009 & October 23 & October 31 & November 8 & 4,543 \\
2010 & October 25 & November 1 & November 7 & 1,925 \\
2011 & October 23 & November 1 & November 9 & 2,158 \\
2012 & October 16 & October 24 & October 31 & 10,697 \\
\hline
\end{tabular}

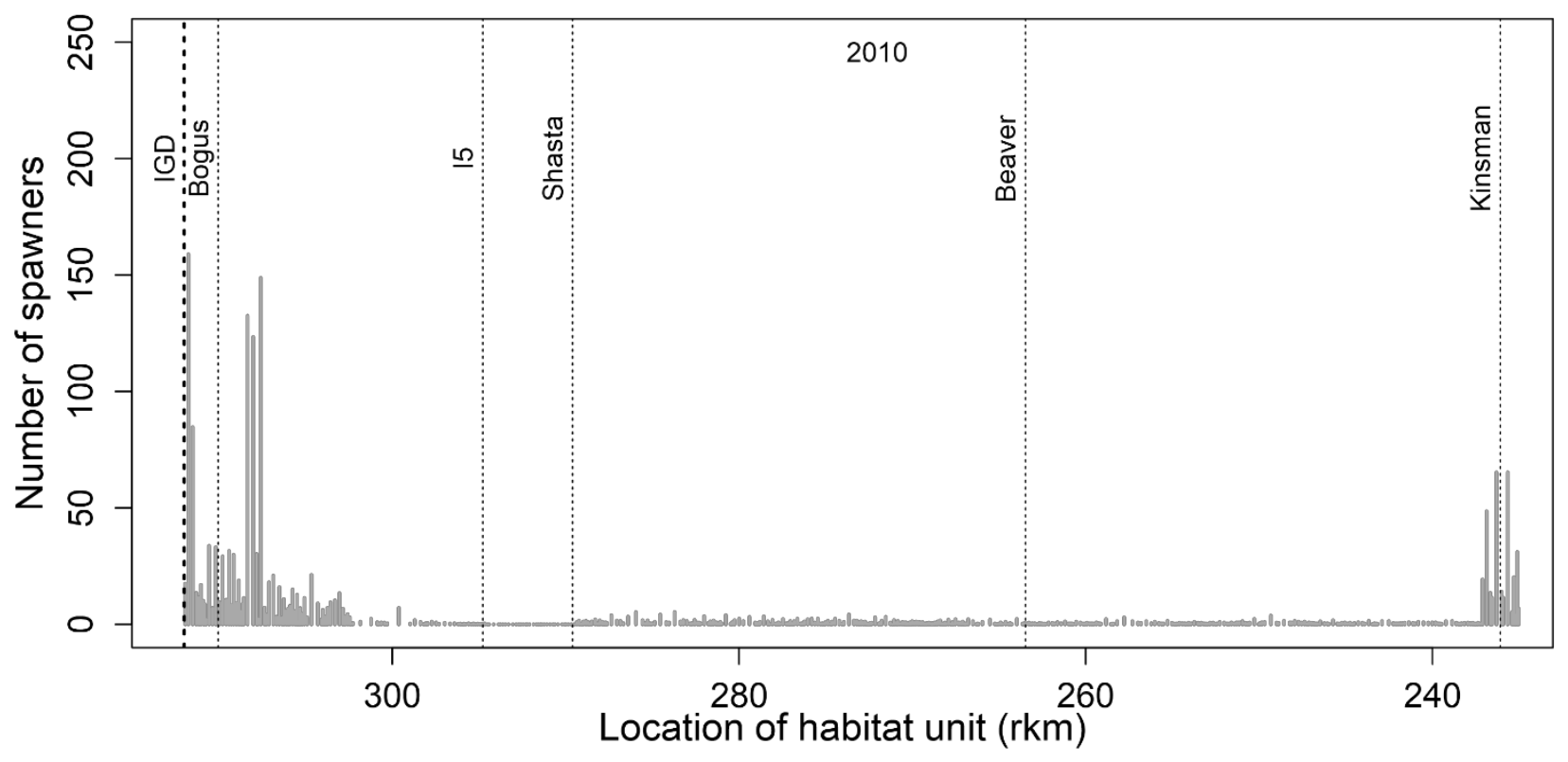

Figure 17. Graph showing spatial distribution of spawning female Chinook salmon used as inputs to the Stream Salmonid Simulator model for the Klamath River, California, brood year 2010. See appendix 5 for remaining years. Beaver, Beaver Creek; Bogus, Bogus Creek; I5, 15 trap near Interstate 5 bridge; IGD, Iron Gate Dam; Kinsman, Kinsman fish trap; Shasta, Shasta River; rkm, river kilometer.

Juveniles from Tributary and Hatchery Sources

The timing of juveniles entering the main-stem Klamath River from tributary and hatchery sources was highly variable. For example, hatchery fish typically were released very late in the year at very high numbers, whereas fish from natural production entering the Klamath River from Bogus Creek and Shasta Rivers had a much more protracted entry timing (fig. 18, appendix 6). The total abundance of fish entering the Klamath River from tributaries also varied widely across source populations and years (table 7). For example, in 2012, 160,530 juvenile Chinook salmon entered the Klamath River from the Shasta River, but in 2013, 5,218,278 fish entered the Klamath River from the Shasta River. On 
average, the numbers of juvenile Chinook salmon entering the Klamath River from each source tributary was 4.35 million fish from Iron Gate Hatchery, 3.31 million fish from Bogus Creek, and 1.37 million fish from the Shasta River. Therefore, the tributary input data provided a wide range of variation from which to model and estimate the potential effects of density dependence at the fry and parr life stages. The abundances from tributaries also are statistical estimates with attendant statistical uncertainty.

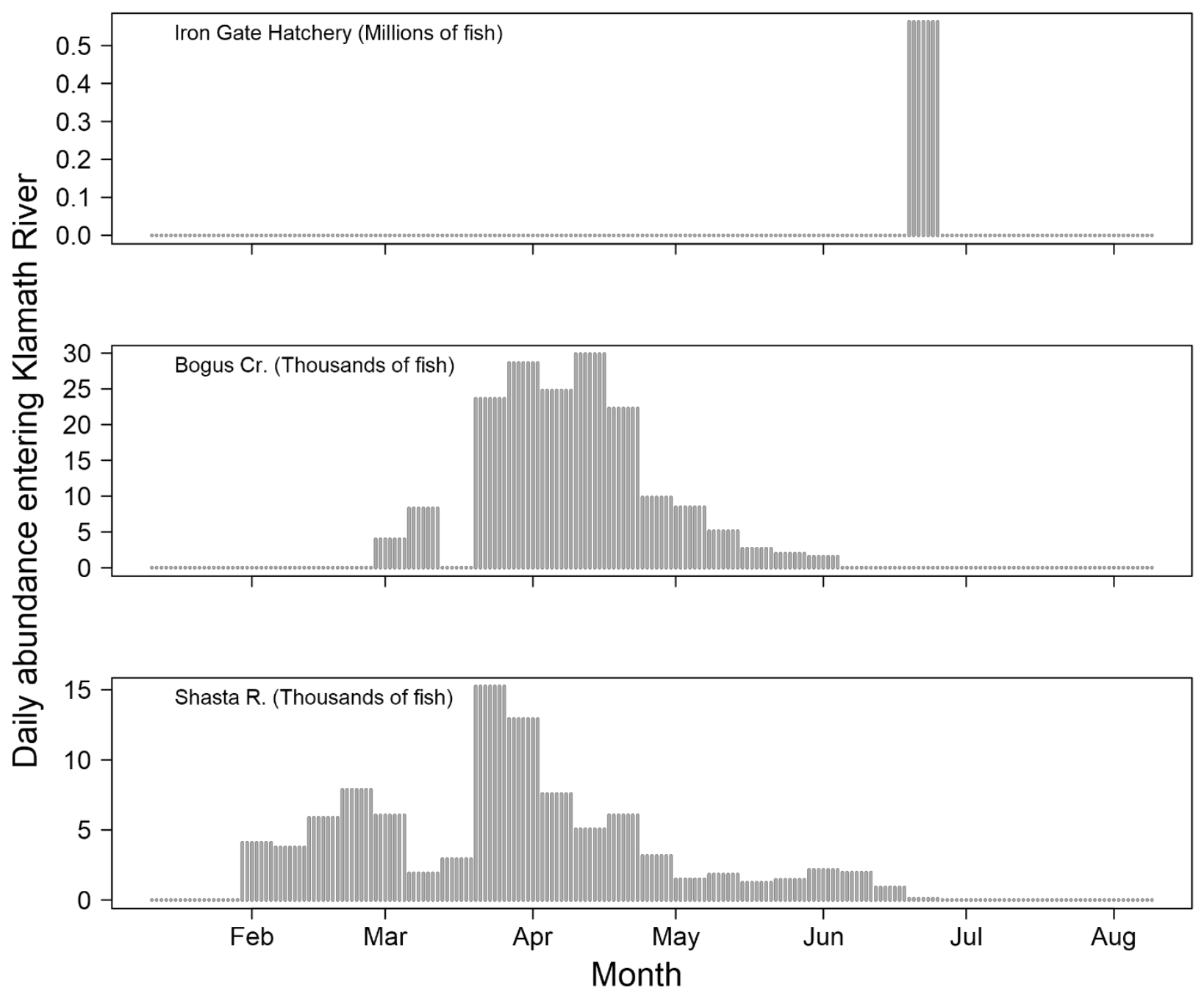

Figure 18. Graphs showing temporal distribution of weekly abundances of juvenile Chinook salmon entering the Klamath River by tributary source, California, migration year 2011. For input to Stream Salmonid Simulator model, weekly abundance estimates were distributed uniformly among days within weeks. Cr., Creek; R., River. 
Table 7. Total abundance estimates of juvenile Chinook salmon entering the main-stem Klamath River, California, and used as inputs to the Stream Salmonid Simulator model, 2005 and 2007-13.

\begin{tabular}{cccc}
\hline Migration year & Iron Gate Hatchery & Bogus Creek & Shasta River \\
\hline 2005 & $5,369,792$ & $1,249,507$ & 295,699 \\
2007 & $5,364,332$ & $1,894,530$ & 579,735 \\
2008 & $5,312,954$ & $3,038,579$ & 988,525 \\
2009 & 993,146 & $1,757,423$ & 723,952 \\
2010 & $4,528,056$ & $5,449,856$ & $2,347,782$ \\
2011 & $3,937,879$ & $1,196,533$ & 654,624 \\
2012 & $5,031,515$ & $6,496,586$ & 160,530 \\
2013 & $4,223,023$ & $5,397,835$ & $5,218,278$ \\
\hline
\end{tabular}

\section{Ceratonova shasta Spore Concentrations}

C. shasta spore concentrations varied considerably among the years used to calibrate S3 (fig. 19). Spore concentrations during the juvenile migration season exceeded 10 spores/L in 5 of the 9 calibration years but remained well below this threshold in other years. Spore concentrations exceeded 50 spores/L in 2007, 2008, and 2009, years in which high disease prevalence was observed (Som, Hetrick, and others, 2016). Although we used a regression model to fill in missing within-year spore concentrations, in 2007 and 2009 spore concentrations were well above the 10 spore/L threshold when data collection began. These are particularly important periods because actual spore concentrations may have been more or less than predicted our regression model, which will influence predictions of $C$. shasta-induced mortality. 


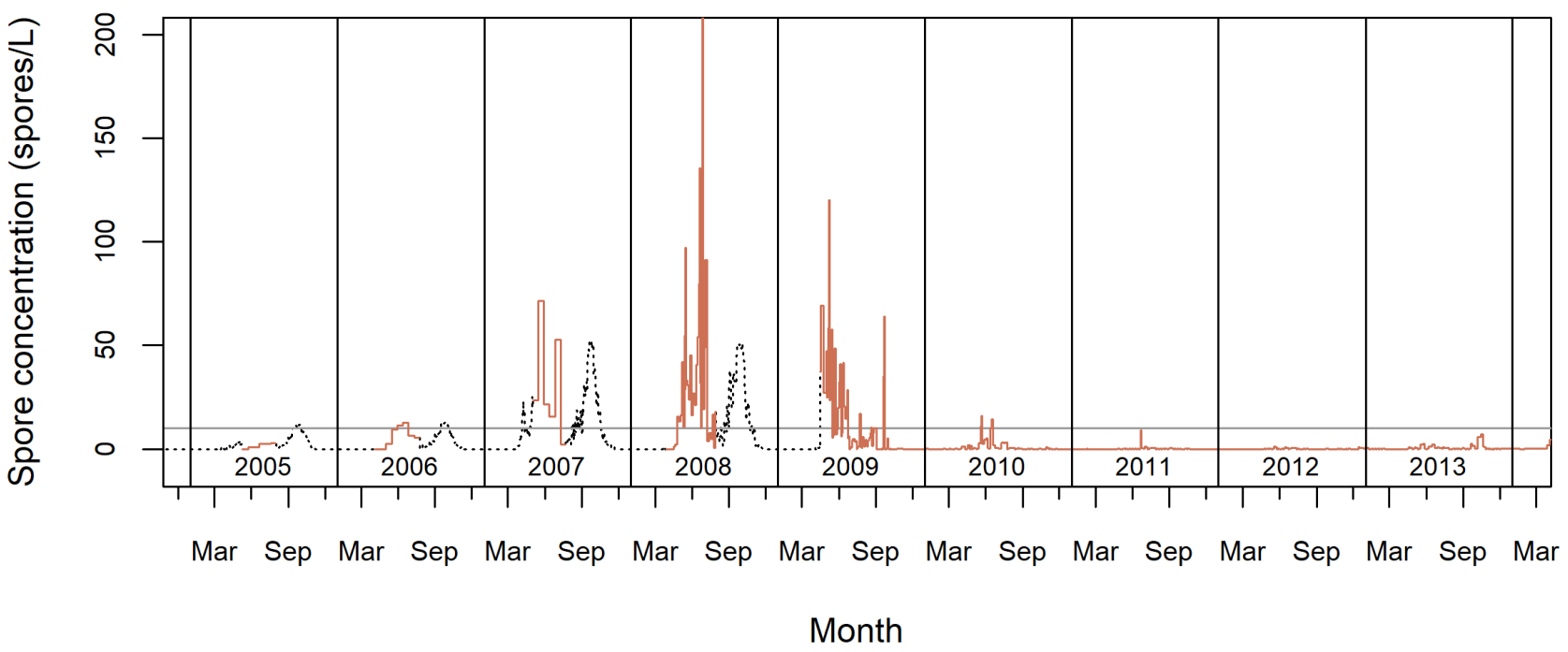

Figure 19. Daily time series of Ceratonova shasta spore concentration used in calibration of Stream Salmonid Simulator model for the Klamath River, California, 2005-13. Orange solid line shows daily spore concentrations for periods when water samples were collected on a biweekly or finer time interval. Dotted line shows spore concentrations imputed by a regression model (see fig. 13) for time periods when spore data were not collected. Horizontal gray reference line marks 10 spores per liter (spores/L), a threshold above which prevalence of infection begins to increase.

Physical Inputs

As expected, mean daily temperatures generally increased with the progression of summer. From November to the following August, mean daily Klamath River temperatures at the Kinsman fish trap ranged from 1.6 to $25.8^{\circ} \mathrm{C}$ (table 8 , fig. 20). Simulated river temperatures varied spatially as well. As an example, mean daily temperatures tended to be slightly higher (about $0.4^{\circ} \mathrm{C}$ ) for a given day of year at the Kinsman fish trap than at 15 bridge.

Table 8. Summary statistics for mean daily temperatures at the Kinsman fish trap from November 1 of a brood year to August 31 of the following juvenile migration year, on the Klamath River, California, 2005 and 2007-13.

\begin{tabular}{cccccc}
\hline & \multicolumn{5}{c}{$\begin{array}{c}\text { Percentile of daily temperatures } \\
\text { (degrees Celsius) }\end{array}$} \\
\cline { 2 - 6 } Migration year & Minimum & $\begin{array}{c}\text { 2.5th } \\
\text { percentile }\end{array}$ & $\begin{array}{c}\text { 50th } \\
\text { percentile }\end{array}$ & $\begin{array}{c}\text { 97.5th } \\
\text { percentile }\end{array}$ & Maximum \\
\hline 2005 & 3.2 & 4.0 & 9.7 & 22.4 & 22.8 \\
2007 & 2.3 & 2.9 & 11.3 & 23.2 & 24.4 \\
2008 & 2.6 & 2.9 & 8.8 & 23.0 & 23.6 \\
2009 & 2.9 & 3.5 & 9.8 & 24.2 & 25.8 \\
2010 & 2.5 & 3.1 & 9.2 & 23.7 & 24.8 \\
2011 & 2.6 & 3.8 & 8.4 & 23.0 & 23.5 \\
2012 & 2.4 & 2.6 & 8.0 & 23.2 & 24.0 \\
2013 & 1.6 & 2.3 & 10.3 & 24.2 & 25.0 \\
\hline
\end{tabular}



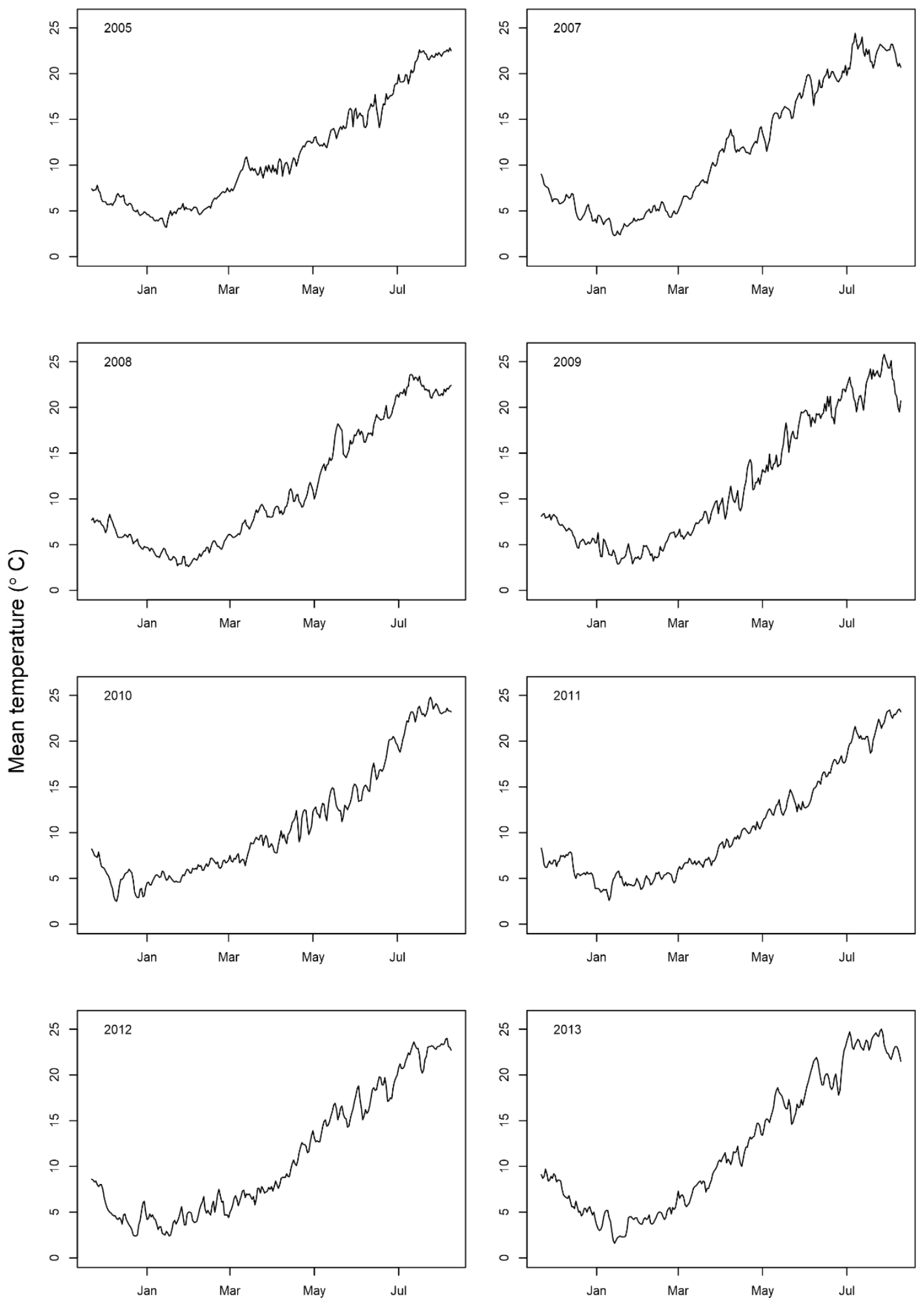

Month

Figure 20. Time series of mean daily temperatures, by migration year, at the Kinsman fish trap, on the Klamath River, California, 2005 and $2007-13 .{ }^{\circ} \mathrm{C}$, degrees Celsius. 
Mean daily river flows showed much more variability between years than mean daily temperatures (table 9, fig. 21). The lowest median river flows were measured during the 2013 migration year (median flow at Kinsman $=1,810 \mathrm{ft}^{3} / \mathrm{s}$ ), yet the highest river flows for the longest duration were measured in the 2011 migration year (peak flow at Kinsman $=8,960 \mathrm{ft}^{3} / \mathrm{s}$ ) with flows $>3,000 \mathrm{ft}^{3} / \mathrm{s}$ from March through July. Peak flows in the Klamath River generally occurred in April or May, but peak flows also were measured in wintertime during the December and January that preceded migration years 2005, 2007, and 2013.

Table 9. Summary statistics for mean daily river flows at the Kinsman fish trap from November 1 of a brood year to August 31 of the following juvenile migration year, on the Klamath River, California, 2005 and 2007-13.

\begin{tabular}{|c|c|c|c|c|c|}
\hline \multirow{2}{*}{ Migration year } & \multicolumn{5}{|c|}{$\begin{array}{l}\text { Percentile of daily river flow } \\
\text { (cubic feet per second) }\end{array}$} \\
\hline & Minimum & $\begin{array}{c}\text { 2.5th } \\
\text { percentile }\end{array}$ & $\begin{array}{c}\text { 50th } \\
\text { percentile }\end{array}$ & $\begin{array}{c}\text { 97.5th } \\
\text { percentile }\end{array}$ & Maximum \\
\hline 2005 & 1,043 & 1,069 & 1,578 & 6,135 & 7,980 \\
\hline 2007 & 1,125 & 1,133 & 2,264 & 5,775 & 6,350 \\
\hline 2008 & 1,183 & 1,192 & 2,705 & 4,357 & 4,680 \\
\hline 2009 & 1,113 & 1,125 & 1,898 & 2,940 & 3,320 \\
\hline 2010 & 1,022 & 1,040 & 1,998 & 3,010 & 4,010 \\
\hline 2011 & 1,373 & 1,467 & 3,274 & 7,255 & 8,960 \\
\hline 2012 & 1,192 & 1,211 & 1,980 & 6,245 & 7,750 \\
\hline 2013 & 952 & 959 & 1,810 & 3,625 & 7,180 \\
\hline
\end{tabular}



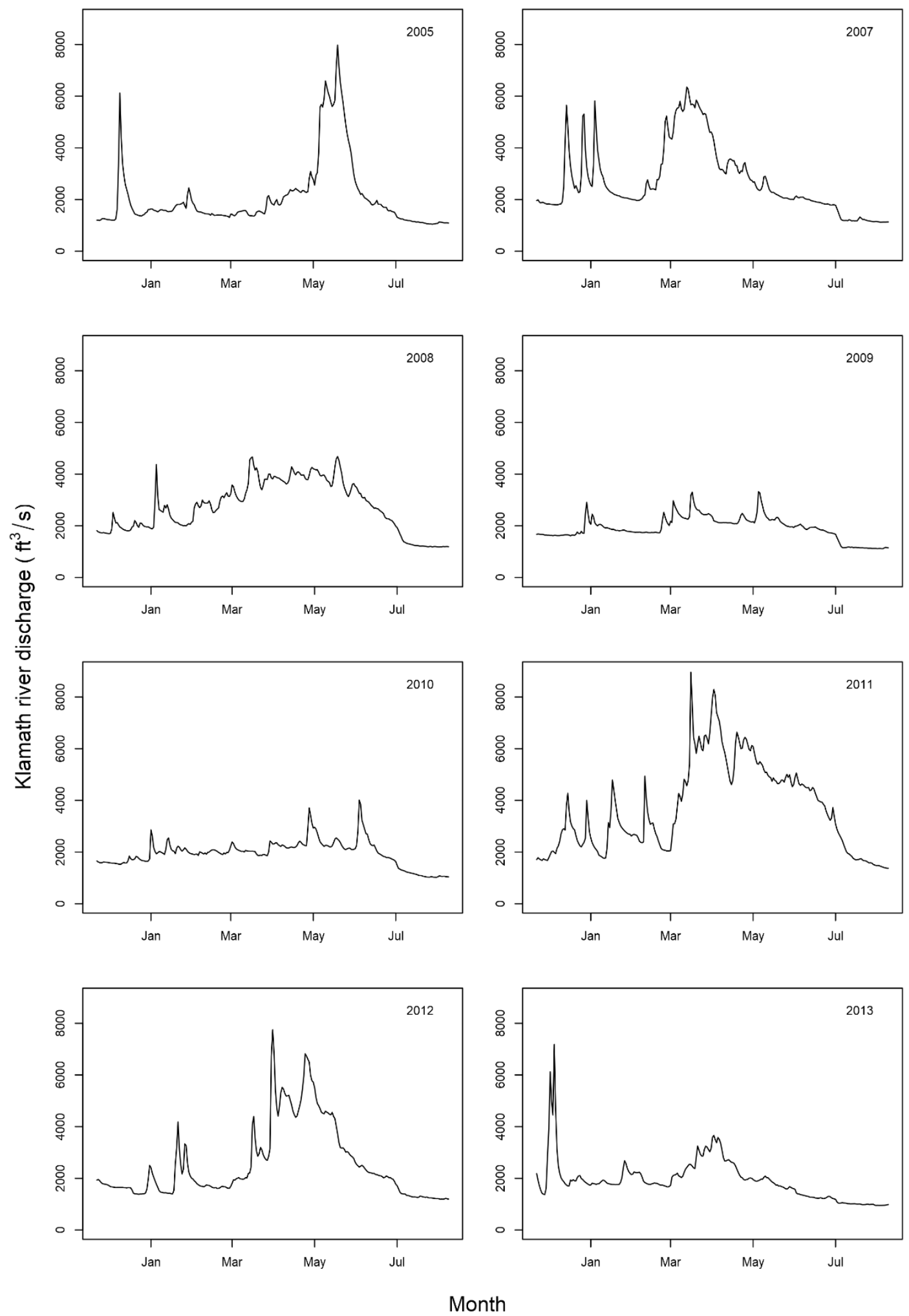

Figure 21. Time series of mean daily river flows, by migration year, at the Kinsman fish trap, on the Klamath River, California, 2005 and 2007-13. $\mathrm{ft}^{3} / \mathrm{s}$, cubic feet per second. 


\section{Egg-to-Fry Survival and Fry Emergence}

The survival of eggs during incubation is determined by the daily temperatures and the baseline daily egg mortality rate. Because overwinter temperatures remained within the optimal range for egg incubation and survival, total egg-to-fry survival was consistent among years (table 10). Spatial variation in egg-to-fry survival is driven primarily by the superimposition model. Thus, slightly lower survival occurs closer to Iron Gate Dam where spawning densities are highest (fig. 22). The spatial distribution of emerging fry (fig. 23) mirrored the spatial distribution of spawning females (fig. 17), with most juvenile salmon emerging in the $12-\mathrm{km}$ stretch of river below Iron Gate Dam. Depending on the year, the median simulated emergence time for Klamath River Chinook salmon was from late March to early April (fig. 24), but fry emergence was observed as early as late December or early January in some years (appendix 7).

Table 10. Percentile dates of emergence timing for simulated juvenile Chinook salmon, by migration year, from Iron Gate Dam (river kilometer [rkm] 312) to Kinsman fish trap (rkm 236), on the Klamath River, California, 2005 and 2007-13.

\begin{tabular}{clllcc}
\hline \multirow{2}{*}{$\begin{array}{c}\text { Migration } \\
\text { year }\end{array}$} & \multicolumn{2}{c}{ Percentile dates for fry emergence } & \multirow{2}{*}{ Total fry emerged } & \multirow{2}{*}{ Egg-to-fry survival } \\
\cline { 2 - 4 } 2005 & 20th percentile & 50th percentile & 80th percentile & & \\
2007 & February 16 & March 9 & March 21 & $6,314,502$ & 0.704 \\
2008 & April 1 & April 10 & April 19 & $4,600,992$ & 0.686 \\
2009 & March 19 & March 24 & April 5 & $9,144,774$ & 0.677 \\
2010 & March 14 & March 25 & April 5 & $6,993,183$ & 0.688 \\
2011 & March 14 & March 27 & April 8 & $9,490,932$ & 0.690 \\
2012 & March 17 & April 3 & April 15 & $4,047,617$ & 0.691 \\
2013 & February 19 & March 10 & March 24 & 19,464,123 & 0.677 \\
\hline
\end{tabular}




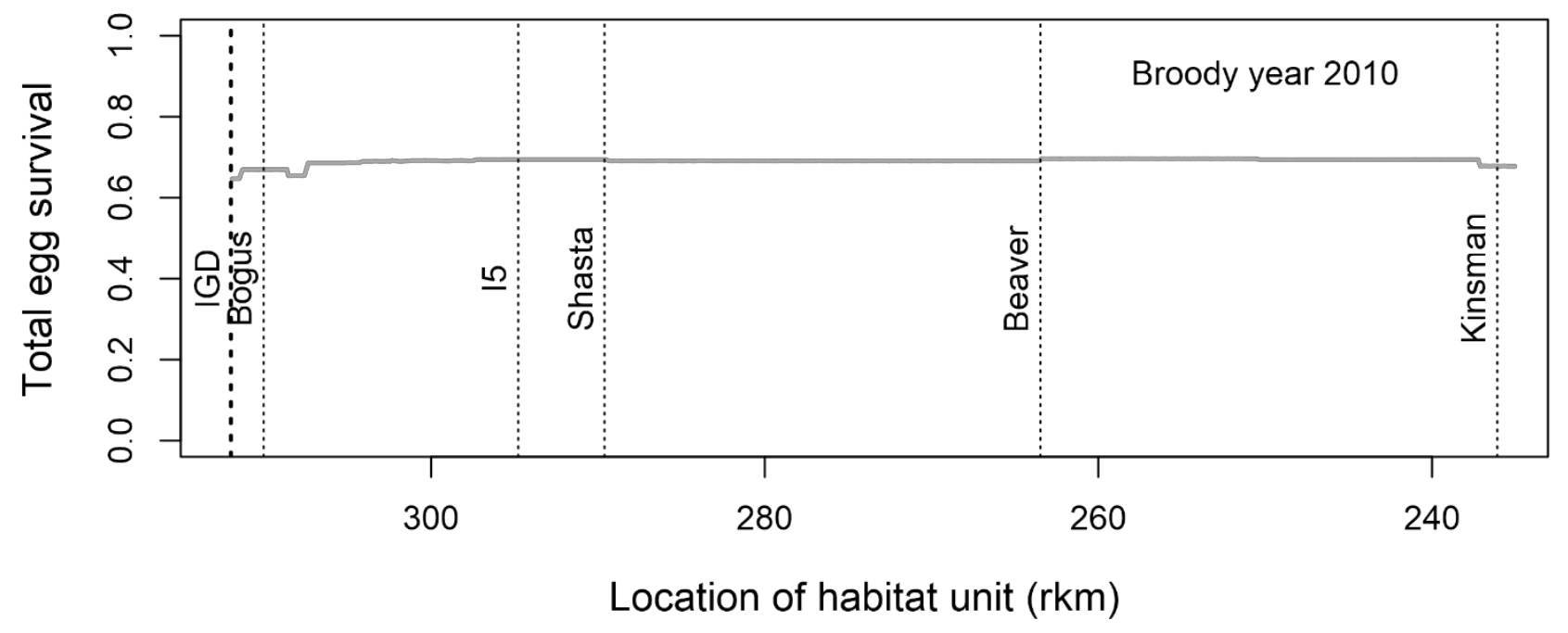

Figure 22. Graph showing spatial distribution of egg-to-fry survival for Chinook salmon in the Klamath River, California, brood year 2010. Beaver, Beaver Creek; Bogus, Bogus Creek; I5, I5 trap near Interstate 5 bridge; IGD, Iron Gate Dam; Kinsman, Kinsman fish trap; Shasta, Shasta River; rkm, river kilometer.

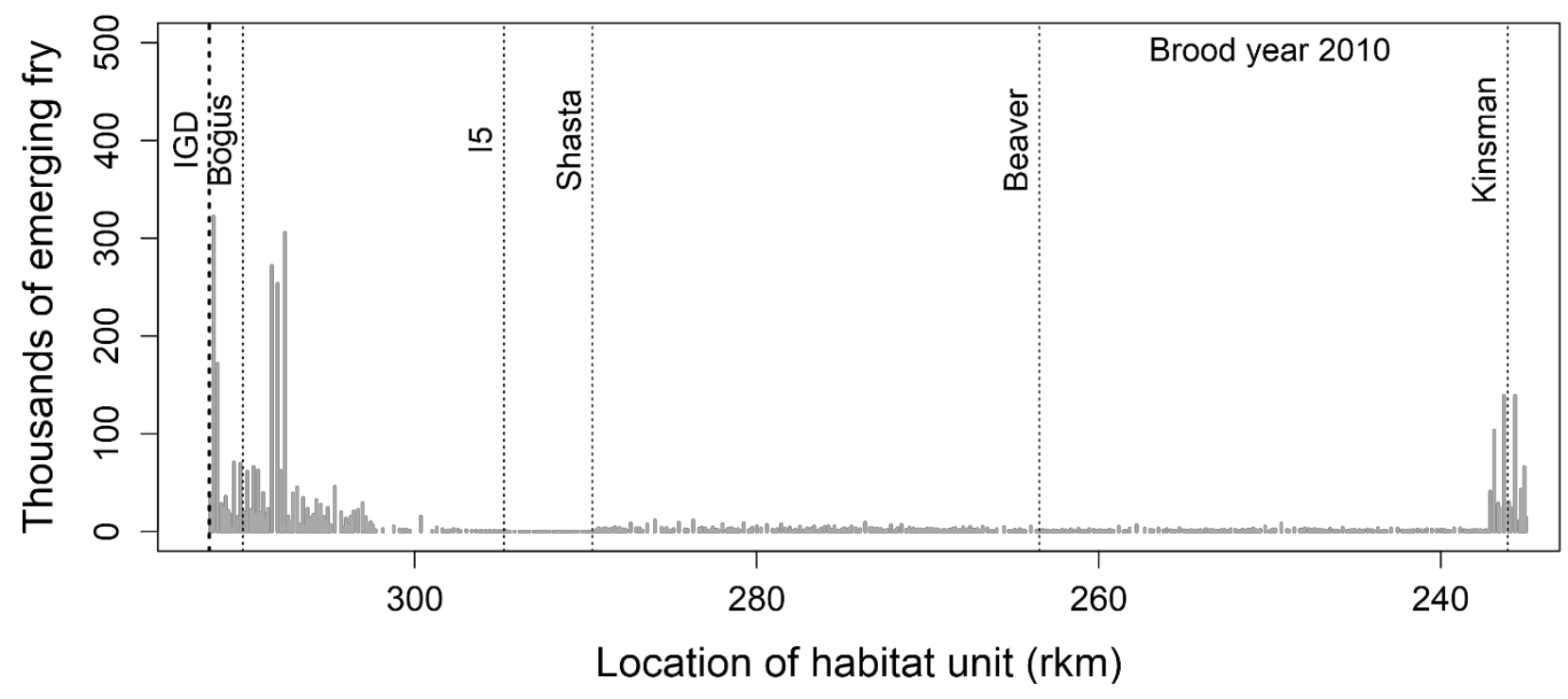

Figure 23. Graph showing spatial distribution of emerging Chinook salmon fry in the Klamath River, California, brood year 2010. Beaver, Beaver Creek; Bogus, Bogus Creek; I5, I5 trap near Interstate 5 bridge; IGD, Iron Gate Dam; Kinsman, Kinsman fish trap; Shasta, Shasta River; rkm, river kilometer. 


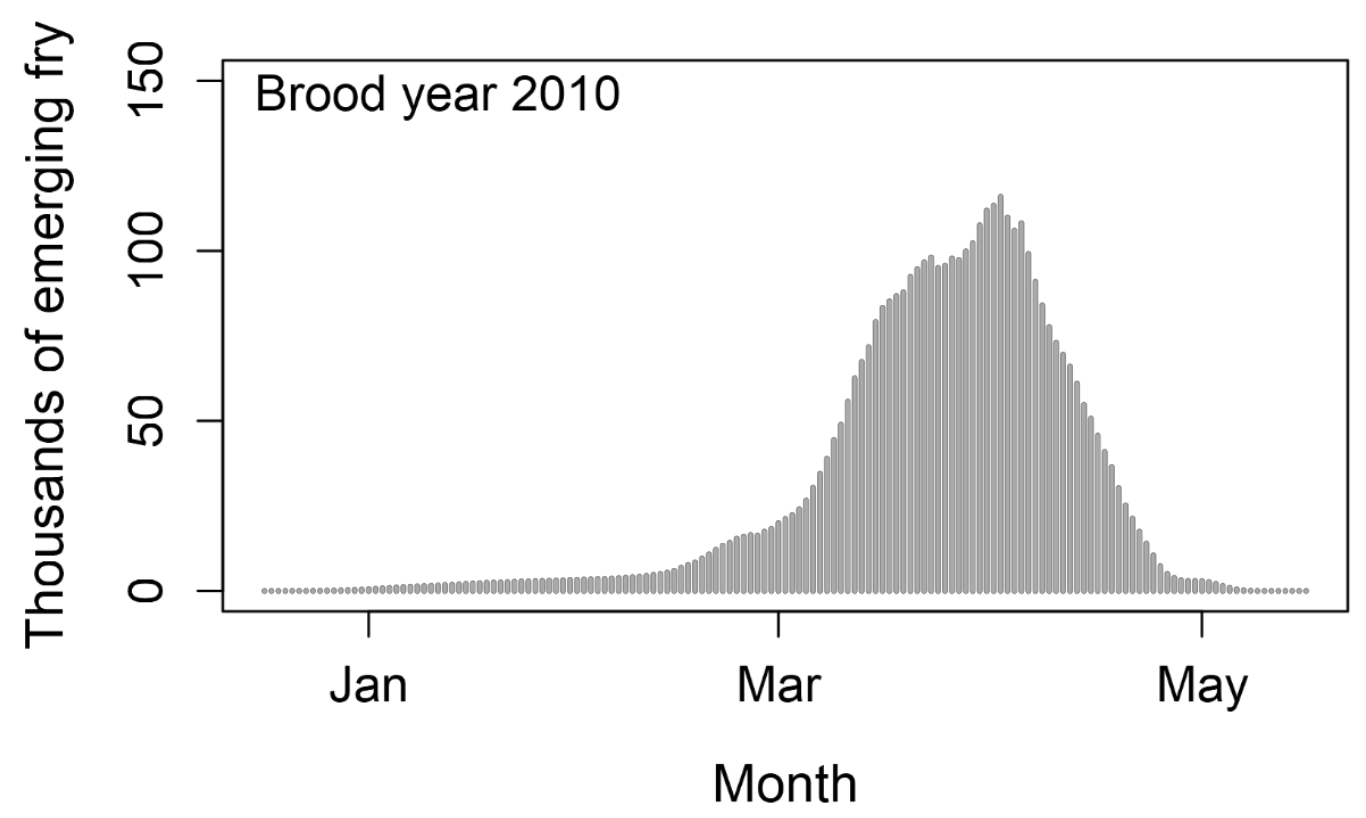

Figure 24. Graph showing temporal distribution of Chinook salmon fry emergence in the Klamath River, California, brood year 2010. See appendix 7 for other modeled brood years.

\section{Calibration, Model Selection, and Parameter Estimates}

Comparison of $\mathrm{AIC}_{\mathrm{c}}$ values among the candidate models indicated differences in model fit to the weekly abundance estimates (table 11). The $\mathrm{AIC}_{\mathrm{c}}$ best model (model 5) included only stage-specific parameters for survival and movement. The second-best model (model 3) was similar but expressed survival as density-independent and movement as density-dependent. Many of the models (models 2,4 , 6,7 , and 8 ) yielded inestimable covariance matrices, suggesting insufficient information in the data to estimate parameters with uncertainty. Model 5 had five parameters and the lowest AIC, but the model was insensitive to density-dependent processes and changes in habitat volume, whereas Model 3 had the lowest $\mathrm{AIC}_{\mathrm{c}}$ and, only three parameters, so we selected this model for simulation and comparison of model fit.

Although we selected model 3 for inference, we provide estimated parameter values under all models for comparison (tables 12 and 13). Under model 3, we estimated a maximum density of 47.6 juveniles per square meter of weighted usable area. Along with the estimate of 0.5178 for $P_{\text {stay }}$, figure 25 shows how daily movement probability increases with fish density. 
Table 11. Model-selection results based on Akaike's Information Criterion for small samples $\left(\mathrm{AIC}_{\mathrm{c}}\right)$, showing number of parameters, negative log-likelihood (NLL), and the relative difference $\left(\triangle \mathrm{AIC}_{\mathrm{c}}\right)$ of candidate Stream Salmonid Simulator models fit to weekly abundance estimates at the Kinsman fish trap, for the Klamath River, California.

[See table 5 for explanation of model nomenclature. "--" indicates that the model did not converge]

\begin{tabular}{clcccc}
\hline Model number & \multicolumn{1}{c}{ Model } & $\begin{array}{c}\text { Number of } \\
\text { parameters }\end{array}$ & NLL & AlC c & $\begin{array}{c}\Delta \text { AlC }_{\text {c relative to }} \\
\text { best model }\end{array}$ \\
\hline 1 & $\mathrm{~S}(.) \mathrm{M}()$. & 2 & 1927.906 & 3859.812 & 5.4 \\
12 & $\mathrm{~S}(\mathrm{BH}) \mathrm{M}()$. & 4 & 1933.272 & 3874.544 & 20.1 \\
3 & $\mathrm{~S}(.) \mathrm{M}(\mathrm{BH})$ & 3 & 1926.102 & 3858.205 & 3.8 \\
14 & $\mathrm{~S}(\mathrm{BH}) \mathrm{M}(\mathrm{BH})$ & 5 & 1925.200 & 3860.399 & 5.9 \\
5 & $\mathrm{~S}(\mathrm{~s}) \mathrm{M}(\mathrm{s})$ & 5 & 1922.223 & 3854.445 & 0 \\
${ }^{1} 6$ & $\mathrm{~S}(\mathrm{~s}, \mathrm{BH}) \mathrm{M}(\mathrm{s})$ & 7 & 1924.912 & 3863.823 & 9.4 \\
17 & $\mathrm{~S}(\mathrm{~s}) \mathrm{M}(\mathrm{s}, \mathrm{BH})$ & 7 & - & - & - \\
18 & $\mathrm{~S}(\mathrm{~s}, \mathrm{BH}) \mathrm{M}(\mathrm{s}, \mathrm{BH})$ & 9 & - & - & - \\
\hline
\end{tabular}

${ }^{1}$ Lack of model convergence or inestimable variance-covariance matrix.

Table 12. Parameter estimates for the four Stream Salmonid Simulator candidate models that expressed survival and movement parameters as constant between fry and parr life stages, for the Klamath River, California.

[Standard errors, where estimable, are shown in parentheses. "-" indicates that the parameter was not estimated under the given model]

\begin{tabular}{llllc}
\hline \multicolumn{1}{c}{ Parameter } & \multicolumn{1}{c}{ Model 1 } & \multicolumn{1}{c}{ Model 2 } & \multicolumn{1}{c}{ Model 3 } & Model 4 \\
\hline$S_{\text {fry }}, S_{\text {parr }}$ & $0.9561(0.0019)$ & 0.9690 & $0.9581(0.0051)$ & 0.9826 \\
$S_{\text {smolt }}$ & - & $0.9537(0.0103)$ & - & $0.9555(0.0119)$ \\
$c_{\text {surv,fry }}, c_{\text {surv,parr }}$ & - & 35,463 & - & 5,001 \\
$P_{\text {stay,fry }}, P_{\text {stay,parr }}$ & $0.292(0.0098)$ & $0.5(0.0100)$ & $0.5718(0.0332)$ & 0.7779 \\
$c_{\text {mov,fry }}, c_{\text {mov,parr }}$ & - & - & $47.59(6.4205)$ & $25.5188(1.4645)$ \\
\hline
\end{tabular}

Table 13. Parameter values for the four Stream Salmonid Simulator candidate models that expressed survival and movement parameters separately between fry and parr life stages, for the Klamath River, California.

["-" indicates that the model did not converge. "NA" indicates that the parameter was not estimated under the given model.]

\begin{tabular}{lcccc}
\hline \multicolumn{1}{c}{ Parameter } & Model 5 & Model 6 & Model 7 & Model 8 \\
\hline$S_{\text {fry }}$ & $0.9675(0.0013)$ & $0.9567(0.0012)$ & - & - \\
$c_{\text {surv,fry }}$ & NA & 23,325 & - & - \\
$P_{\text {stay,fry }}$ & $0.1166(0.0057)$ & $0.0100(0.0004)$ & - & - \\
$c_{\text {mov,fry }}$ & NA & NA & - & - \\
$S_{\text {parr }}$ & $0.9466(0.0094)$ & $0.9828(0.0008)$ & - & - \\
$c_{\text {surv,parr }}$ & $\mathrm{NA}$ & 35,470 & - & - \\
$P_{\text {stay,parr }}$ & $0.5825(0.0164)$ & $0.4249(0.0122)$ & - & - \\
$c_{\text {mov,parr }}$ & $\mathrm{NA}$ & $\mathrm{NA}$ & - & - \\
$S_{\text {smolt }}$ & $0.9500(0.0096)$ & $0.9511(0.0091)$ & - & - \\
\hline
\end{tabular}




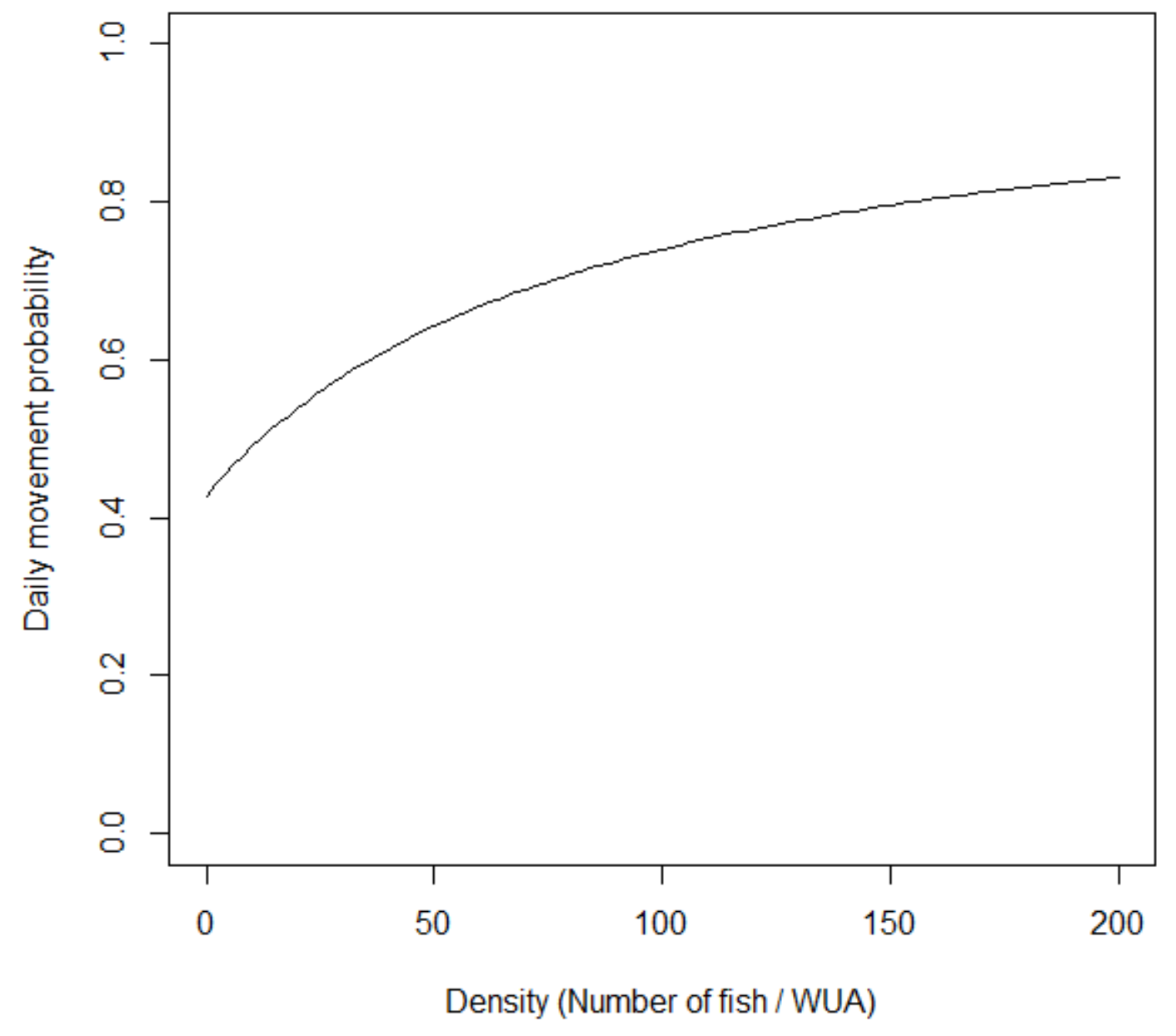

Figure 25. Graph showing effect of fish density on the daily probability of juvenile fall Chinook salmon moving downstream in the Klamath River, California. Number of fish / WUA, number of fish divided by weighted usable habitat area.

\section{Goodness of Fit}

\section{Simulated and Estimated Abundance}

Overall, the S3 model predicted the total annual abundances of juvenile Chinook salmon at the Kinsman fish trap reasonably well in most years except when abundance was high. There was little indication of outlying values in the relation between the simulated annual abundances and those estimated at the trap except for the two highest-abundance years when the model underpredicted the observed abundance (fig. 26). The largest outlying value between simulated and estimated abundances was observed at the Kinsman fish trap during the 2013 migration year. In contrast, there was much more variation between estimated and simulated weekly abundances compared to the annual abundances (fig. 27). 
Although weekly abundance simulated by S3 generally tracked observed weekly abundance (fig. 28), this pattern was better matched in some years (fig. 29). For example, S3 considerably overpredicted estimated abundance in migration year 2013 but matched weekly abundance reasonably well in the other years.

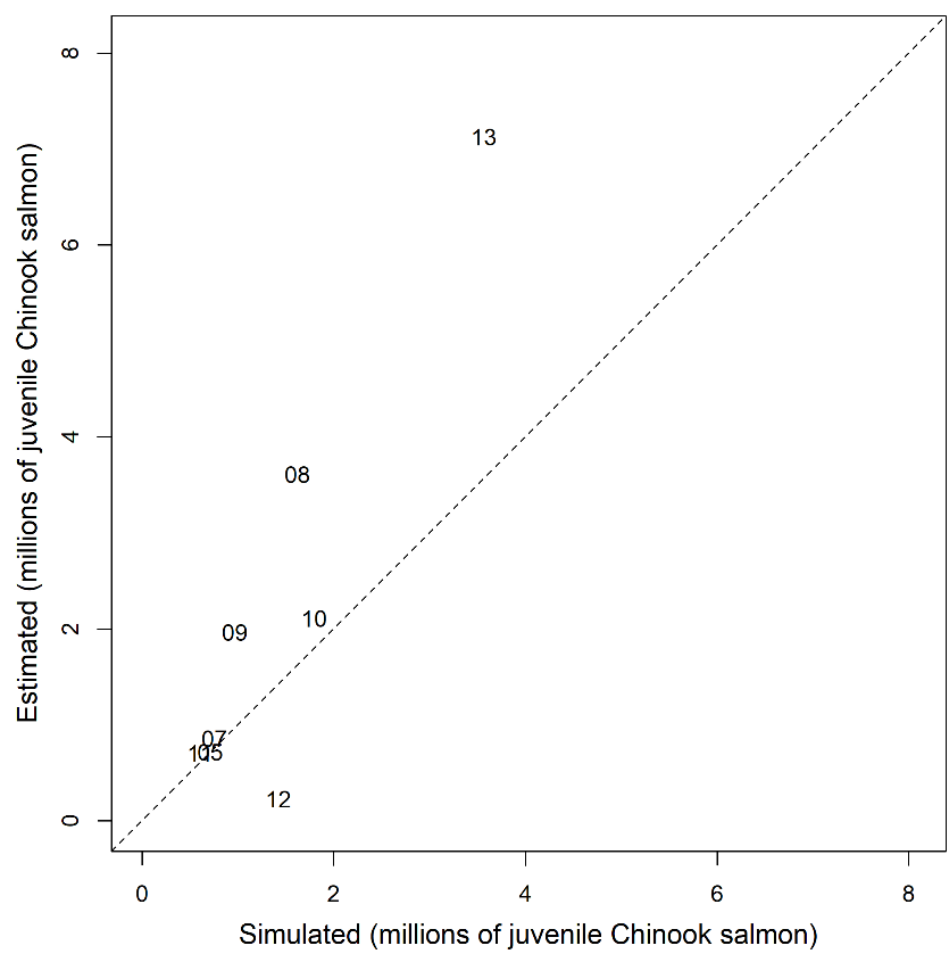

Figure 26. Graph showing annual abundance estimates for juvenile fall Chinook salmon that passed the Kinsman fish trap compared to those simulated by Stream Salmonid Simulator model, on the Klamath River, California, 2005 and 2007-13. Data points represent the last two digits of the migration year. 

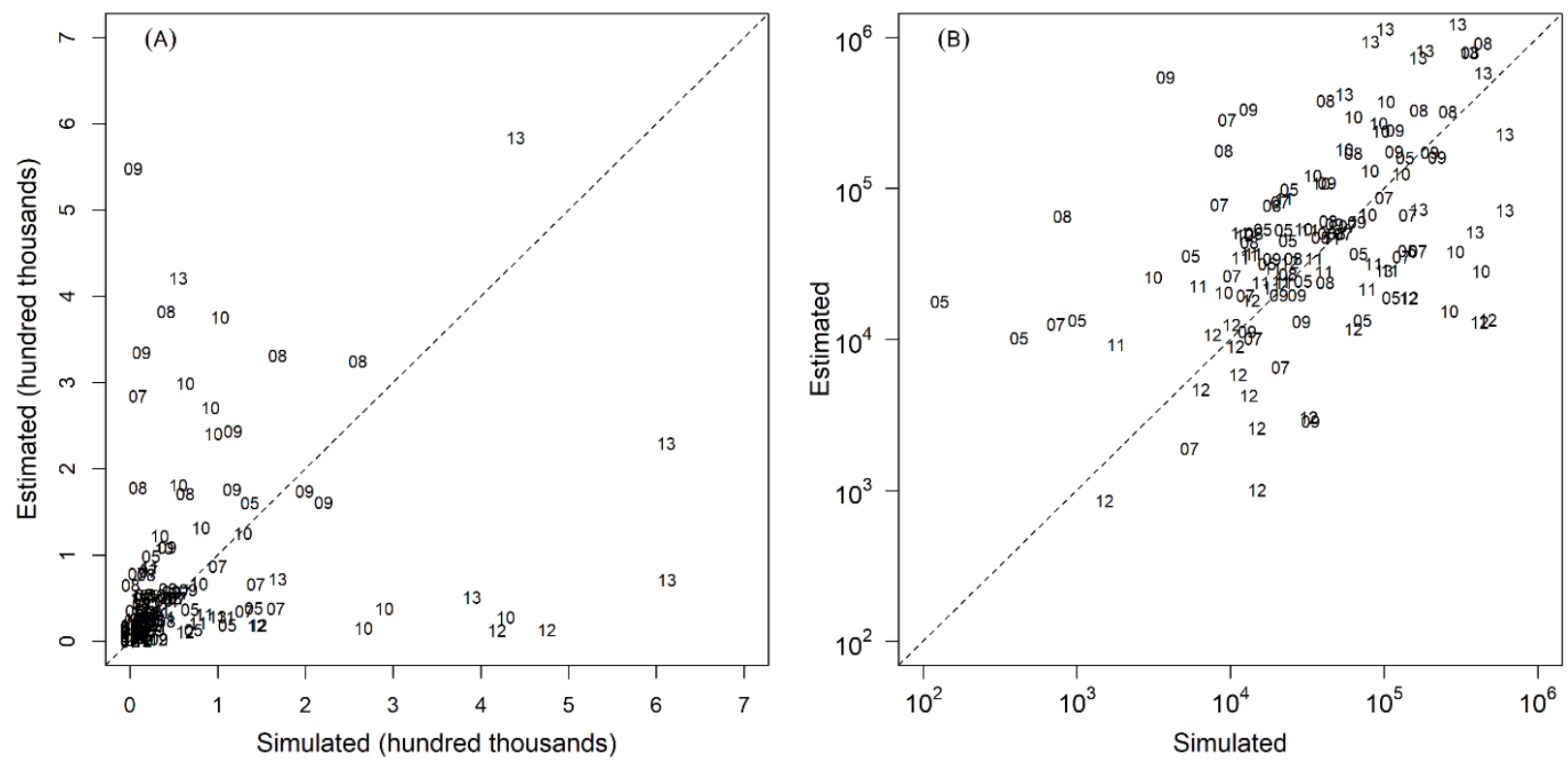

Figure 27. Graphs showing weekly abundance estimates on the $\log (A)$ and observed $(B)$ scales, for fall Chinook salmon that passed Kinsman fish trap compared to those simulated by the Stream Salmonid Simulator model, on the Klamath River, California, 2005 and 2007-13. Data points represent the last two digits of the migration year.

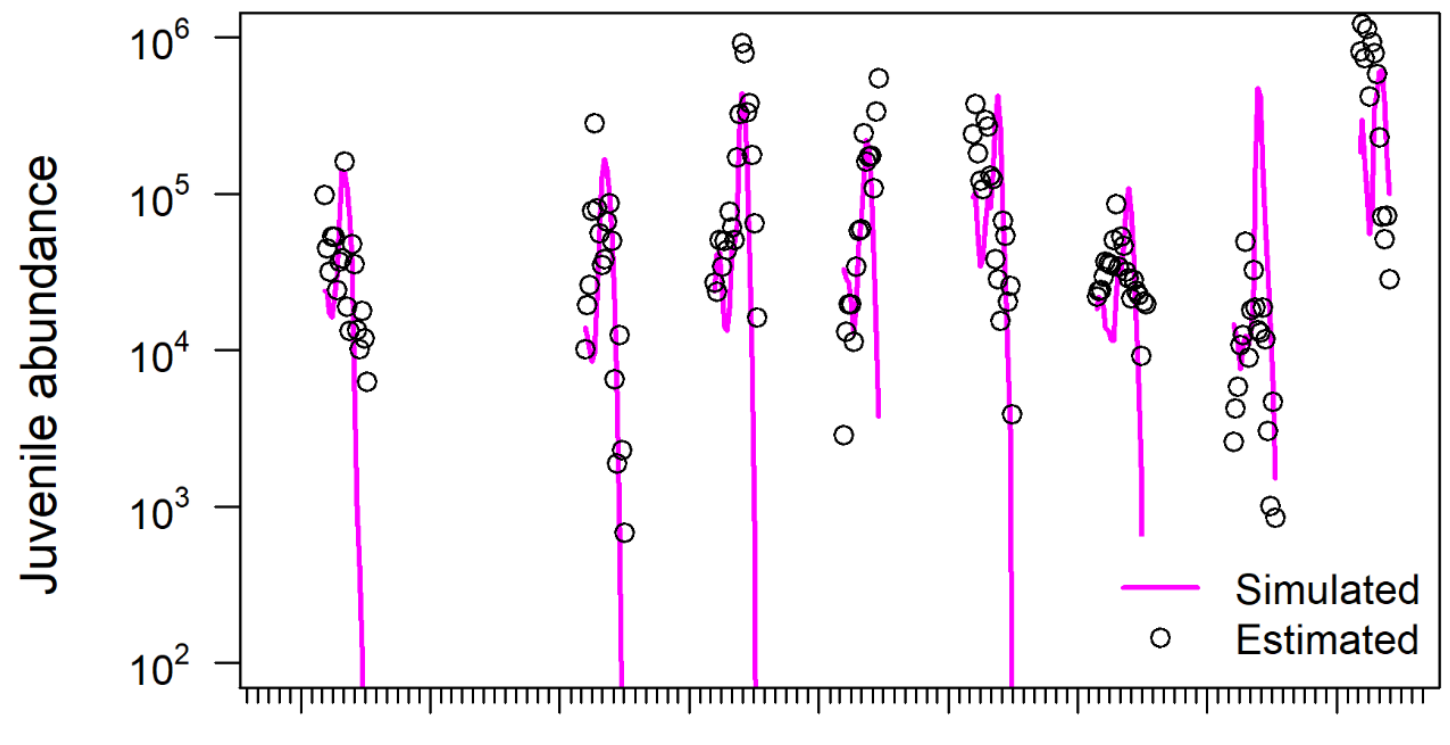

200520062007200820092010201120122013

Figure 28. Graph showing weekly abundance estimates (log-scale) for fall Chinook salmon that passed Kinsman fish trap and those simulated by the Stream Salmonid Simulator model, on the Klamath River, California, 2005-13. 

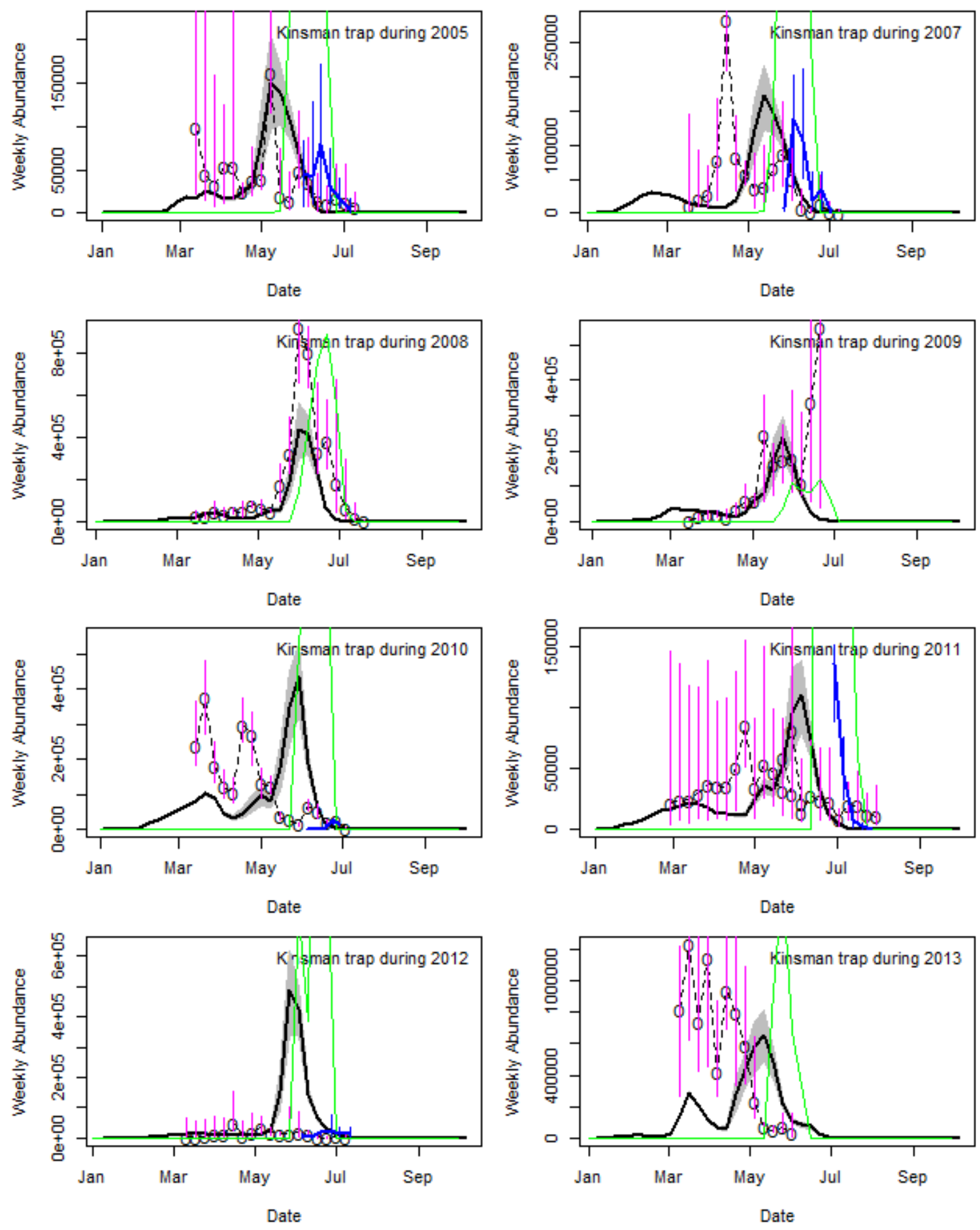

Figure 29. Graphs showing estimated abundance of juvenile fall Chinook salmon passing the Kinsman fish trap, in the Klamath River, California, migration years 2005 and 2007-13. Black solid lines represents the simulated abundance of naturally produced juvenile fall Chinook salmon, and gray shaded area represent the 2.5 th and 97.5th percentiles about the simulated abundances. Open circles and dashed lines represent the weekly abundance estimates from mark-recapture studies and vertical pink lines are the 95-percent credible intervals about these estimates. Curved solid green lines represent simulated abundances of hatchery fish and blue lines represent the estimated abundances of hatchery fish from mark-recapture studies. 


\section{Simulated and Estimated Migration Timing}

Migration timing of juvenile Chinook salmon passing the Kinsman fish trap was well approximated by S3 over the 8 years of data (figs. 30 and 31). Comparison of the estimated and simulated 20th, 50th, and 80th percentiles in migration dates to the Kinsman trap showed that the 50th percentile of the migration in 2013 was simulated later than the estimated 50th percentile of the migration. However, the quantiles of simulated migration timing in 2009 were consistently earlier than estimated from the monitoring data. In contrast, in migration year 2010, simulated run timing was consistently later than that estimated from monitoring data.

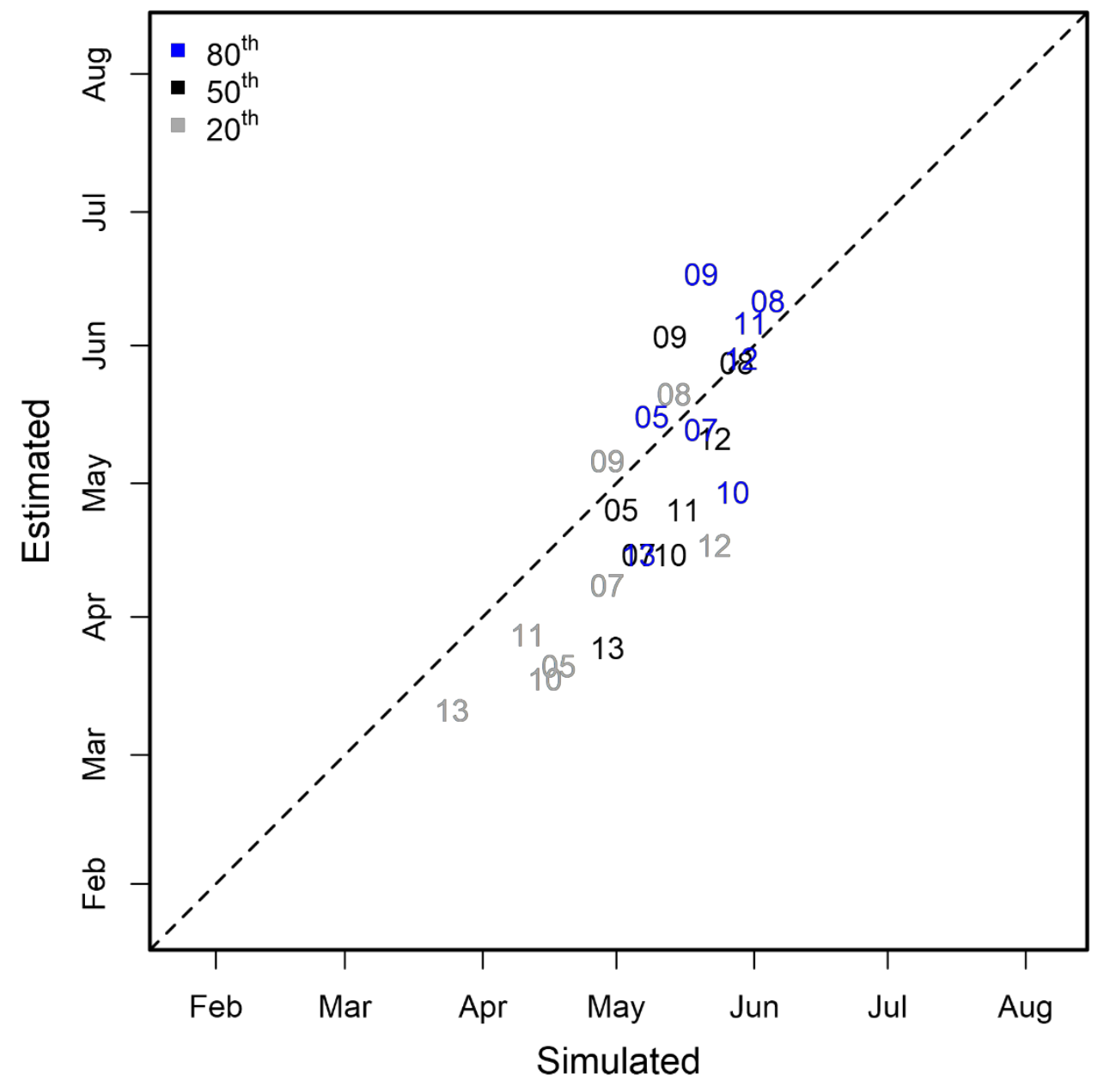

Figure 30. Graph showing 20th, 50th, and 80th percentiles in the migration dates for fall Chinook salmon that passed the Kinsman fish trap compared to those that were simulated by the Stream Salmonid Simulator model, in the Klamath River, California, 2005 and 2007-13. Data points represent the last two digits of the migration year. 


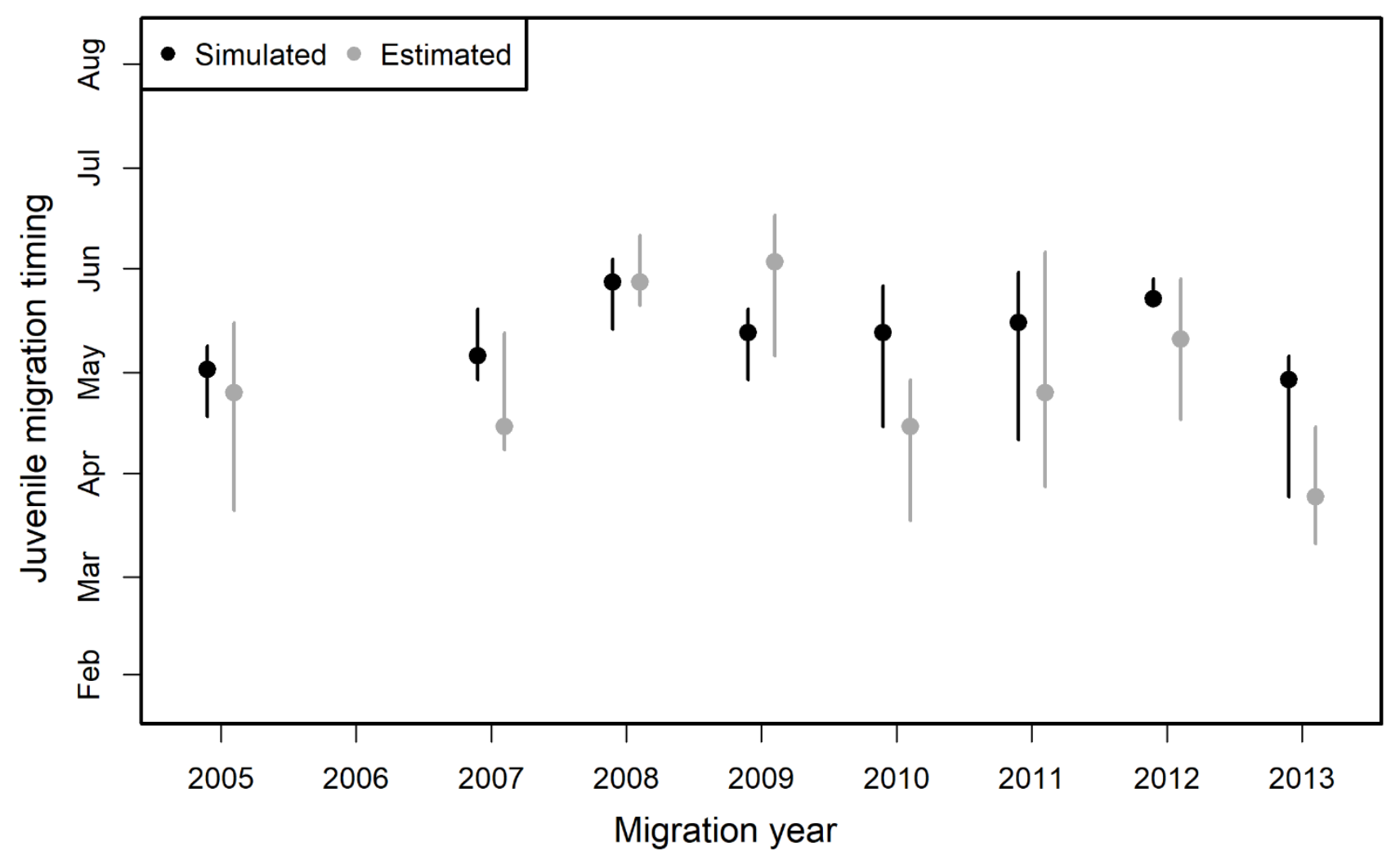

Figure 31. Graph showing 20th (top of bar), 50th (filled circle), and 80th (bottom of bar) percentiles in the emigration dates for fall Chinook salmon that passed the Kinsman fish traps compared to those simulated by the Stream Salmonid Simulator model, in the Klamath River, California, 2005 and 2007-13.

\section{Simulated and Observed Fish Size}

Although we used a literature-based average value for $p\left(\mathrm{C}_{\max }\right)$, simulated mean fish length tracked the trend in the size of fish passing the Kinsman trap (fig. 32). We observed differences in size among fish from the different tributary sources. Across all years, juvenile Chinook salmon originating from the Shasta River were much larger at a given date than the fish from other sources. Although the source population of fish captured by the trap is unknown, the range of individual fish lengths measured at the trap overlapped the mean length of fish from different populations simulated by S3. 

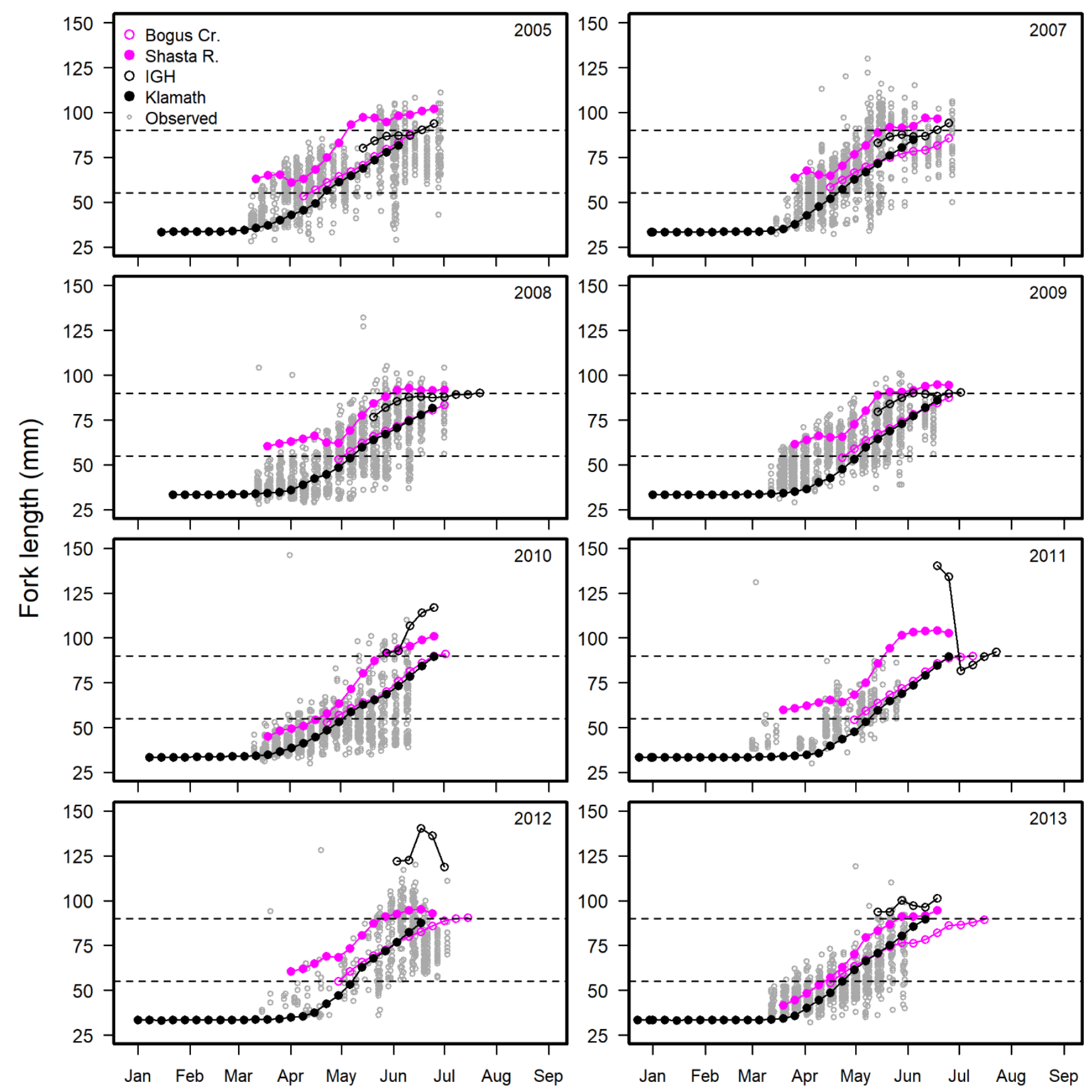

Figure 32. Graphs showing simulated compared to observed fork length of fall Chinook salmon that passed the Kinsman fish trap, on the Klamath River, California, 2005 and 2007-13. Simulated fork-lengths are presented as a weekly average, whereas observed fork lengths show the size of individual fish. Horizontal dashed lines show size cut-offs used to define fry, parr, and smolts in the Stream Salmonid Simulator model. Cr., Creek; IGH, Iron Gate Hatchery; Klamath, Klamath River; R., River; mm, millimeters. 


\section{Disease Model Output}

The S3 model simulates the exposure of each source population to C. shasta and estimates the time-specific proportion of the population infected. During 2007-09, when spore concentrations were high, each population had a different exposure to spores owing to differences in migration timing (fig. 33). Fish from the Klamath River tend to have the longest exposure period relative to fish entering the Klamath River from the Shasta River or Bogus Creek (fig. 33). For example, in 2009, fish from the Klamath River were exposed to high spore concentrations beginning in early April, whereas fish from the Shasta River began exposure in late April and fish from Bogus Creek began exposure in early May, when spore concentrations had declined somewhat. Hatchery-origin fish were released in late spring, and, therefore, had a different exposure profile to $C$. shasta spores. For example, hatchery-origin fish in 2007 had lower spore concentrations than natural-origin fish (fig. 33).

Among years, the highest prevalence of infection occurred in 2007, 2008, and 2009 (fig. 34). In these years, the daily prevalence of infection approached 100 percent, although the timing of infection varied among years. For example, in 2007, prevalence of infection began increasing in mid-April. In contrast, in 2009, despite high spore concentrations in mid-April, prevalence of infection did not begin increasing until mid-May (fig. 34).

We determined that the magnitude and spatial distribution of $C$. shasta mortality simulated by S3 varied among years and occurred predominately downstream of the Kinsman trap and the infectious zone (fig. 35). For example, in 2007, simulated disease-caused mortality was widely distributed between Beaver Creek and the ocean. The highest magnitude of mortality occurred in 2008, and simulations suggest this mortality was widely distributed throughout the lower Klamath River. In contrast, in 2009, the model suggests mortality caused by $C$. shasta was concentrated in the infectious zone and just downstream of the zone, with less mortality in the lower river. Coincident with years of high spore concentrations and infection, most disease-related mortality occurred in 2007, 2008, and 2009. 

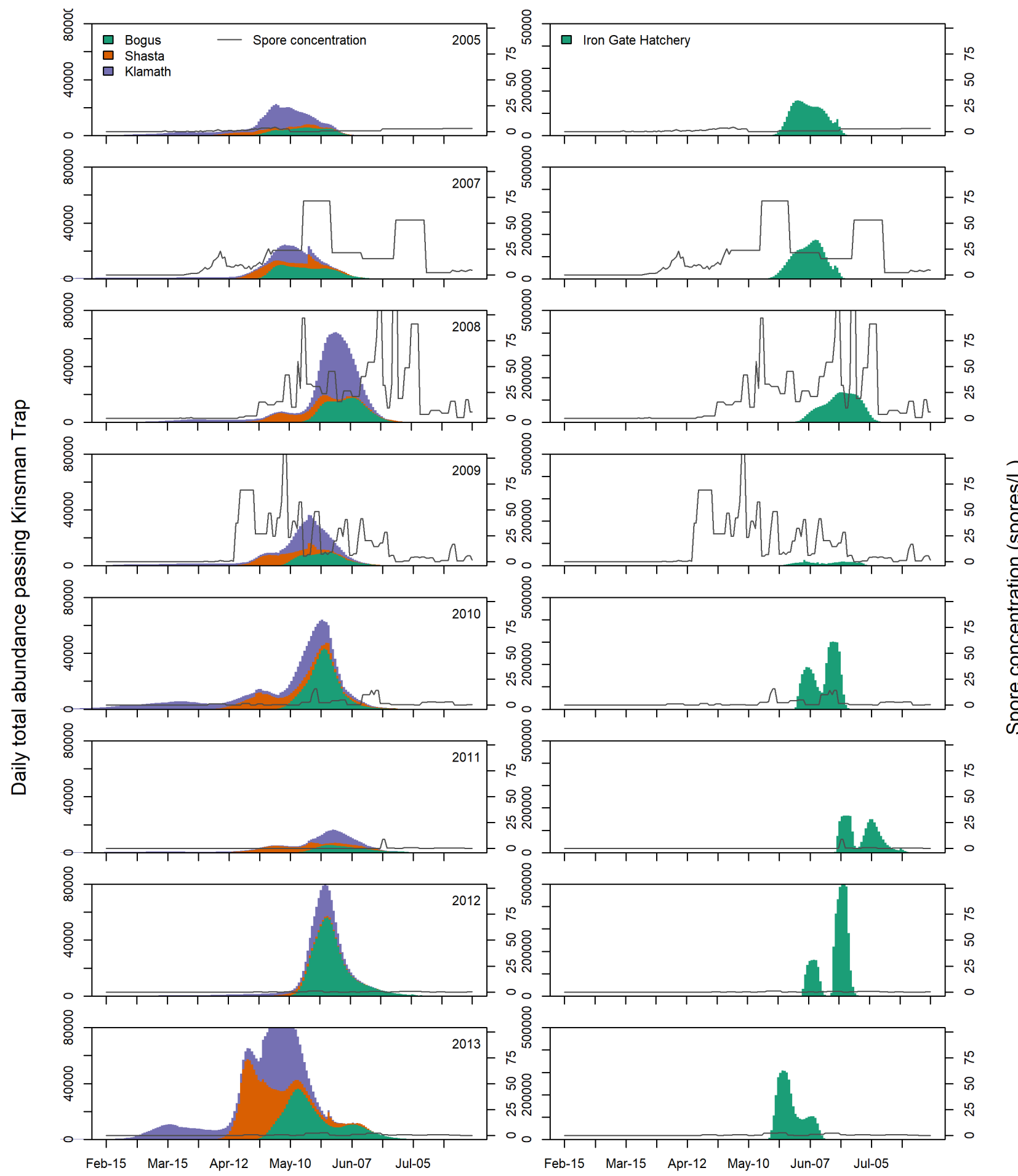

Figure 33. Stacked bar charts showing simulated daily abundance of each source population of juvenile fall Chinook salmon passing the Kinsman trap (left y-axis) and time series of daily spore concentrations (right y-axis), in the Klamath River, California, 2005 and 2007-13. Bogus, Bogus Creek; Klamath, Klamath River; Shasta, Shasta River; spores/L, spores per liter. 


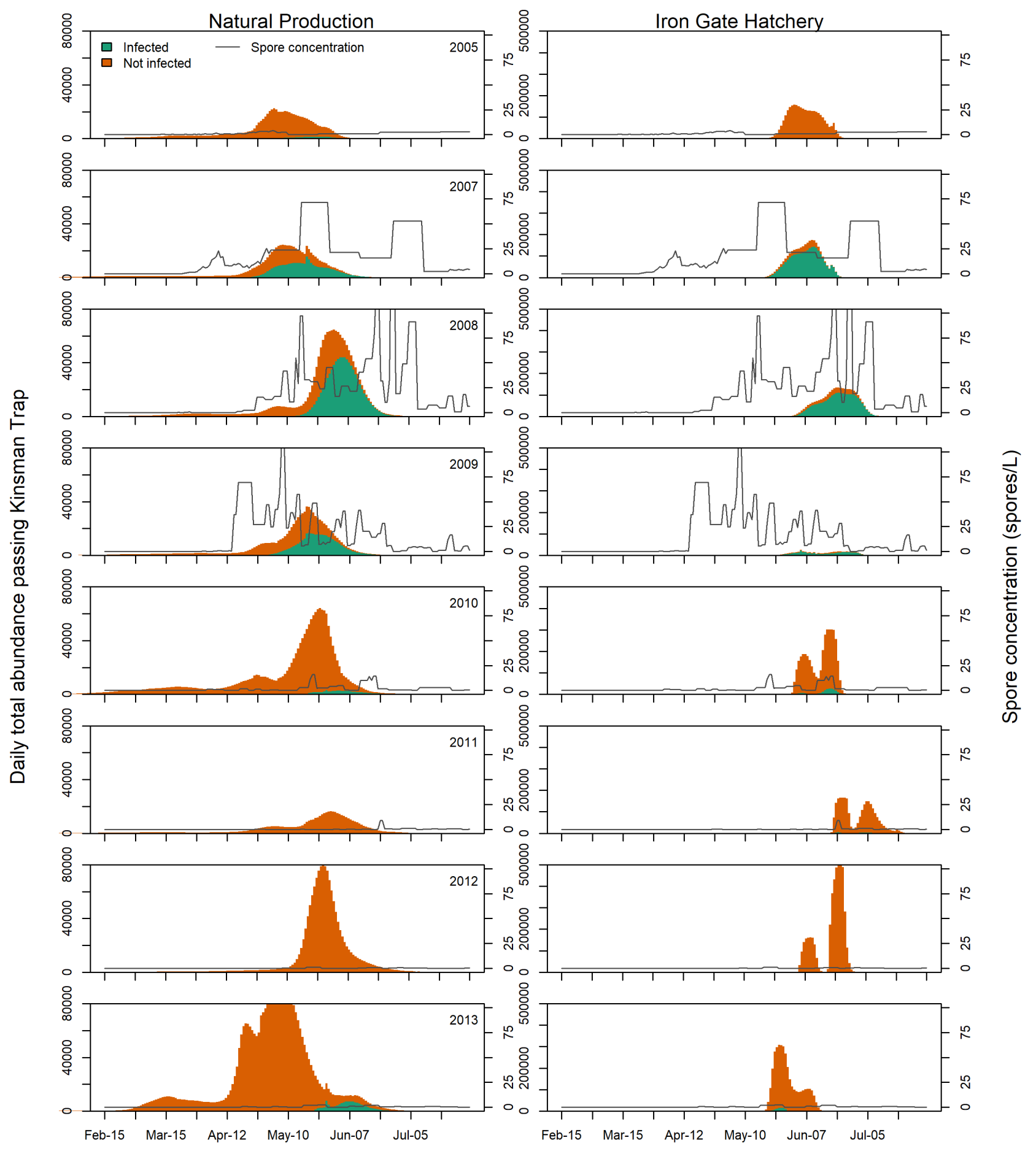

Figure 34. Stacked bar charts showing simulated daily abundance of uninfected fish and juvenile fall Chinook salmon infected with Ceratonova shasta (left y-axis) and time series of daily spore concentrations (right y-axis), in the Klamath River, California, 2005 and 2007-13. 

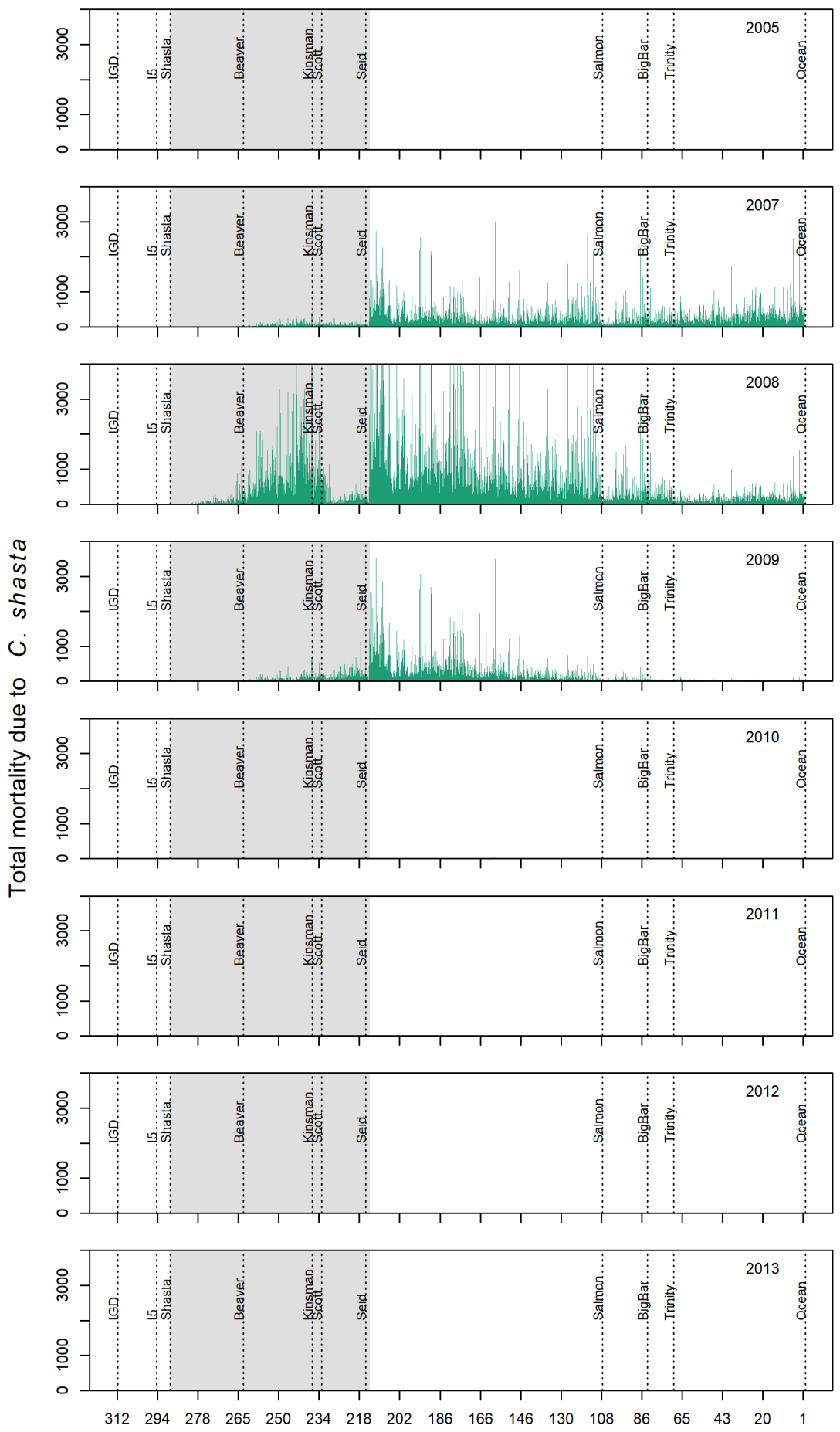

River kilometer

Figure 35. Graphs showing spatial distribution of juvenile fall Chinook salmon mortality owing to Ceratonova shasta, in the Klamath River, California, 2005 and 2007-13. Dashed lines show landmarks of key locations such as tributaries. Gray shaded regions show $C$. shasta disease zone defined in the Stream Salmonid Simulator model. Dashed lines show landmarks along the Klamath River: IGD, Iron Gate Dam; I5, Interstate 5 juvenile salmon trap; Shasta, Shasta River; Kinsman, Kinsman Creek juvenile salmon trap; Scott, Scott River; Salmon, Salmon River; BigBar, Big Bar juvenile salmon trap; Trinity, Trinity River; Ocean, Pacific Ocean. 


\section{Discussion}

The S3 model for the Klamath River provides a unique mesoscale perspective on the population dynamics of juvenile Chinook salmon by modeling the spatiotemporal dynamics of growth, movement, and survival in response to river flow, habitat availability, water temperature, and pathogen exposure. By fitting the S3 model to weekly abundance estimates of juvenile Chinook salmon, we were able to estimate daily movement and survival rates. We compared alternative models for density-dependent and density-independent dynamics and determined that a model supporting density-dependent movement and density-independent survival was most supported by the data, although there was evidence that a more complex stage-specific parameter set could be supported if auxiliary information were available. Additionally, we developed a submodel for disease caused by C. Shasta, which provided insights about prevalence of infection, the spatial distribution of mortality, and exposure of different populations to $C$. shasta spores. Construction of S3 for the Klamath River also helped to highlight knowledge gaps, data limitations, and areas of future improvement. Nonetheless, because water temperature, daily river flows, habitat quality and quantity, and disease-related mortality are key management parameters under consideration in the Klamath River, S3 provides an ideal framework for assessing how water management actions affect freshwater population dynamics of juvenile salmon.

Given that the model was initialized with only the spatiotemporal distribution of spawners and juveniles entering from tributaries, it performed remarkably well at capturing the essential features of the outmigration that governed growth, movement, and mortality rates. However, we noted that some aspects of the calibrated model fit the data better than others. Because we used a common set of parameters for all years, the calibration process estimated parameter values that best captured the average abundance across all years. Therefore, simulated abundance matched estimated abundance in some years, but fit particularly poorly in other years. For example, the model over-predicted abundance in 2008 but underpredicted abundance in 2012 (fig. 29). Lack of fit can arise from multiple causes including (1) incorrectly specified model inputs, (2) imprecise or inaccurate abundance estimates to which model outputs are compared, (3) inaccurate values of fixed parameters (those not estimated during calibration), (4) wrong model structure for demographic rates, or (5) important demographic drivers that are not included in the model. For example, S3 assumes a constant daily egg survival probability and mortality owing to superimposition. Thus, interannual variability in egg survival due to other processes not accounted for in S3 (for example, redd scour) is one factor that could induce lack of fit. Although abundance in some years did not fit as well as in other years, the fitted model performed well at simulating the outmigration timing (figs. 26 and 29). Thus, the dynamic processes of movement, survival, and growth included in the S3 model were able to capture the trend in weekly abundance in most years.

Given that none of the growth parameters were estimated as part of calibration, S3 performed particularly well at predicting the size of juvenile fall Chinook salmon passing the Kinsman trap (fig. 32). This finding is encouraging because the model must predict growth in response to varying temperature for fish that enter the model domain over a wide range of initial sizes, ranging from fry emerging from redds to smolts entering from tributaries and hatcheries. Our primary null hypothesis was that food availability did not limit growth of juveniles in the Klamath River. This hypothesis was modeled by setting the proportion of maximum consumption to 0.66 in the bioenergetics model, which is consistent with the average value in the field reported by Armstrong and Schindler (2011) and matches growth of juvenile Chinook salmon fed an ad libitum diet in the laboratory (Perry and others, 2015). Although S3 predicted average size well under the assumption of constant ration, densitydependent growth is a widely recognized phenomenon in juvenile salmonids (Grant and Imre, 2005). 
Thus, density-dependent growth could occur at the local scale of habitat units where high densities are observed, such as at the mouths of tributaries where large numbers of juveniles enter the Klamath River over short time periods (for example, fig. 18).

Weekly abundance estimates from a juvenile monitoring site just upstream of the mouth of the Shasta River (referred to as the "I5 Trap" owing to its proximity to Interstate 5) were used in model calibration during the preliminary phases of model fitting, but we decided to use only Kinsman Trap data for the final calibration. During initial phases, we determined that S3 was unable to simultaneously match weekly abundance estimates at both trapping sites when using a common set of parameters for the entire spatial domain. For example, when using the model calibrated to Kinsman Trap abundance estimates, simulated abundance passing the I5 trap overpredicted the estimated weekly abundance in nearly all years (appendix 4). If we take the weekly abundance estimates to be unbiased, then this finding suggests that mortality rates must be higher in the reach upstream of I5 and lower in the reach downstream of I5 for the model to simultaneously match abundance estimates at both sites. Yet the reach downstream of I5 is known to be the "highly infectious zone" where mortality rates would be expected to be higher than upstream of I5, at least in years with high spore concentrations. Furthermore, neither density-dependent nor density-independent survival rates were able to simultaneously predict abundance at both sites. Although we could have estimated different survival rates in reaches upstream and downstream of the I5 trap, we had no biological basis for doing so. Therefore, we decided to calibrate the model using only data from the Kinsman Trap since this location captures upstream dynamics for a much greater length of the Klamath River. Future efforts should evaluate whether this disagreement is caused by (1) bias in trap abundance estimates used for fitting, (2) bias in spawner and juvenile abundance estimates used to construct model inputs, or (3) some fundamental biological driver causing differences in survival in reaches upstream and downstream of the I5 trap.

Estimates of weekly abundance are critically important data sources for informing model parameters, but these estimates are imperfect. Relative to the juvenile monitoring program on the Trinity River, the Klamath River program completely samples the outmigration of all naturally produced juveniles in fewer years and conducts fewer mark-recapture trials each year. These aspects of the monitoring program lead to less-precise abundance estimates. These differences stem largely from reduced hatchery fish available for mark-recapture studies and limited fiscal resources rather than issues of sampling design, but nonetheless affect the quality of the model fit to the data. For example, with our Trinity River S3 model, we were able to estimate life-stage-specific parameters as well as the associated variance-covariance matrix (Perry and others, 2018b), whereas variance-covariance matrices could not be estimated for models of similar structure for the Klamath River. This result could be caused by the absence of a complete weekly time series of abundance in many years. Because model fit is driven only by weeks with valid estimates of trap abundance, the overall fit is a function of (1) model parameter values, (2) simulated abundance that overlaps weeks with valid trap abundance estimates, and (3) simulated abundance for weeks with no valid abundance estimates.

Future calibration of the S3 model could be improved in three key ways. First, a more complete time series of abundance estimates within the Klamath River (that is, with fewer missing weeks) and estimating the abundance of each life stage separately could allow more complex models to be fit to the data. Second, the model is calibrated to abundance estimates at a trap that is located only 25 percent of total distance between Iron Gate Dam and the ocean. Therefore, having estimates of abundance at another location much farther downriver is critical for ensuring that the model is performing adequately in the reach downstream of the Kinsman Trap. Furthermore, having an additional downstream location for calibration is desirable because the effects of disease and other sources of mortality will manifest downstream of the Kinsman fish trap, as we showed by simulating the spatial distribution of disease- 
caused mortality (fig. 35). Finally, field studies targeted at directly estimating movement or survival could provide independent estimates of demographic parameters generated outside the calibration procedure. For example, PIT (Passive Integrated Transponder) tag technology is now a common approach for studying growth, movement, and survival of juvenile salmonids. Instream antennas that continuously monitor for tags provide passive "recaptures" of tagged fish, thereby increasing recapture rates. Additionally, PIT-tag size has been reduced, allowing fish as small as $45 \mathrm{~mm}$ to be tagged (Tiffan and others, 2015). Although PIT-tag studies historically have been limited to small streams owing to limited read range, advances in antenna technology are now making it feasible to conduct PIT-tag studies on relatively large rivers such as the Klamath River (Rundio and others, 2017). A focused markrecapture study using PIT tags in the Klamath River would provide considerable additional data for parameterizing demographic rates in S3, especially with respect to fish mortality due to disease.

Variation in habitat availability driven by river flow is a key mechanism in S3 that influences population dynamics through density-dependent processes. Density dependence may manifest as either changes in growth (Grant and Imre, 2005), movement (Hendrix and others, 2014), or survival rates (Einum and others, 2006) as fish density increases. Therefore, we constructed the S3 modeling framework to allow density dependence to be expressed in all three demographic rates, providing the user flexibility to apply density dependence through just one mechanism or combinations of mechanisms at different life stages. This is important because how each density-dependent process is expected to manifest will determine the simulated response of juvenile salmon to spatiotemporal variation in habitat quantity. Model-selection criteria favored models that included density-dependent movement as opposed to density-dependent survival as the best descriptor of juvenile salmon abundance and population dynamics. A similar conclusion also was reached when the S3 model was fit to juvenile Chinook salmon abundances in the Trinity River (Perry and others, 2018b). Furthermore, our estimate of maximum fish density as a measure of habitat capacity (average across habitats and fry and parr life stages) for our selected model was $52.3 \mathrm{fish} / \mathrm{m}^{2}$ of WUA, which was within the range of empirical estimates of 30-500 fish $/ \mathrm{m}^{2}$ based on juvenile Chinook salmon holding station in tightly organized schools (Neuswanger and others, 2016). Furthermore, this estimate of capacity is like that of the Trinity River (32-75 fish $/ \mathrm{m}^{2}$ ) based on estimates using the model of Som and others (2018). Important conclusions from the application of S3 to two separate rivers are as follows:

1. Density-dependent movement was the best supported model in both rivers,

2. Estimates of average capacity were similar in both rivers, and

3. Capacity estimates compare favorably to independent estimates.

Further application of the S3 model to different reaches of other rivers will help to determine whether density-dependent movement is a general phenomenon that occurs across a wide range of riverine habitats.

We developed a novel method for extrapolating weighted usable habitat area from modeled to unmodeled habitat units. This methodology is based on foundational principles of hydraulic geometry (Leopold and Maddock, 1953). Although fundamentally sound, future work on the Klamath S3 model should consider estimating available habitat for all habitat units rather than extrapolating from relatively few measured habitat units. Of the $312 \mathrm{~km}$ of modeled river habitat, the $2 \mathrm{D}$ hydrodynamic models represented just $11.3 \mathrm{~km}$ of river (3.6 percent of the length of the river) and just 36 unique habitat types. Thus, although the extrapolation succeeds in "resizing" modeled WUA relations to match geomorphically similar mesohabitat types, the limited number of modeled habitat units almost certainly underestimates the true variability in habitat area among habitat units in the Klamath River. New 
approaches are currently (2019) under development on the Trinity River to estimate habitat availability given lidar data, bathymetry data, and one-dimensional hydraulic models. Given this type of data for the Klamath River, direct estimates of habitat area could be made for every habitat unit, thereby fully capturing variation in habitat across the entire model domain.

Incorporating disease dynamics in S3 to adequately represent infection and mortality is a major challenge that we have been able to address through analysis of the recent extended sentinel experiments. Although future refinements will improve functionality of the disease model, strengths of the current model include the ability to (1) quantify how different populations are differentially affected by $C$. shasta, (2) examine the spatial distribution of mortality, and (3) evaluate water-management alternatives in the context of disease risk. Field data collection is unable to address the first two of these aspects of disease dynamics, making S3 an important tool for understanding potential populationspecific consequences of disease caused by $C$. shasta. For example, our simulation model showed how most mortality due to $C$. shasta is expected to occur well downstream of the infectious zone. Future refinements will increase accuracy of the disease model. One limitation of the current disease model is that it is insensitive to water-management actions intended to influence actinospores because spore concentrations are provided as model inputs. New projects are currently underway to develop spore models as a function of both flushing flows and dilution flows. These models will improve the utility of $\mathrm{S} 3$ for assessing water-management actions aimed at mitigating disease caused by C. shasta.

In constructing this first version of the S3 model, we made many decisions about model structure and which demographic drivers to include or exclude. Recognizing that the baseline structure of S3 is already complex, our goal was to keep the model as simple as possible by including the minimal amount of structure required to emulate observed population dynamics. For example, although redd scour is an important process driving egg mortality, we decided to leave this process out of the first version of the model because (1) more work is needed to develop a detailed scour model that fits within the S3 framework and accurately captures this process in the Klamath River, and (2) high flows likely to scour redds were absent in the brood years we used for calibrating the model. As another example, predation could be an important mortality mechanism for juvenile fish in the Klamath River. Although we have constructed a predator-prey submodel that would allow predation rates to vary spatially, we decided not to implement this model because it requires spatially explicit information about predator densities. Furthermore, because primary management decisions revolve around flow management, disease dynamics, and temperature, it was paramount to focus the model structure on these variables.

The S3 model offers the opportunity to integrate biological and physical characteristics over the entire temporal and spatial freshwater residency of juvenile salmonid populations. Likewise, the S3 model can provide valuable insights into how fish production may change in response to management decisions in the Klamath River such as dam removal, flow management, and optimization of hatchery releases. Combinations of system attributes (for example, physical habitat, hydrographs) subject to manipulation by managers can be translated into scenarios that form the inputs for S3 model runs. The S3 model can provide expected outcomes for these scenarios and information about the relative effects of management actions on the abundance, size, and run timing of juvenile Chinook salmon. These predictions, in turn, will inform management decisions to maximize joint benefits to both Klamath River water users and salmon populations. 


\section{Acknowledgments}

This work was funded by Interagency Agreement numbers 130813 and 4500083352 from the U.S. Fish and Wildlife Service to the U.S. Geological Survey and Interagency Grant number R13PG20189 from the U.S. Bureau of Reclamation to the U.S. Geological Survey. We thank the Oregon State University Aquatic Animal Health Laboratory and U.S. Fish and Wildlife Service California-Nevada Fish Health Center for providing data and support that made the disease modeling possible. This research was facilitated by high-performance computing resources provided by the Core Science Analytics, Synthesis, \& Libraries (CSASL) Advanced Research Computing (ARC) group at the U.S. Geological Survey. We are grateful to staff of multiple State, Federal, and Tribal agencies who have collected the field data on which our modeling efforts are based.

\section{References Cited}

Alexander, J.D., Bartholomew, J.L., Wright, K.A., Som, N.A. and Hetrick, N.J., 2016, Integrating models to predict distribution of the invertebrate host of myxosporean parasites: Freshwater Science, v. 35, no. 4, p.1263-1275, https://doi.org/10.1086/68834.

Armstrong, J.B., and Schindler, D.E., 2011, Excess digestive capacity in predators reflects a life of feast and famine: Nature, v. 476, p. 84-87, https://doi.org/10.1038/nature10240.

Bartholow, J.M., 1996, Sensitivity of a salmon population model to alternative formulations and initial conditions: Ecological Modelling, v. 88, nos. 1-3, p. 215-226.

Bartholow, J.M., Laake, J.L., Stalnaker, C.B., and Williamson, S.C., 1993, A salmonid population model with emphasis on habitat limitations: Rivers, v. 4, no. 4, p. 265-279.

Bartholow, J., Heasley, J., Laake, J., Sandelin, J., Coughlan, B.A.K., and Moos, A., 2002, SALMODA population model for salmonids-User's manual, Version W3: Fort Collins, Colorado, U.S. Geological Survey, 76 p., accessed November 29, 2017, at https://doi.org/10.3133/96234.

Bartholomew, J., Hallett, S., Holt, R., Alexander, J., Buckles, G., Ray, A., Craig, R., and Atkinson, S., 2015, Klamath River fish health Studies-Second reporting cycle, April 01, 2014-June 30, 2015Annual report: Corvallis, Oregon State University, GSA Contract GS09T13BHD0052, 49 p.

Burnham, K.P., and Anderson, D.R., 2002, Model selection and multimodel inference - A practical information-theoretic approach: New York, Springer.

California Rivers Assessment, 2011, Watershed information by basin, average precipitation per year: California Rivers Assessment, watershed database, accessed November 13, 2018, at http://ice.ucdavis.edu/project/cara.

Chesney, W.R., Crombey, W.B., and Langendorf, H.D., 2009. Final Report—Shasta and Scott River juvenile salmonid outmigration monitoring project P0610354: California Department of Fish and Game, 60 p.

Deriso, R.B., Maunder, M.N., and Skalski, J.R., 2007, Variance estimation in integrated assessment models and its importance for hypothesis testing: Canadian Journal of Fisheries and Aquatic Sciences, v. 64, no. 2, p. 187-197, https://doi.org/10.1139/f06-178.

Einum, S., Sundt-Hansen, L., and Nislow, K.H., 2006, The partitioning of density-dependent dispersal, growth and survival throughout ontogeny in a highly fecund organism: Oikos, v. 113, no. 3, p. 489496, https://doi.org/10.1111/j.2006.0030-1299.14806.x.

Foott, J.S., Bartholomew, J.L., Perry, R.W., and Walker, C.E., 2011, Conceptual model for disease effects in the Klamath River: Report to the Secretary of Interior, 12 p., accessed March 26, 2019, at https://klamathrestoration.gov/sites/klamathrestoration.gov/files/Disease_conceptual\%20model_6-111.pdf. 
Geist, D.R., Abernethy, S.C., Hand, K.D., Cullinan, V.I., Chandler, J.A, and Groves, P.A., 2006, Survival, development, and growth of fall Chinook salmon embryos, alevins, and fry exposed to variable thermal and dissolved oxygen regimes: Transactions of the American Fisheries Society, v. 135, no. 6, p. 1462-1477, https://doi.org/10.1577/T05-294.1.

Gough, S.A., David, A.T., and Pinnix, W.D., 2015, Summary of abundance and biological data collected during juvenile salmonid monitoring in the mainstem Klamath River below Iron Gate Dam, California, 2000-2013: U.S. Fish and Wildlife Service, Arcata Fish and Wildlife Office, Arcata, California, Arcata Fisheries Data Series Report Number DS 2015-43, 95 p. plus appendixes.

Gough, S.A., and Som, N.S. 2015, Fall Chinook salmon run characteristics and escapement for the mainstem Klamath River, 2013-2015: U.S. Fish and Wildlife Service, Arcata Fish and Wildlife Office, Arcata, California, Arcata Fisheries Data Series Report Number DS 2017-50, 34 p.

Grant, J.W.A., and Imre, I., 2005, Patterns of density-dependent growth in juvenile stream-dwelling salmonids. Journal of Fish Biology, v. 67, p. 100-110, https://doi.org/10.1111/j.00221112.2005.00916.x.

Hallett, S.L., Ray, R.A., Hurst, C.N., Holt, R.A., Buckles, G.R., Atkinson, S.D., and Bartholomew, J.L., 2012, Density of the waterborne parasite Ceratomyxa shasta and its biological effects on salmon: Applied and Environmental Microbiology, v. 78, p. 3724-3731, https://doi.org/10.1128/AEM.0780111.

Hardy, T.B, Addley, R.C., and Saraeva, E., 2006, Evaluation of instream flow needs in the lower Klamath River Phase II: Final report to the U.S. Department of the Interior, 247 p.

Hardy, T.B, and Shaw, T., 2011, SALMOD-Meso-habitat development Keno to estuary, in Hendrix, N., Campbell, S., Hampton, M., Hardy, T., Huntington, C., Lindley, S., Perry, R., Shaw, T., and Williamson, S., Fall Chinook salmon life cycle production model report to expert panel: Prepared for Expert Panel reviewing Chinook salmon of the Klamath River Basin, p. 4-1-4-32, accessed March 26, 2019, at

https://www.fws.gov/arcata/fisheries/reports/technical/Fall\%20Chinook\%20Report\%20of\%20FPM\% 20Team\%20to\%20Expert\%20Panel\%20DRAFT\%201\%202011.pdf.

Hendrix, N., Criss, A., Danner, E., Greene, C.M., Imaki, H., Pike, A., and Lindley, S.T., 2014, Life cycle modeling framework for Sacramento River winter run Chinook salmon: National Oceanic and Atmospheric Administration Technical Memorandum NOAA-TM-NMFS-SWFSC-530, 30p., accessed October 31, 2017, at https://swfsc.noaa.gov/publications/TM/SWFSC/NOAA-TM-NMFSSWFSC-530.pdf.

Klamath Basin Restoration Agreement, 2010, Klamath Basin restoration agreement for the sustainability of public and trust resources and affected communities, 378 p., accessed November 13, 2018, at https://www.doi.gov/sites/doi.gov/files/migrated/news/pressreleases/upload/Klamath-BasinRestoration-Agreement-2-18-10.pdf.

Klamath Hydroelectric Settlement Agreement, 2016, Klamath hydroelectric settlement agreement February 18, 2010 as amended April 6, 2016, 208 p., accessed November 13, 2018, at https://www.doi.gov/sites/doi.gov/files/uploads/FINAL\%20KHSA\%20PDF.pdf .

Leopold, L.B., and Maddock, T., 1953, The hydraulic geometry of stream channels and some physiographic implications: U.S. Geological Survey Professional Paper 252, 57 p.

Neuswanger, J.R., Wipfli, M.S., Rosenberger, A.E., and Hughes, N.F. 2016. Measuring fish and their physical habitats - Versatile 2D and 3D video techniques with user-friendly software: Canadian Journal of Fisheries and Aquatic Sciences, v. 73, no. 12, p. 1861-1873, https://doi.org/10.1139/cjfas2016-0010. 
Peng, Y., Dear, K.B.G., and Denham, J.W., 1998, A generalized F mixture model for cure rate estimation: Statistics in Medicine, v. 17, p. 813-830.

Perry, R.W., Plumb, J.M., and Huntington, C.W., 2015, Using a laboratory-based growth model to estimate mass-and temperature-dependent growth parameters across populations of juvenile Chinook salmon: Transactions of the American Fisheries Society, v. 144, no. 2, p. 331-336.

Perry, R.W., Plumb, J.M., Jones, E.C., Som, N.A., Hetrick, N.J., and Hardy, T.B., 2018b, Application of the Stream Salmonid Simulator (S3) to Klamath River fall Chinook salmon: U.S. Geological Survey Open-File Report 2018-1056, 32 p.

Perry, R.W., Plumb, J.M., Jones, E.C., Som, N.A., Hetrick, N.J., and Hardy, T.B., 2018a, Model structure of the Stream Salmonid Simulator (S3) — A dynamic model for simulating growth, movement, and survival of juvenile salmonids: U.S. Geological Survey Open-File Report 2018-1056, 32 p., https://doi.org/10.3133/ofr20181056.

Perry, R.W., Risley, J.C., Brewer, S.J., Jones, E.C., and Rondorf, D.W., 2011, Simulating daily water temperatures of the Klamath River under dam removal and climate change scenarios: U.S. Geological Survey Open-File Report 2011-1243, 78 p., https://doi.org/10.3133/ofr20111243.

Plumb, J.M., 2012, Evaluation of models and the factors affecting the migration and growth of naturally-produced subyearling fall Chinook salmon (Oncorhynchus tshawytscha) in the lower Snake River: Moscow, University of Idaho, Ph.D. dissertation.

Plumb, J.M., and Moffitt, C.M., 2015, Re-estimating temperature-dependent consumption parameters in bioenergetics models for juvenile Chinook salmon: Transactions of the American Fisheries Society, $\mathrm{v}$. 144, no. 2, p. 323-330, https://doi.org/10.1080/00028487.2014.986336.

R Core Team, 2017, R-A language and environment for statistical computing: Vienna, Austria, $\mathrm{R}$ Foundation for Statistical Computing, https://www.R-project.org/.

Ray, R.A., Perry, R.W., Som, N.A., and Bartholomew J.L., 2014, Using cure models for analyzing the influence of pathogens on salmon survival: Transactions of the American Fisheries Society, v. 143, no. 2, p. 387-398, https://doi.org/10.1080/00028487.2013.862183.

Rundio, D.E., Montgomery, A.N., Nesbit, M.G., Morris, M.S., Brooks, G.T., Axel, G.A., Lamb, J.J., Zabel, R.W., Ferguson, J.W., and Lindley, S.T., 2017, Central Valley passive integrated transponder (PIT) tag array feasibility study: National Oceanic and Atmospheric Administration technical memorandum NMFS, NOAA-TM-NMFS-SWFSC-573, 130 p.

Rymer, R., 2008, Reuniting a river: Klamath Forest Alliance news article, accessed November 13, 2018, at http://www.klamathforestalliance.org/Newsarticles/newsarticle20081201.html.

Som, N.A., Goodman, D.H., Perry, R.W., and Hardy, T.B., 2016, Habitat suitability criteria via parametric distributions - Estimation, model selection and uncertainty: River Research and Applications, v. 32, no. 5, p. 1128-1137, https://doi.org/10.1002/rra.2900.

Som, N.A., Hetrick, N.J., Alexander, J., Shea, C., Foott, J.S., and True, K., 2016, Technical Memorandums Regarding Ceratonova shasta in the Klamath River: Response to Request for Technical Assistance from the Yurok and Karuk Tribes, U.S. Fish and Wildlife Service. Arcata Fish and Wildlife Office, Arcata, California, https:/www.fws.gov/arcata/fisheries/reportsDisplay.html.

Som, N.A., Perry, R.W., Jones, E.C., De Juilio, K., Petros, P., Pinnix, W.D. and Rupert, D.L., 2018, Nmix for fish-Estimating riverine salmonid habitat selection via N-mixture models: Canadian Journal of Fisheries and Aquatic Sciences, v. 75, no. 7, p. 1048-1058, www.nrcresearchpress.com/doi/10.1139/cjfas-2017-0027. 
Tiffan, K.F., Perry, R.W., Connor, W.P., Mullins, F.L., Rabe, C.D., and Nelson, D.D., 2015, Survival, growth, and tag retention in age-0 Chinook salmon implanted with 8-, 9-, and 12-mm PIT tags: North American Journal of Fisheries Management, v. 35, no. 4, p. 845-852, https://doi.org/10.1080/02755947.2015.1052163.

U.S. Department of Interior, 2013, Klamath Dam removal overview report for the Secretary of the Interior-An assessment of science and technical information: Prepared by U.S. Department of Interior and U.S. Department of Commerce, National Marine Fisheries Service, 420 p., accessed November 13, 2018, at https://klamathrestoration.gov/sites/klamathrestoration.gov/files/Full\%20SDOR\%20accessible\%2002 2216.pdf.

Williamson, S.C., Bartholow, J.M. and Stalnaker, C.B., 1993, Conceptual model for quantifying presmolt production from flow-dependent physical habitat and water temperature: River Research and Applications, v. 8, nos. 1-2, p. 15-28.

Zabel, R.W., and Anderson, J.J., 1997, A model of the travel time of migrating juvenile salmon, with an application to Snake River spring Chinook salmon: North American Journal of Fisheries Management, v. 17, no. 1, p. 93-100.

Zabel, R.W., 2002, Using "travel time" data to characterize the behavior of migrating animals: American Naturalist, v. 159, no. 4, p. 372-387. 


\section{Appendix 1. Composite Two-Dimensional Weighted Usable Habitat Area Curves}

Appendix 1 is an Adobe Acrobat ${ }^{\circledR}$ file and is available for download at https://doi.org/10.3133/ofr20191107. 


\section{Appendix 2. Fish Weight and Length Conversions}

\section{Fish Size Conversions}

Data on fish length (fork length [FL, in millimeters]), but generally not weight (or mass $[M$, in grams]) are routinely collected at Klamath River fish traps. To facilitate conversion and comparison of Stream Salmonid Simulator (S3) output to observations of fish length at the fish traps, regression equations between fish length and weight were developed from more than 28,876 Klamath River subyearling fall Chinook salmon (fig. 2.1). The equation to predict fish weight from length is:

$$
F L=\left(\frac{M}{1.88845 \times 10^{-6}}\right)^{\left(\frac{1}{3.410685138}\right)}
$$

Rearranging to solve for mass:

$$
M=\left(1.88845 \times 10^{-6}\right) \cdot F L^{3.410685138} .
$$

Because the S3 growth models predict mass is in grams, the S3 model uses the above equations to convert between measures of fish mass and length or vice versa when comparing fish size between model output and observations.

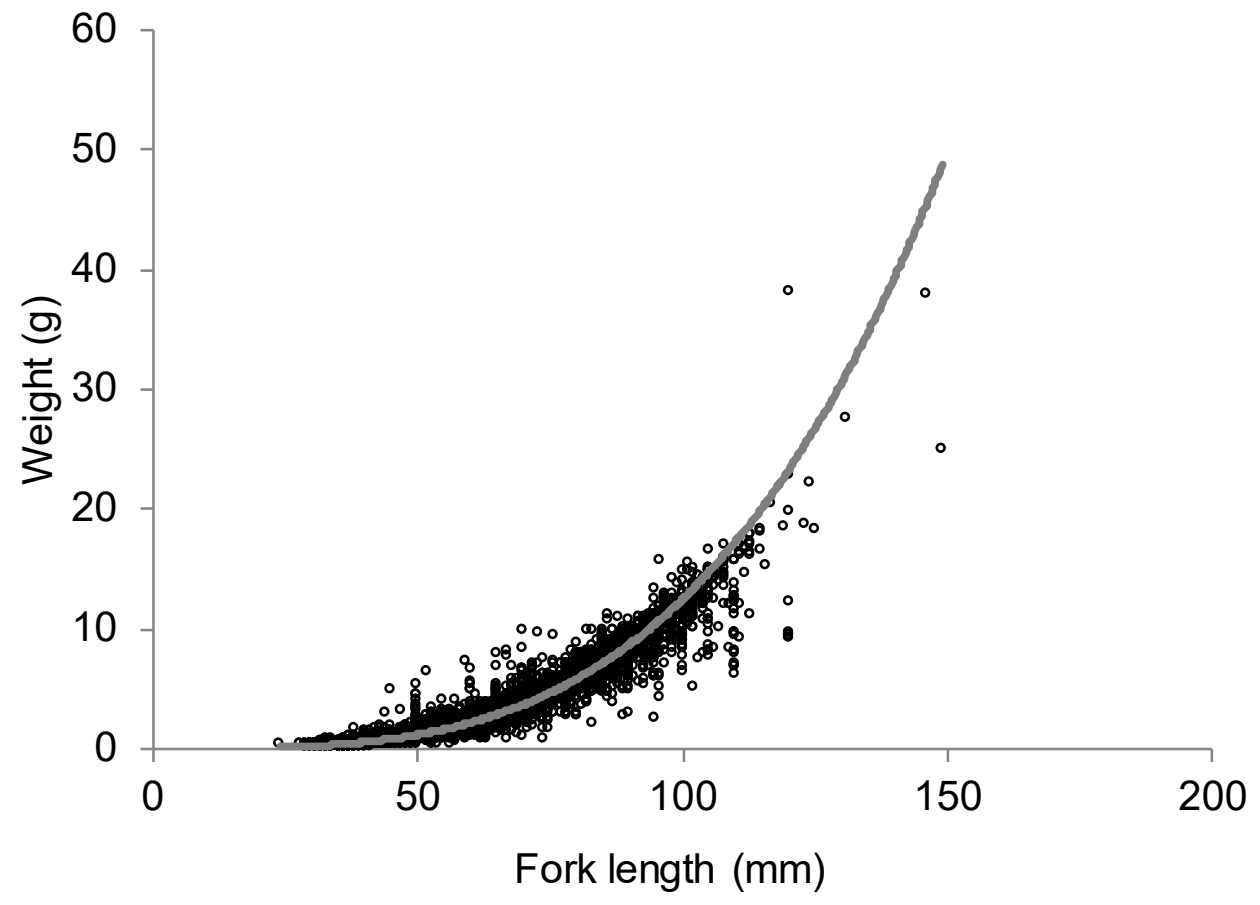

Figure 2.1. Log-to-log regression (gray line) fit to 28,876 subyearling fall Chinook salmon that were caught at fish traps on the Klamath River, California. Parameter values from the regression were used in the Stream Salmonid Simulator model to perform length-to-weight and weight-to-length conversions. g, grams; mm, millimeters. 


\section{Appendix 3. Estimating Mortality and Time to Death of Juvenile Chinook Salmon Exposed to Ceratonova shasta}

The myxozoan parasite Ceratonova shasta can cause high infection prevalence and mortality of juvenile Chinook salmon in the Klamath River. Therefore, we developed a disease submodel for S3 to simulate mortality of juvenile Chinook salmon owing to C. shasta. This appendix details our statistical analysis of sentinel trial data to parameterize the Stream Salmonid Simulator disease submodel for the Klamath River.

\section{Methods}

We fit a survival cure model (Ray and others, 2014) to sentinel trial data from a study known as the extended sentinel experiment. The goal of the extended sentinel experiment was to quantify how mortality owing to $C$. shasta is influenced by exposure duration, spore concentration during exposure, water temperature during exposure, and water temperature during the post-exposure holding period. Twenty-one sentinel trials were conducted in 2014 and 2015; each trial was conducted by:

1. Exposing 27-30 juvenile Chinook salmon in the infectious zone for 1-7 days;

2. Recording daily spore concentration and water temperature during the exposure period;

3. Transporting fish to the Aquatic Animal Health Laboratory at Oregon State University where fish were held at either $13{ }^{\circ} \mathrm{C}, 15^{\circ} \mathrm{C}$, or $18^{\circ} \mathrm{C}$; and

4. Recording the time to death of each fish for as many as 90 days, at which point the number of survivors was recorded.

Because sentinel trials were conducted during a period of high spore concentrations (all trials occurred when spore concentration was greater than 10 spores per liter [spores/L]), we combined this dataset with data from 12 sentinel trials reported by Ray and others (2014) that were conducted when spore concentrations were less than 10 spores/L (table 3.1). This ensured that our model parameters were estimated across the entire range of spore concentrations observed in the Klamath River.

The survival cure model is composed of two components: (1) a "cure" probability, which is the proportion of the population expected to survive the disease, and (2) a time-to-death function for individuals expected to die from disease:

$$
S(t)=(1-\pi)+\pi S(t \mid \text { death }),
$$

where $S(t) \quad$ is the overall probability of surviving $t$ days after infection,

$\pi \quad$ is the proportion of fish that become infected and eventually die from ceratomyxosis,

$1-\pi \quad$ is the proportion of infected fish that survive exposure to C. shasta, and

$S(t \mid$ death $) \quad$ is the proportion of fish that survive to time $t$ of those expected to die from C. shasta. 
Table 3.1. Summary of sentinel trials used to fit the survival cure model used in Stream Salmonid Simulator.

[Trials from 2014 and 2015 were conducted as part of the extended sentinel experiment. Trials for 2006-10 with spore concentrations less than 10 spores per liter were obtained from the study of Ray and others (2014) Exposure duration: $E, d$, exposure duration, in days. Mean exposure: $T_{\mathrm{E}},{ }^{\circ} \mathrm{C}$, mean water temperature during exposure period, in degrees Celsius.

Holding temperature: $T_{\mathrm{H}},{ }^{\circ} \mathrm{C}$, water temperature during holding period, in degrees Celsius. Mean spore concentration: $C$, spores/L, natural logarithm of total Ceratonova shasta spore concentration, in spores per liter]

\begin{tabular}{|c|c|c|c|c|c|c|c|}
\hline $\begin{array}{c}\text { Trial } \\
\text { number }\end{array}$ & Year & $\begin{array}{l}\text { Number } \\
\text { of fish }\end{array}$ & $\begin{array}{c}\text { Exposure } \\
\text { duration } \\
(E, d)\end{array}$ & $\begin{array}{c}\text { Mean exposure } \\
\text { temperature } \\
\left(T_{\mathrm{E}},{ }^{\circ} \mathrm{C}\right)\end{array}$ & $\begin{array}{c}\text { Holding } \\
\text { temperature } \\
\left(T_{\mathrm{H}}{ }^{\circ} \mathrm{C}\right)\end{array}$ & $\begin{array}{c}\text { Mean spore } \\
\text { concentration } \\
\text { (C, spores/L) } \\
\end{array}$ & Total mortality \\
\hline 1 & 2006 & 37 & 3 & 12.2 & 13.0 & 0.5 & 0.00 \\
\hline 2 & 2006 & 39 & 3 & 20.0 & 13.0 & 0.3 & 0.00 \\
\hline 3 & 2007 & 41 & 3 & 20.8 & 13.0 & 6.0 & 0.07 \\
\hline 4 & 2007 & 40 & 3 & 20.8 & 18.0 & 6.0 & 0.03 \\
\hline 5 & 2009 & 39 & 3 & 19.9 & 13.0 & 0.0 & 0.00 \\
\hline 6 & 2009 & 40 & 3 & 19.9 & 18.0 & 0.0 & 0.00 \\
\hline 7 & 2010 & 42 & 3 & 12.6 & 13.0 & 0.1 & 0.00 \\
\hline 8 & 2010 & 41 & 3 & 12.6 & 18.0 & 0.1 & 0.17 \\
\hline 9 & 2010 & 35 & 3 & 13.6 & 13.0 & 5.7 & 0.00 \\
\hline 10 & 2010 & 45 & 3 & 13.6 & 16.0 & 5.7 & 0.16 \\
\hline 11 & 2010 & 39 & 3 & 17.0 & 13.0 & 0.1 & 0.00 \\
\hline 12 & 2010 & 40 & 3 & 17.0 & 18.0 & 0.1 & 0.00 \\
\hline 13 & 2014 & 31 & 1 & 19.4 & 18.0 & 109.9 & 0.10 \\
\hline 14 & 2014 & 31 & 1 & 17.1 & 13.0 & 10.3 & 0.03 \\
\hline 15 & 2014 & 29 & 3 & 18.0 & 13.0 & 18.6 & 0.21 \\
\hline 16 & 2014 & 29 & 5 & 18.2 & 13.0 & 66.4 & 0.38 \\
\hline 17 & 2014 & 29 & 7 & 18.0 & 13.0 & 63.7 & 0.52 \\
\hline 18 & 2014 & 30 & 1 & 17.1 & 15.0 & 10.3 & 0.07 \\
\hline 19 & 2014 & 27 & 3 & 18.0 & 15.0 & 18.6 & 0.41 \\
\hline 20 & 2014 & 29 & 5 & 18.2 & 15.0 & 66.4 & 0.62 \\
\hline 21 & 2014 & 30 & 7 & 18.0 & 15.0 & 63.7 & 0.63 \\
\hline 22 & 2015 & 28 & 1 & 9.6 & 13.0 & 39.1 & 0.00 \\
\hline 23 & 2015 & 30 & 3 & 10.6 & 13.0 & 211.0 & 0.23 \\
\hline 24 & 2015 & 30 & 5 & 11.1 & 13.0 & 328.4 & 0.47 \\
\hline 25 & 2015 & 30 & 7 & 11.3 & 13.0 & 392.6 & 0.67 \\
\hline 26 & 2015 & 28 & 1 & 19.5 & 18.0 & 410.1 & 0.25 \\
\hline 27 & 2015 & 29 & 3 & 19.8 & 18.0 & 350.5 & 0.48 \\
\hline 28 & 2015 & 30 & 5 & 20.6 & 18.0 & 428.5 & 0.67 \\
\hline 29 & 2015 & 22 & 7 & 21.2 & 18.0 & 375.9 & 0.64 \\
\hline 30 & 2015 & 30 & 1 & 15.9 & 16.0 & 294.0 & 0.17 \\
\hline 31 & 2015 & 30 & 3 & 15.8 & 16.0 & 595.9 & 0.80 \\
\hline 32 & 2015 & 29 & 5 & 16.2 & 16.0 & 639.2 & 0.93 \\
\hline 33 & 2015 & 30 & 7 & 16.2 & 16.0 & 659.6 & 1.00 \\
\hline
\end{tabular}


We used the gfcure package (Peng and others, 1998) in the R statistical programming language (R Core Team, 2017) to fit the cure model to the sentinel trial data using maximum likelihood methods. The data required to fit the model is the vector $x_{i}=\left(t_{i}, c_{i}\right)$, where $t_{i}$ is either the recorded time of death of the $i$ th individual or the censoring time (that is, the time when the trial ended if the $i$ th fish remained alive for the duration of the trial), and $c_{i}$ is the censoring indicator ( $c_{i}=0$ if $t_{i}=$ time of death, $c_{i}=1$ if the $t_{i}=$ trial duration). The cure model allows both the probability of infection and eventual death, $\pi$, and the time-to-death, $S(t \mid$ death $)$, to be modeled separately as functions of covariates. The probability of infection and death is modeled as a function of covariates using a logit link function. We decided to use the log-logistic distribution for $S(t \mid$ death) and modeled its location parameter as a function of covariates.

We used a two-stage model-selection process to identify the best-fit cure model. First, we used a binomial generalized linear model (GLM) to analyze the total mortality in each trial, which provided an estimate of $\pi$ in the cure model. We used the GLM to identify the set of covariates that best fit the total mortality data, and then used that model structure for $\pi$ in the cure model during the second stage. The second stage involved identifying the best set of covariates for $S(t \mid$ death $)$ by fitting the full cure model, which simultaneously estimated parameters associated with covariates for both $\pi$ and $S(t \mid$ death). For both response parameters, we used the following covariates: (1) exposure duration (days), (2) logarithm of mean total spore concentration (in spores per liter) during the exposure duration, (3) mean water temperature (in degrees Celsius) during the exposure duration, and (4) mean water temperature during the post-exposure holding period. Additionally, we included all two-way interactions between the covariates. However, to avoid overfitting, we retained only those interactions whose removal from the model resulted in an increase of Akaike's Information Criterion (AIC) scores by more than 9. All main effects were retained in the model, as each of the covariates are known to influence total mortality and time-to-death (Ray and others, 2014).

\section{Results}

For the binomial GLM, only the interaction term between exposure temperature $\left(T_{\mathrm{E}}\right)$ and holding temperature $\left(T_{\mathrm{H}}\right)$ increased AIC by more than 9 upon removal from the full model, indicating that including this interaction term substantially improved model fit to the data (table 3.2). The AIC score for the main-effects model with no interactions was 187.1 , whereas adding $T_{\mathrm{E}} \times T_{\mathrm{H}}$ to the main-effects model reduced AIC by 53.9 points to 133.1 . Comparing observed to predicted mortality showed that the model fit the observed data well with little evidence of lack of fit (fig. 3.1). Therefore, we used this model structure for $\pi$ when fitting the cure model.

For the $S(t \mid$ death), only the interaction between spore concentration and exposure duration increased AIC by more than 9 points (table 3.3), and, therefore, only this interaction term was retained in the final model. The AIC for the main-effects model was 739.4 but adding $C \times E$ to the main-effects model reduced AIC by 21 points to 718.4. Comparing the predicted survival curve from the cure model to an empirical Kaplan-Meir curve showed that the model predicted well both the proportion of fish surviving and their time to death (fig. 3.2). Therefore, we used this model structure along with the model structure for $\pi$ identified in the GLM as the final model for predicting infection and time to death in S3. Parameter estimates are given in table 4 and predicted $\pi$ and $S(t \mid$ death) over a range of covariate values are shown in figures 15 and 16 , respectively. 
Table 3.2. Model-selection table for the binomial generalized linear model of total mortality in each sentinel trial.

[Table shows Akaike's Information Criterion (AIC) for the full model, the AIC when removing each interaction term from the full model, and the difference in AIC relative to the full model ( $\triangle \mathrm{AIC}$ ). Model: $E$, Exposure duration (d); $C$, natural logarithm of total spore concentration (in spores per liter) during the exposure period; $T_{\mathrm{E}}$, mean water temperature during the exposure period; $T_{\mathrm{H}}$, mean water temperature during the post-exposure holding period]

\begin{tabular}{lcccc}
\hline \multicolumn{1}{c}{ Model } & $\begin{array}{c}\text { Number of } \\
\text { parameters }\end{array}$ & Deviance & AIC & AAIC \\
\hline Full (main effects + all interactions) & 11 & 29.9 & 128.8 & 0 \\
$-C \times T_{\mathrm{E}}$ & 10 & 32.7 & 129.7 & 0.9 \\
$-C \times T_{\mathrm{H}}$ & 10 & 33.6 & 130.5 & 1.7 \\
$-C \times E$ & 10 & 30.9 & 127.8 & -1.0 \\
$-T_{\mathrm{E}} \times T_{\mathrm{H}}$ & 10 & 74.5 & 171.5 & 42.7 \\
$-T_{\mathrm{E}} \times E$ & 10 & 38.3 & 135.3 & 6.5 \\
$-T_{\mathrm{H}} \times E$ & 10 & 39.3 & 136.3 & 7.5 \\
\hline
\end{tabular}




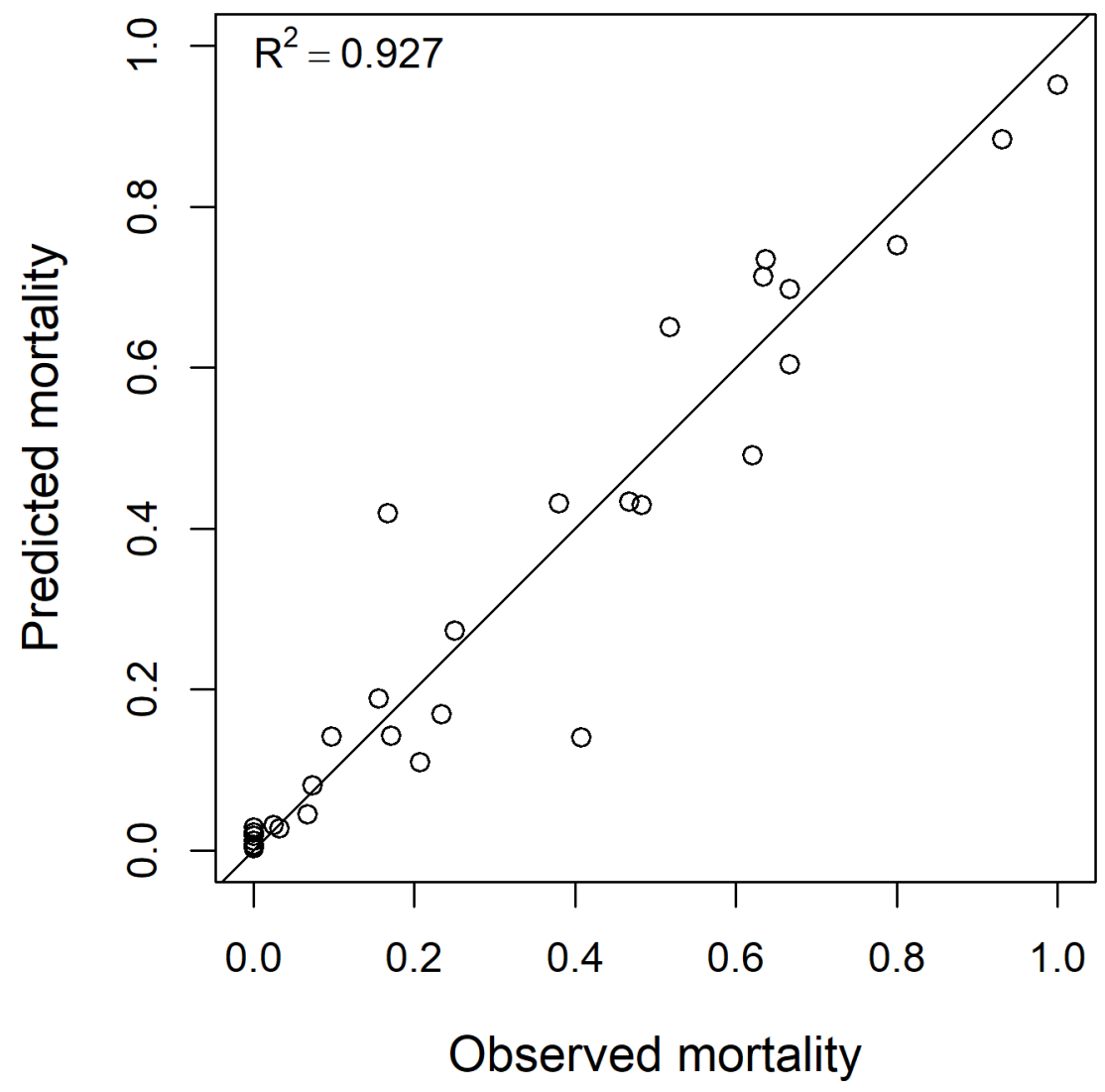

Figure 3.1. Total mortality observed for sentinel trials compared to predicted total mortality from the best-fit binomial generalized linear model. Reference line shows where observed mortality equals predicted mortality. $\mathrm{R}^{2}$, coefficient of determination. 
Table 3.3 Model-selection table for the time-to-death component [S(t|death)] of the survival cure model.

[Table shows Akaike's Information Criterion (AIC) for the full model, the AIC when removing each interaction term from the full model, and the difference in AIC relative to the full model $(\triangle \mathrm{AIC})$. Model: $E$, Exposure duration (d); $C$, natural logarithm of total spore concentration (in spores per liter) during the exposure period; $T_{\mathrm{E}}$, mean water temperature during the exposure period; $T_{\mathrm{H}}$, mean water temperature during the post-exposure holding period]

\begin{tabular}{lcccc}
\hline \multicolumn{1}{c}{ Model } & $\begin{array}{c}\text { Number of } \\
\text { parameters }\end{array}$ & Deviance & AIC & AAIC \\
\hline Full (main effects + all interactions) & 18 & 685.8 & 721.8 & 0 \\
$-C \times T_{\mathrm{E}}$ & 17 & 685.8 & 719.8 & -2.0 \\
$-C \times T_{\mathrm{H}}$ & 17 & 685.9 & 719.8 & -2.0 \\
$-C \times E$ & 17 & 697.3 & 731.3 & 9.4 \\
$-T_{\mathrm{E}} \times T_{\mathrm{H}}$ & 17 & 690.4 & 724.4 & 2.6 \\
$-T_{\mathrm{E}} \times E$ & 17 & 686.2 & 720.2 & -1.6 \\
$-T_{\mathrm{H}} \times E$ & 17 & 685.9 & 719.9 & -1.9 \\
\hline
\end{tabular}



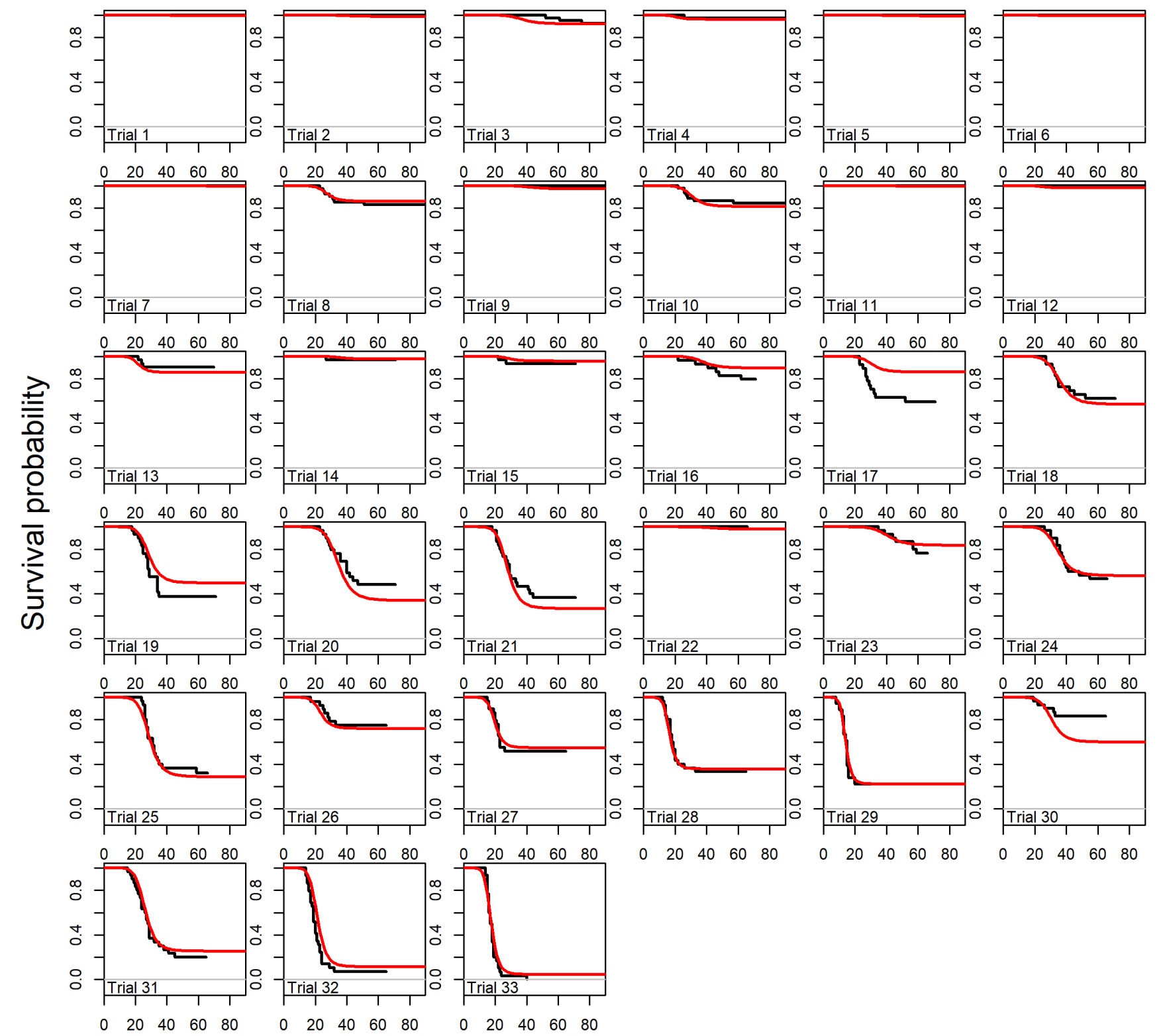

Time since initial exposure $(d)$

Figure 3.2. Predicted cure survival curve (red) compared to empirical Kaplan-Meir curve for each sentinel trial. d, days. 


\section{Appendix 4. Comparison to 15 Trap with Parametric Bootstrap Confidence Limits}
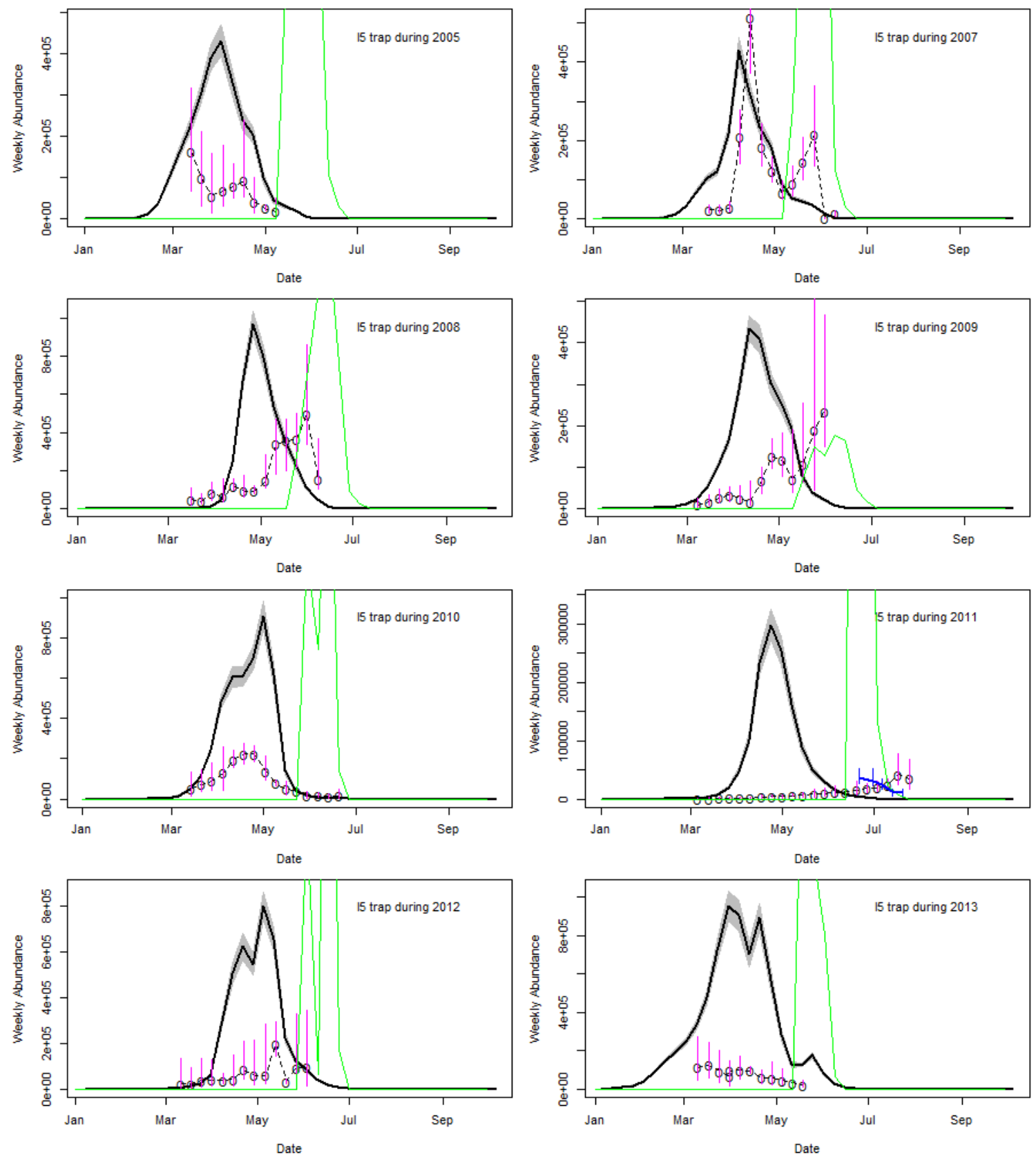

Figure 4.1. Graphs showing estimated abundance of subyearling fall Chinook salmon passing the 15 fish trap whereby the simulated (Stream Salmonid Simulator [S3]) juvenile fall Chinook salmon abundances are compared to the out-of-sample abundance estimates obtained at the 15 fish trap, Klamath River, California, migration years 2005, and 2007-13. Black solid lines represent S3-simulated abundance and gray shaded areas represent 2.5th and 97.5th percentiles about the S3-simulated abundances. Open circles and dashed lines represent weekly abundance estimates from mark-recapture studies and vertical pink lines are the 95percent credible intervals about these trap estimates. Curved solid green lines represent S3-simulated abundances for hatchery fish and blue lines represent estimated abundances of hatchery fish from trap markrecapture studies. 


\section{Appendix 5. Spatial Spawning Distributions}

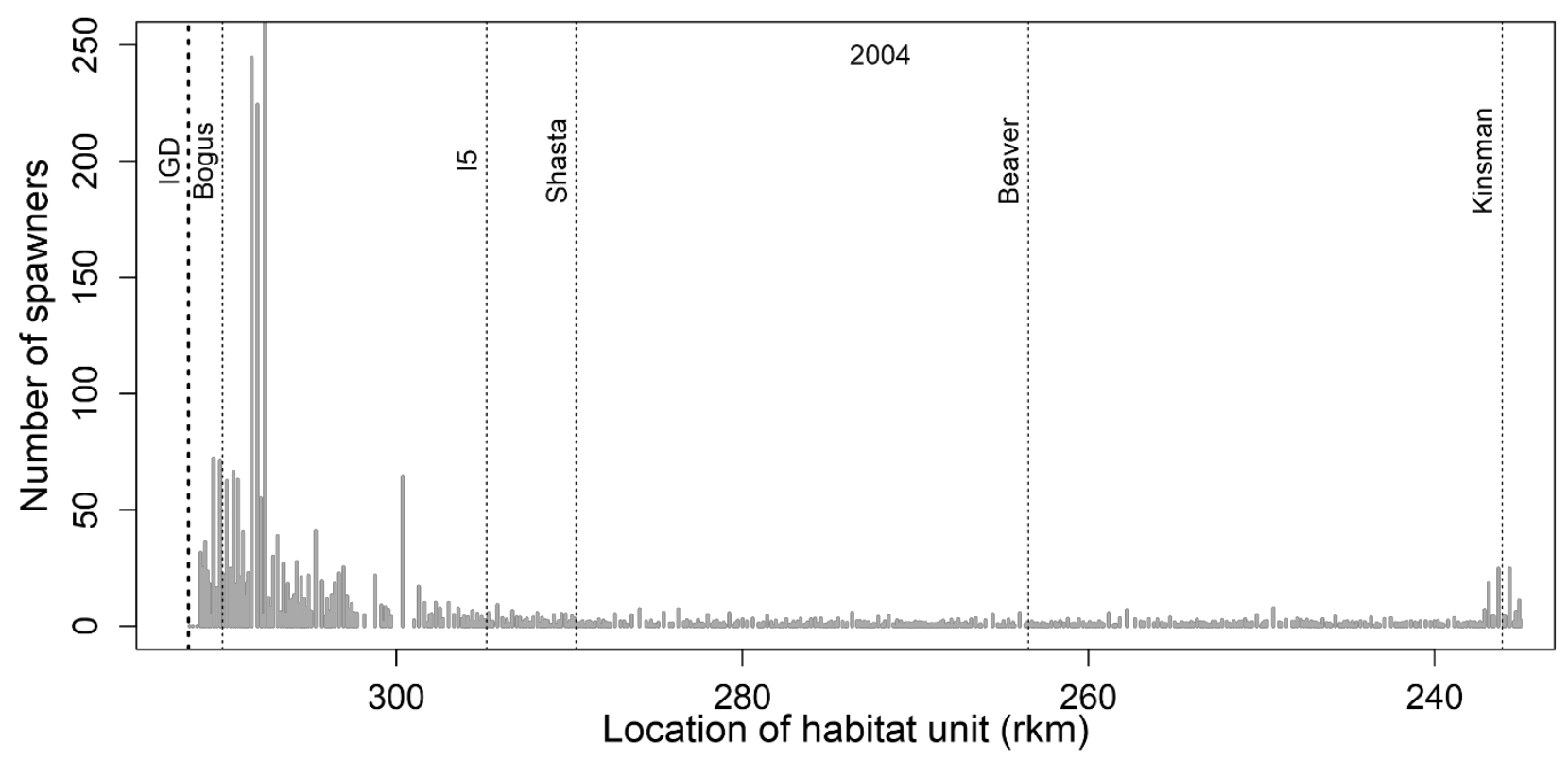

Figure 5.1. Graph showing spatial distribution of spawning female fall Chinook salmon used as inputs to the Stream Salmonid Simulator model for the Klamath River, California, brood year 2004. Beaver, Beaver Creek; Bogus, Bogus Creek; I5, I5 trap near Interstate 5 bridge; IGD, Iron Gate Dam; Kinsman, Kinsman fish trap; Shasta, Shasta River; rkm, river kilometer.

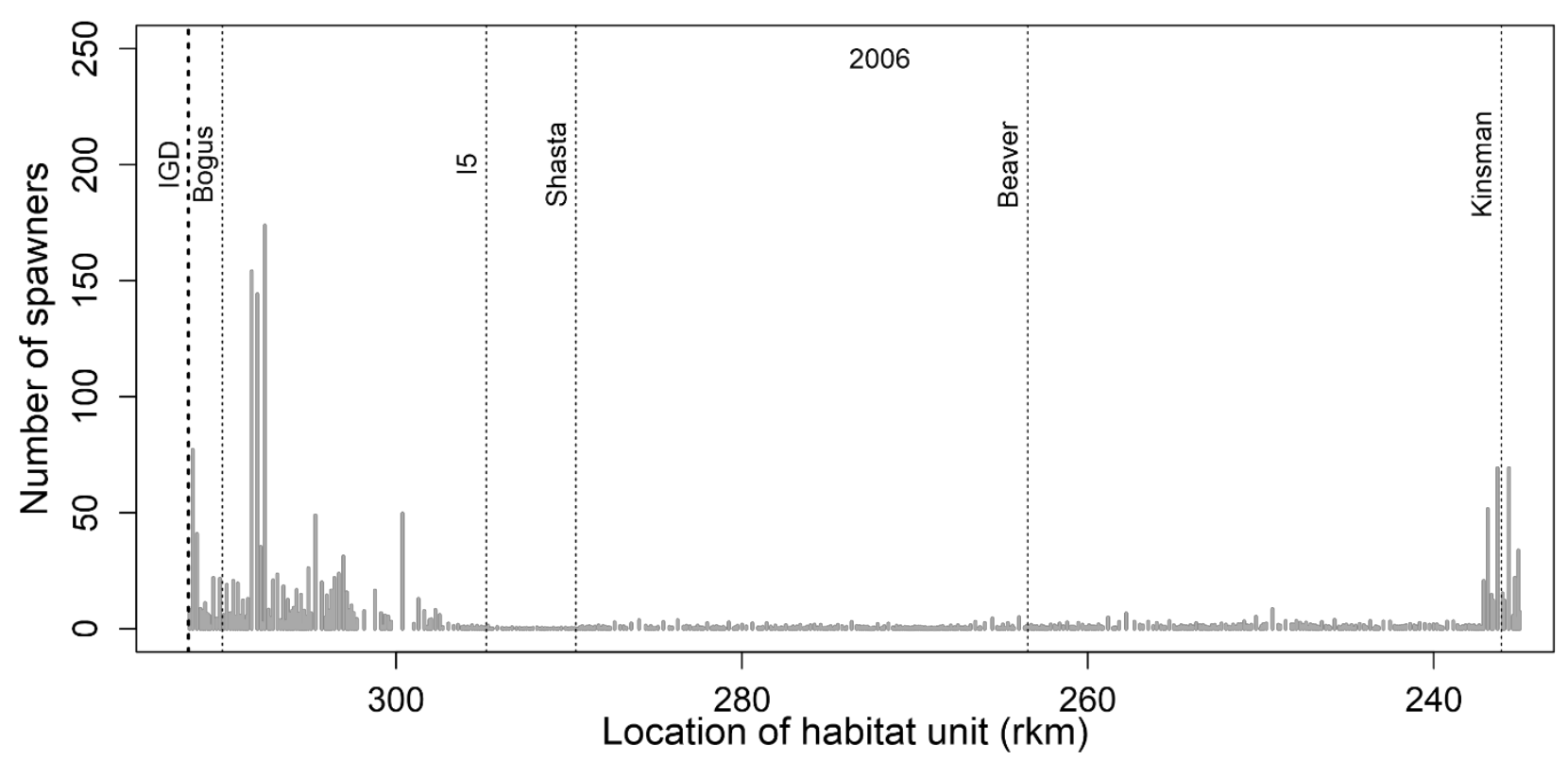

Figure 5.2. Graph showing spatial distribution of spawning female fall Chinook salmon used as inputs to the Stream Salmonid Simulator model for the Klamath River, California, brood year 2006. Beaver, Beaver Creek; Bogus, Bogus Creek; I5, I5 trap near Interstate 5 bridge; IGD, Iron Gate Dam; Kinsman, Kinsman fish trap; Shasta, Shasta River; rkm, river kilometer. 


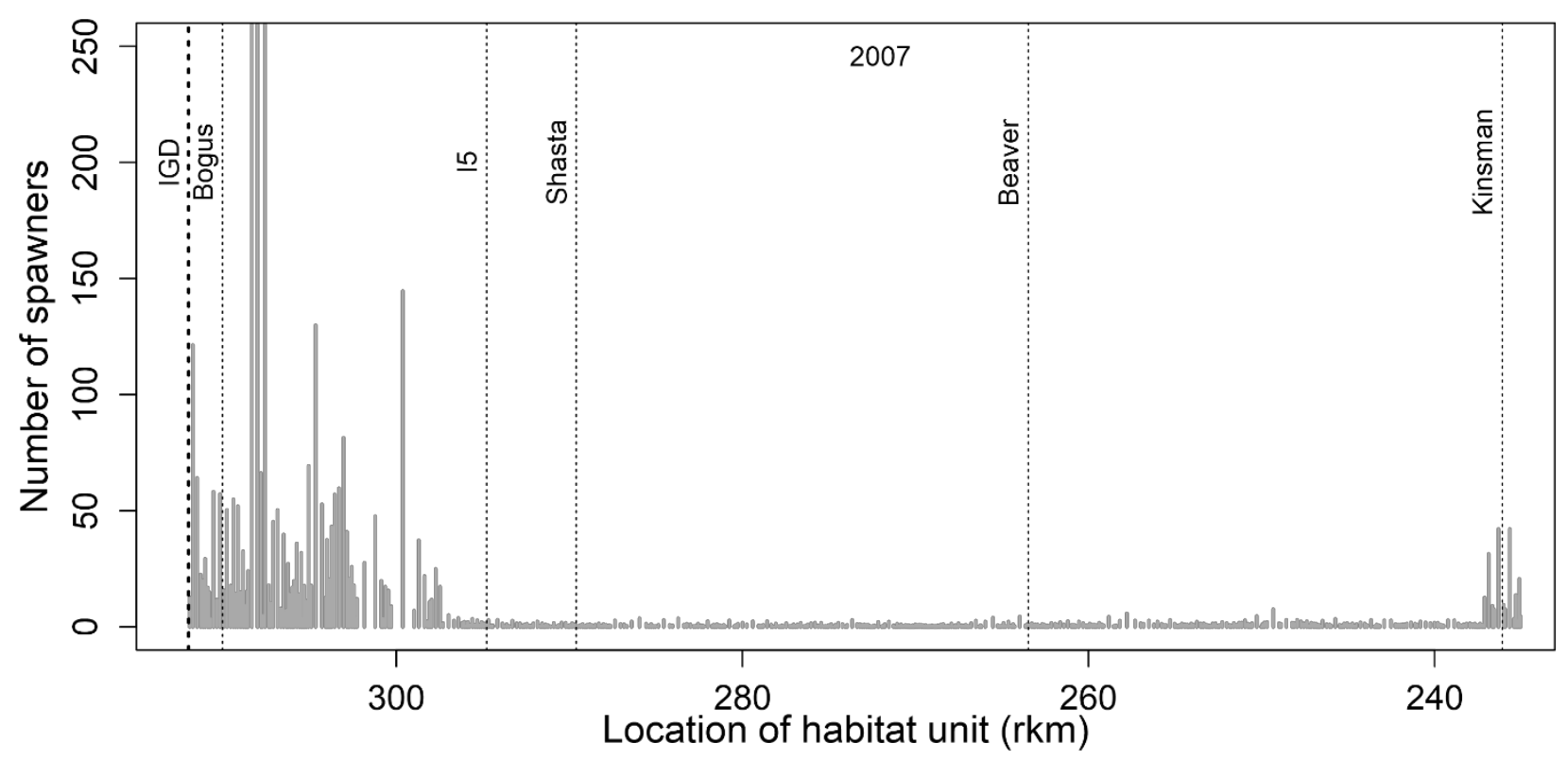

Figure 5.3. Graph showing spatial distribution of spawning female fall Chinook salmon used as inputs to the Stream Salmonid Simulator model for the Klamath River, California, brood year 2007. Beaver, Beaver Creek; Bogus, Bogus Creek; 15, 15 trap near Interstate 5 bridge; IGD, Iron Gate Dam; Kinsman, Kinsman fish trap; Shasta, Shasta River; rkm, river kilometer.

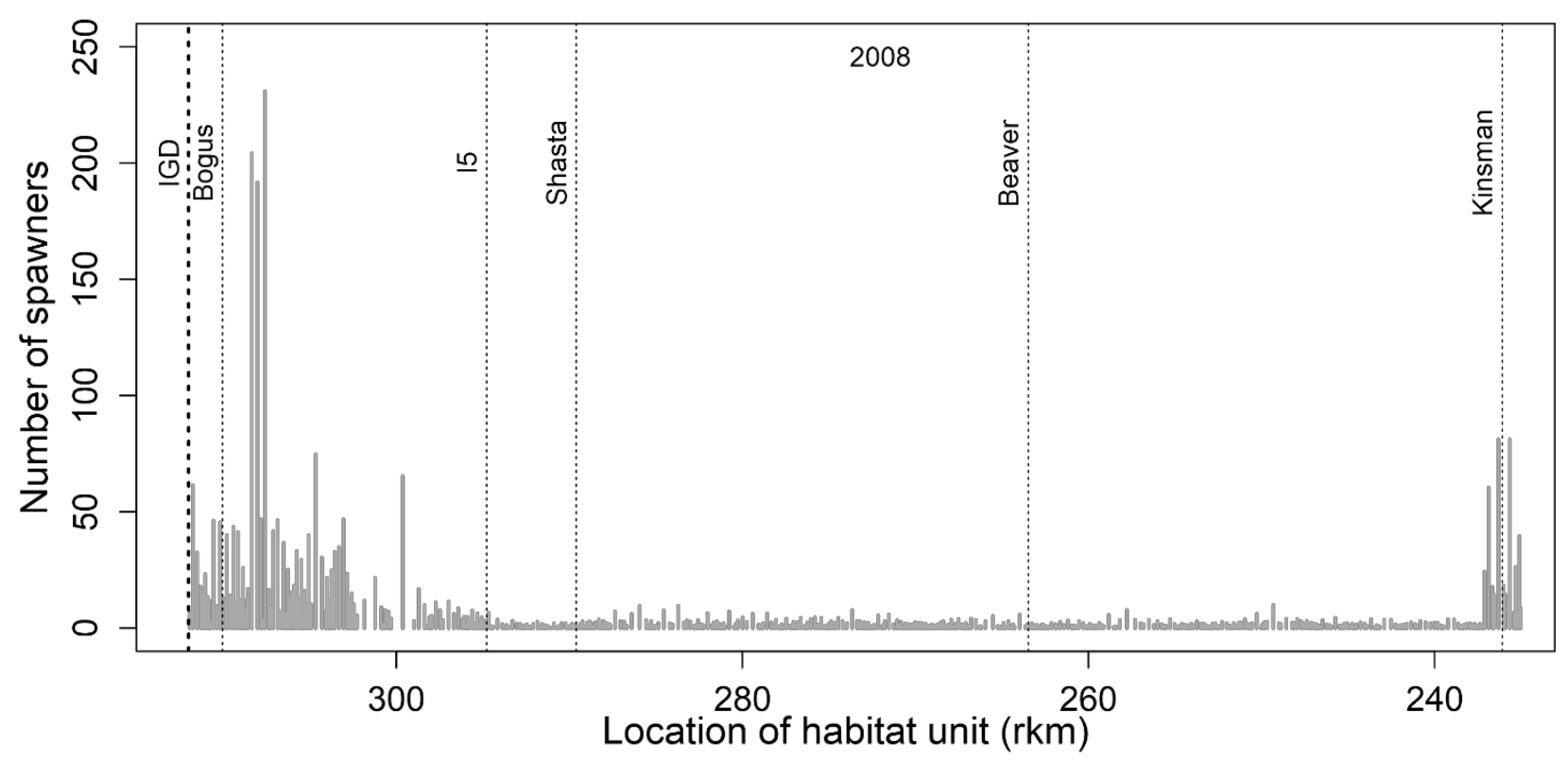

Figure 5.4. Graph showing spatial distribution of spawning female fall Chinook salmon used as inputs to the Stream Salmonid Simulator model for the Klamath River, California, brood year 2008. Beaver, Beaver Creek; Bogus, Bogus Creek; I5, 15 trap near Interstate 5 bridge; IGD, Iron Gate Dam; Kinsman, Kinsman fish trap; Shasta, Shasta River; rkm, river kilometer. 


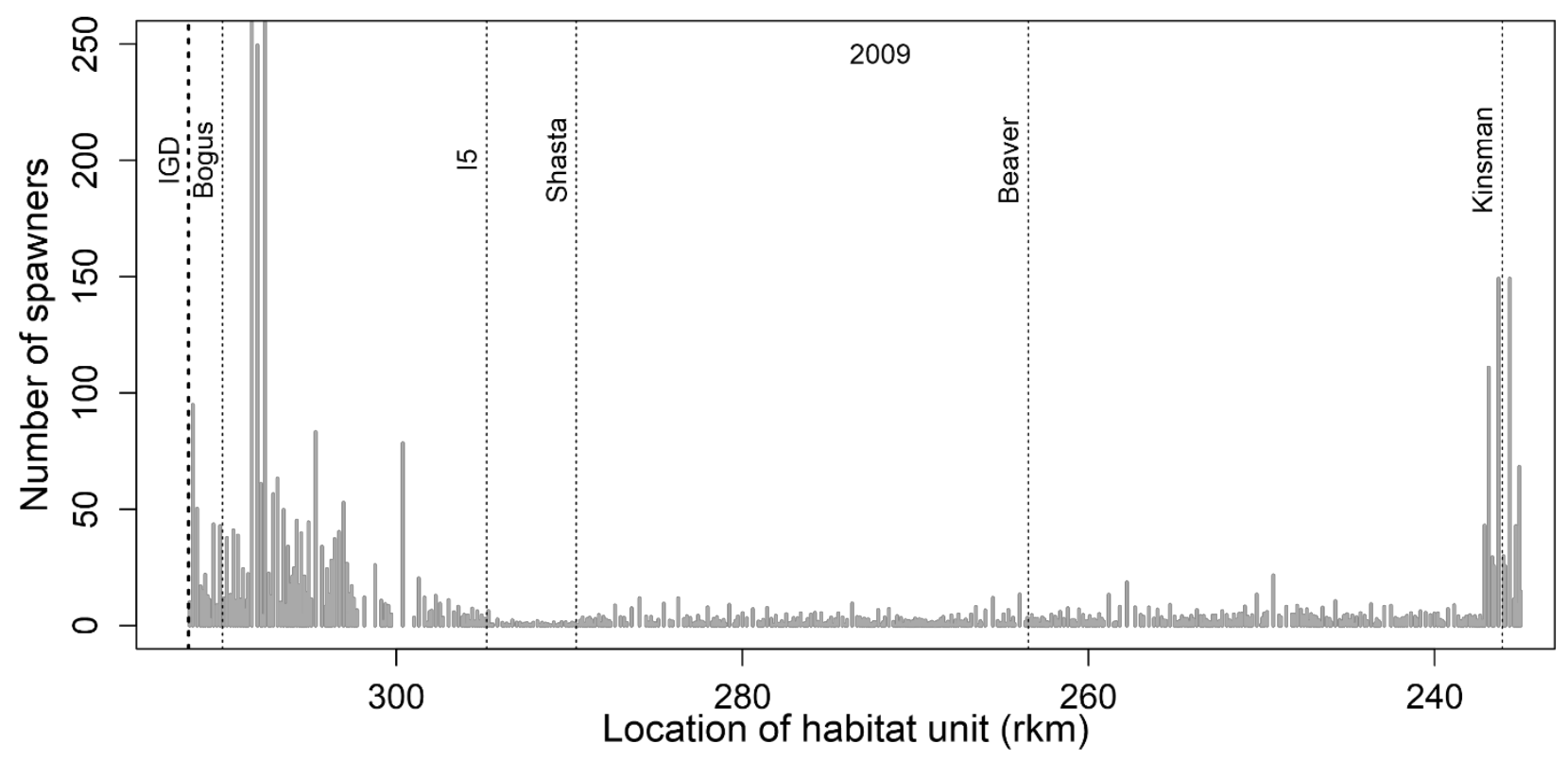

Figure 5.5. Graph showing spatial distribution of spawning female fall Chinook salmon used as inputs to the Stream Salmonid Simulator model for the Klamath River, California, brood year 2009. Beaver, Beaver Creek; Bogus, Bogus Creek; 15, 15 trap near Interstate 5 bridge; IGD, Iron Gate Dam; Kinsman, Kinsman fish trap; Shasta, Shasta River; rkm, river kilometer.

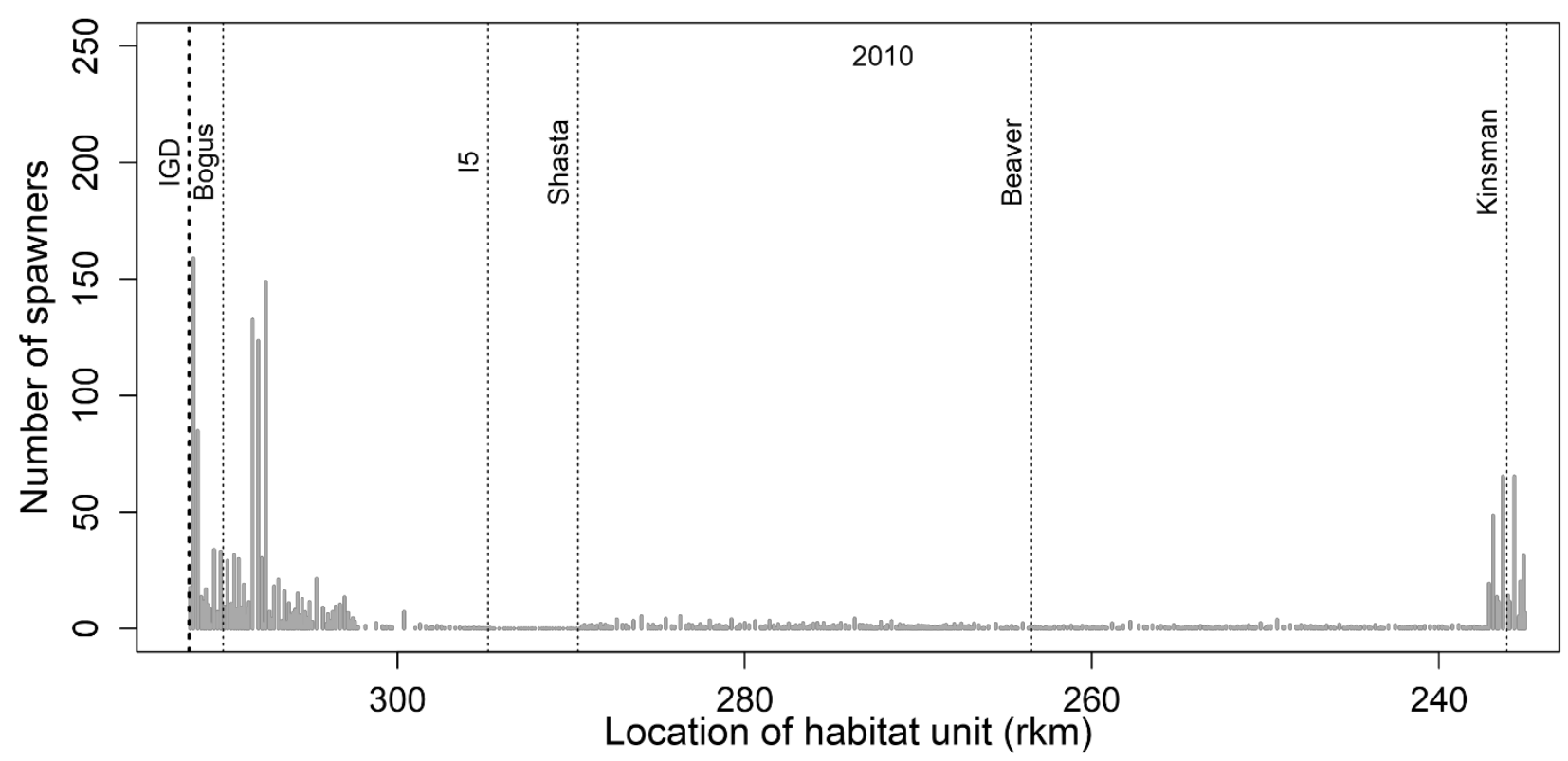

Figure 5.6. Graph showing spatial distribution of spawning female fall Chinook salmon used as inputs to the Stream Salmonid Simulator model for the Klamath River, California, brood year 2010. Beaver, Beaver Creek; Bogus, Bogus Creek; I5, 15 trap near Interstate 5 bridge; IGD, Iron Gate Dam; Kinsman, Kinsman fish trap; Shasta, Shasta River; rkm, river kilometer. 


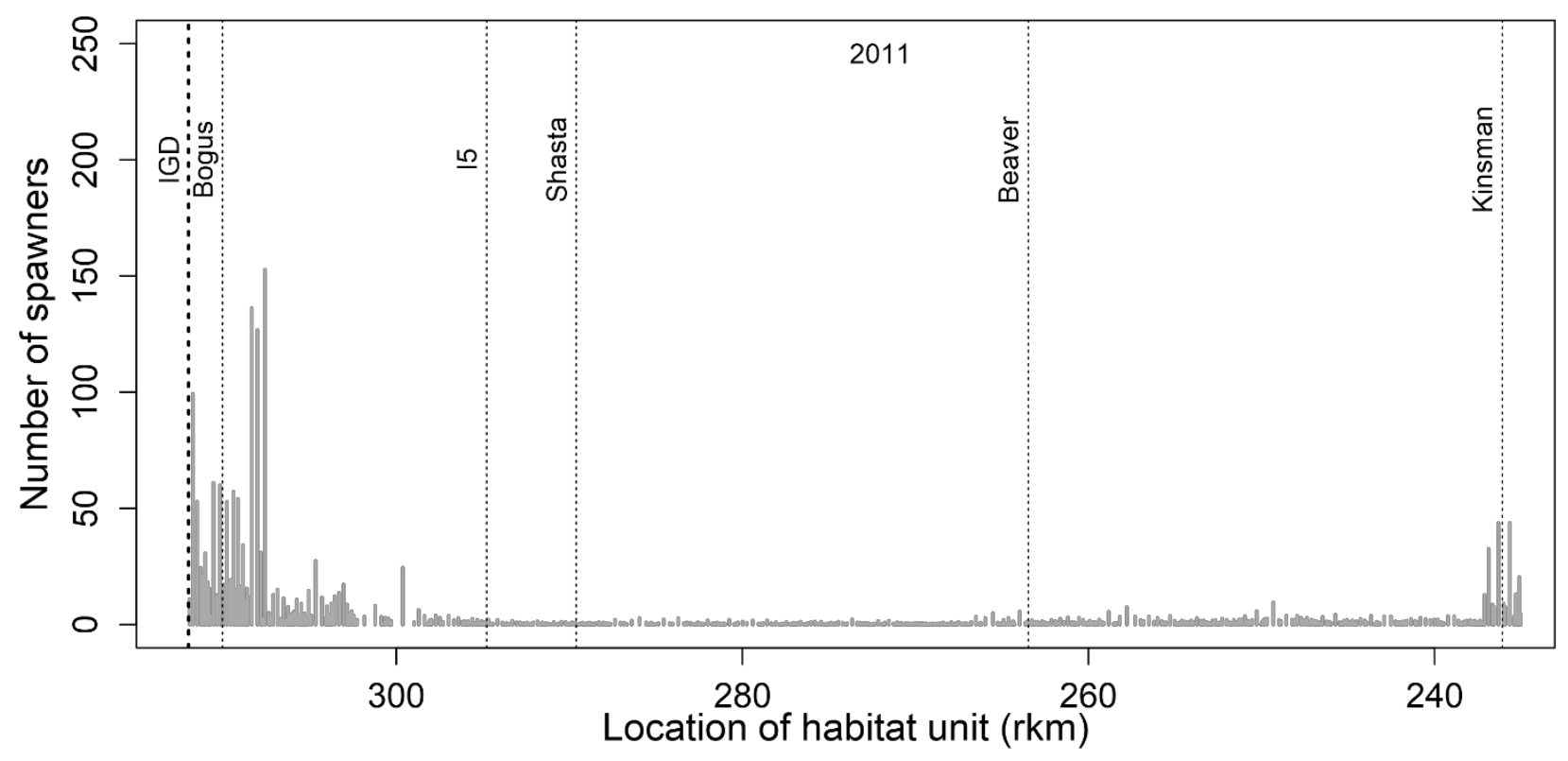

Figure 5.7. Graph showing spatial distribution of spawning female fall Chinook salmon used as inputs to the Stream Salmonid Simulator model for the Klamath River, California, brood year 2011. Beaver, Beaver Creek; Bogus, Bogus Creek; 15 , 15 trap near Interstate 5 bridge; IGD, Iron Gate Dam; Kinsman, Kinsman fish trap; Shasta, Shasta River; rkm, river kilometer.

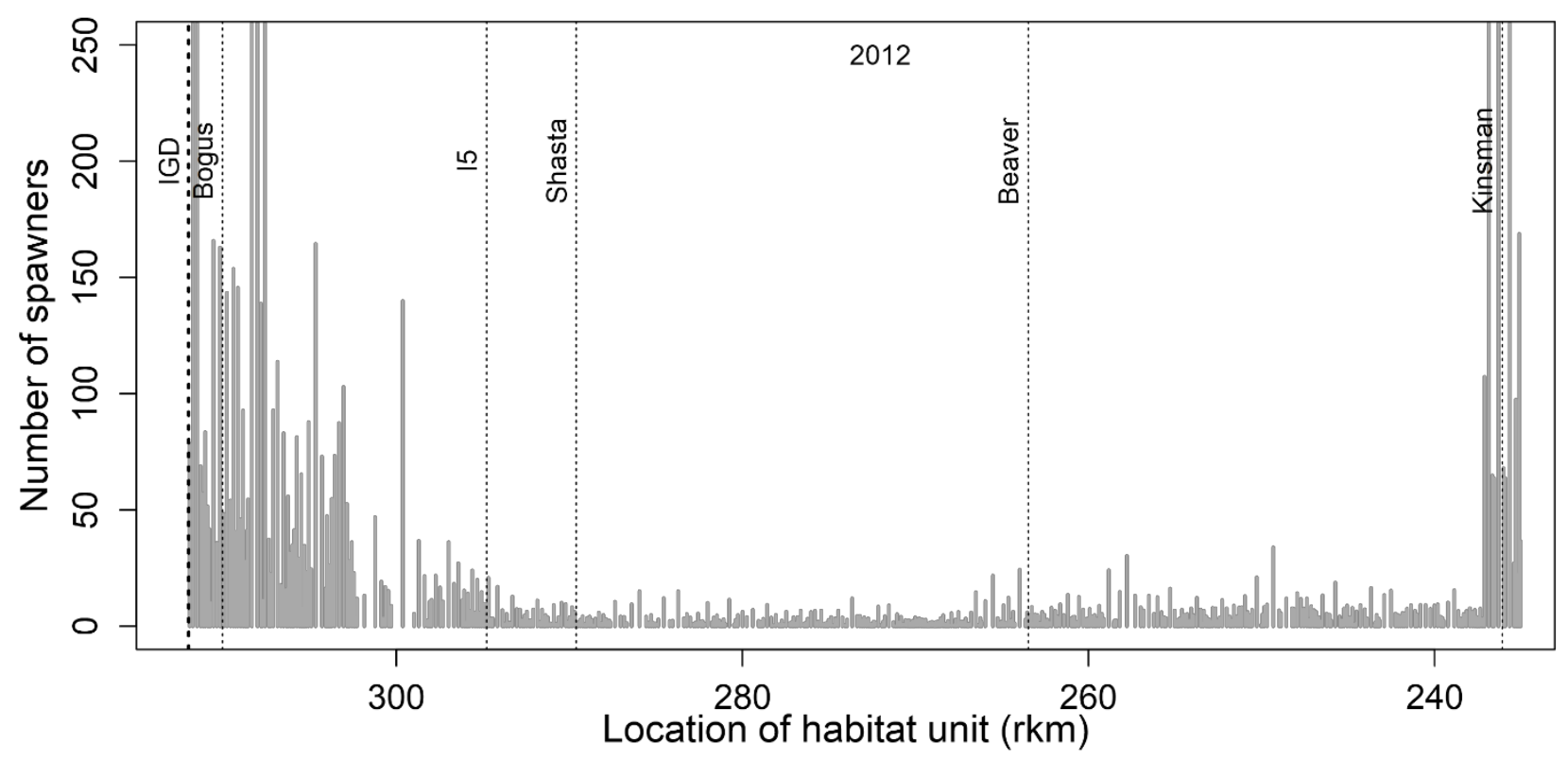

Figure 5.8. Graph showing spatial distribution of spawning female fall Chinook salmon used as inputs into the Stream Salmonid Simulator model for the Klamath River, California, brood year 2012. Beaver, Beaver Creek; Bogus, Bogus Creek; I5, 15 trap near Interstate 5 bridge; IGD, Iron Gate Dam; Kinsman, Kinsman fish trap; Shasta, Shasta River; rkm, river kilometer. 


\section{Appendix 6. Tributary Fish Inputs}

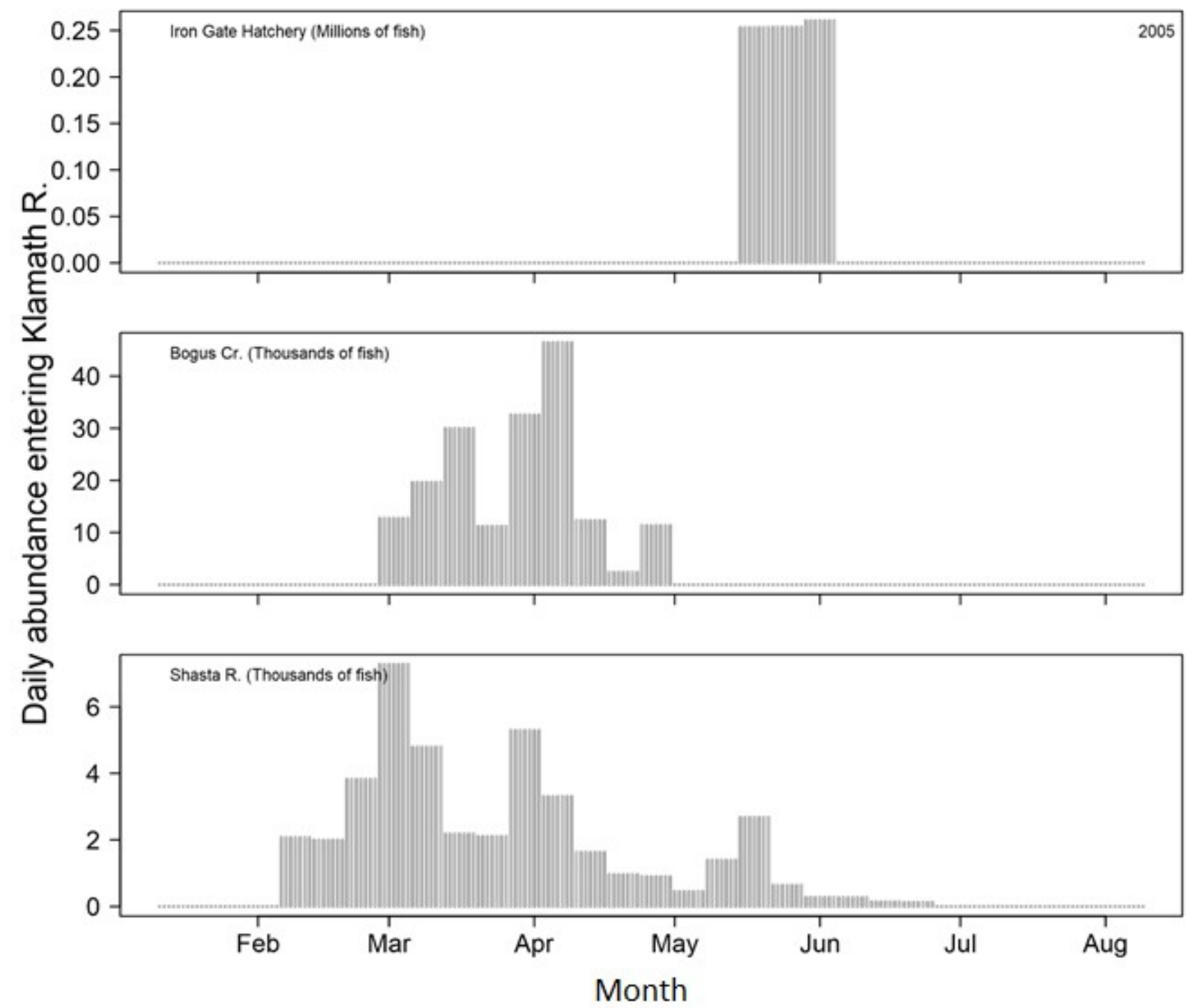

Figure 6.1. Graphs showing temporal distribution of fall Chinook salmon entering from each of the major tributaries that were used as inputs to Stream Salmonid Simulator model for the Klamath River, California, migration year 2005. Cr., Creek; R., River. 


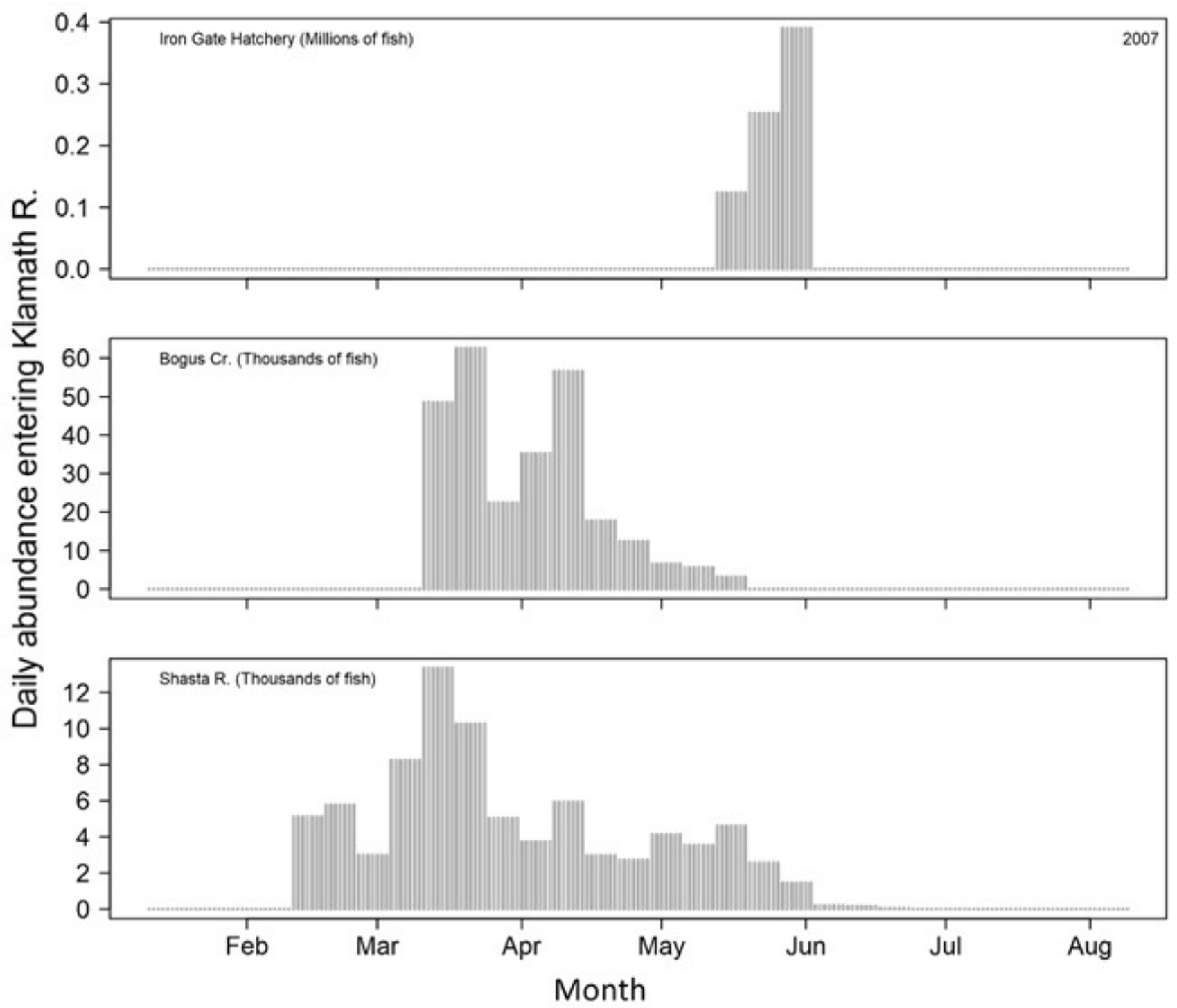

Figure 6.2. Graphs showing temporal distribution of fall Chinook salmon entering from each of the major tributaries that were used as inputs to the Stream Salmonid Simulator model for the Klamath River, California, migration year 2007. Cr., Creek; R., River. 


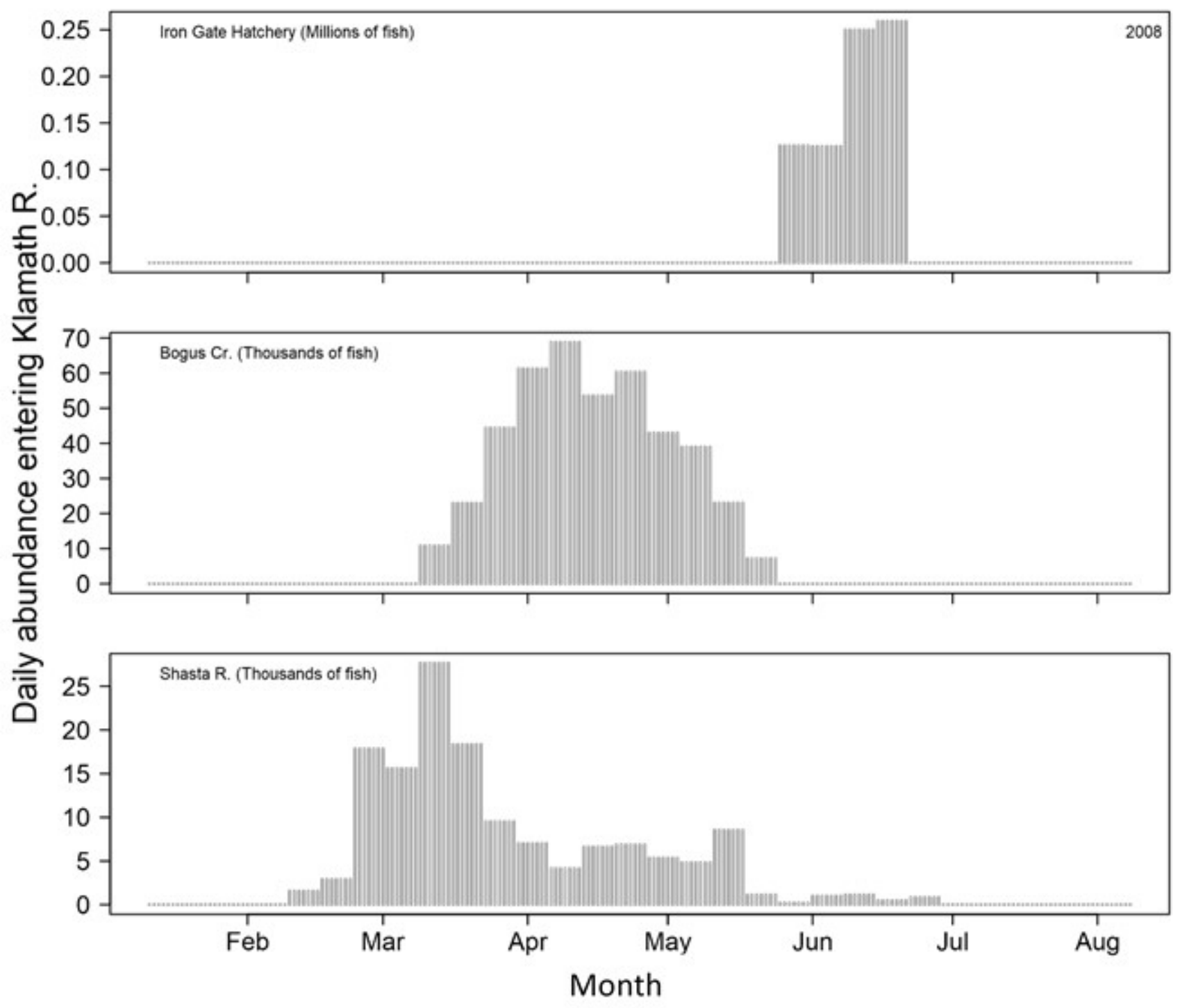

Figure 6.3. Graphs showing temporal distribution of fall Chinook salmon entering from each of the major tributaries that were used as inputs to the Stream Salmonid Simulator model for the Klamath River, California, migration year 2008. Cr., Creek; R., River. 


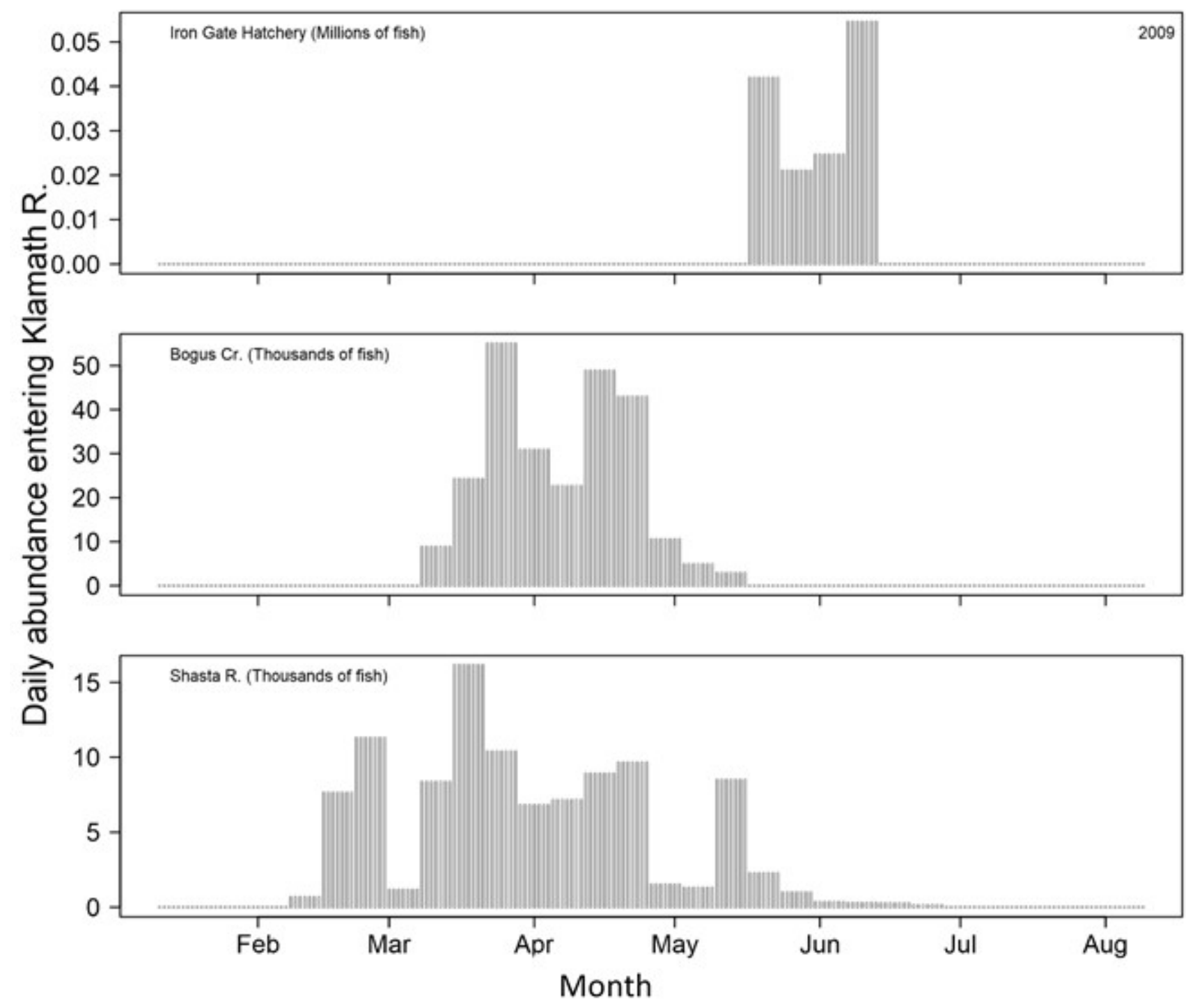

Figure 6.4. Graphs showing temporal distribution of fall Chinook salmon entering from each of the major tributaries that were used as inputs to the Stream Salmonid Simulator model for the Klamath River, California, migration year 2009. Cr., Creek; R., River. 


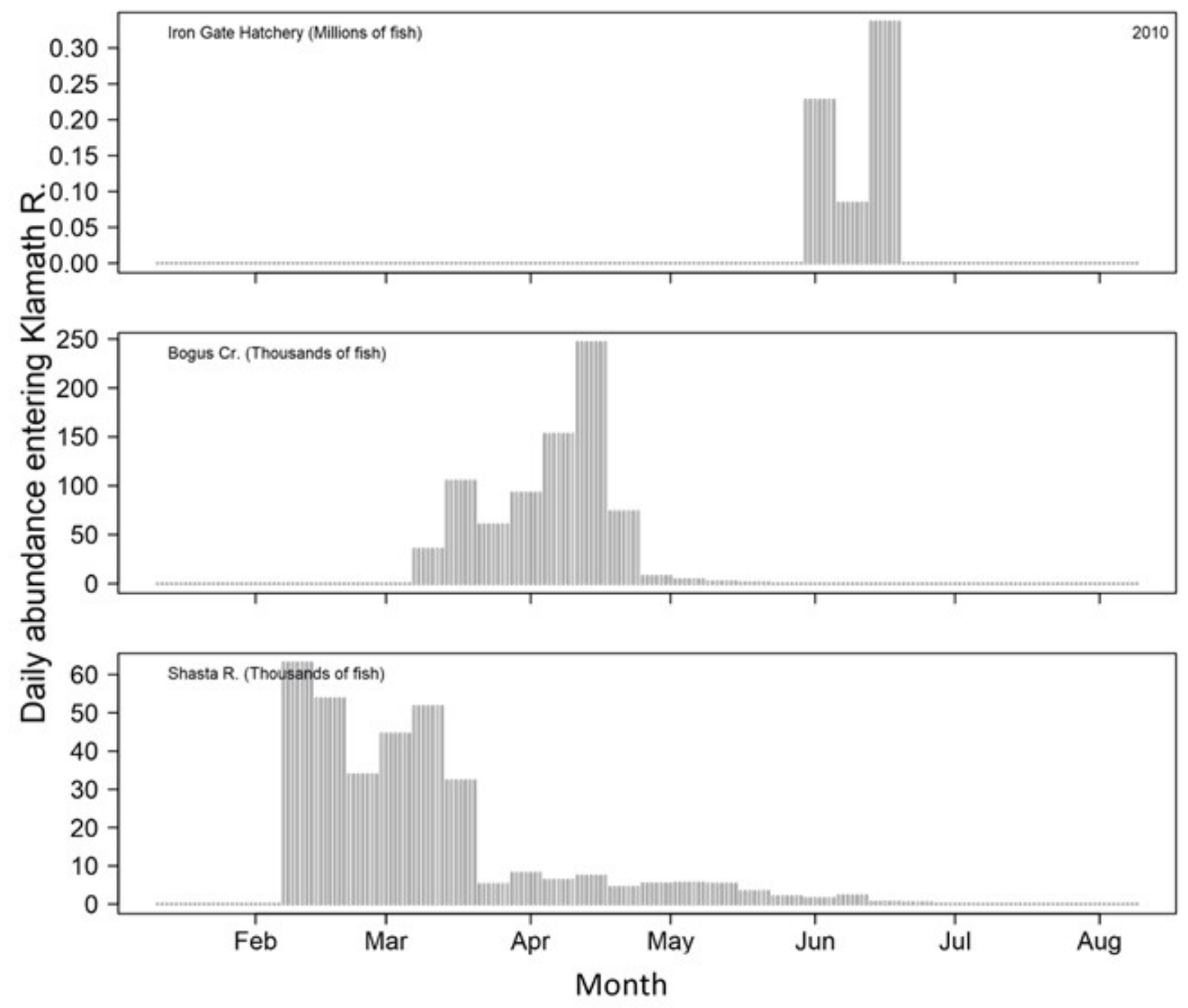

Figure 6.5. Graphs showing temporal distribution of fall Chinook salmon entering from each of the major tributaries that were used as inputs io the Stream Salmonid Simulator model for the Klamath River, California, migration year 2010. Cr., Creek; R., River. 


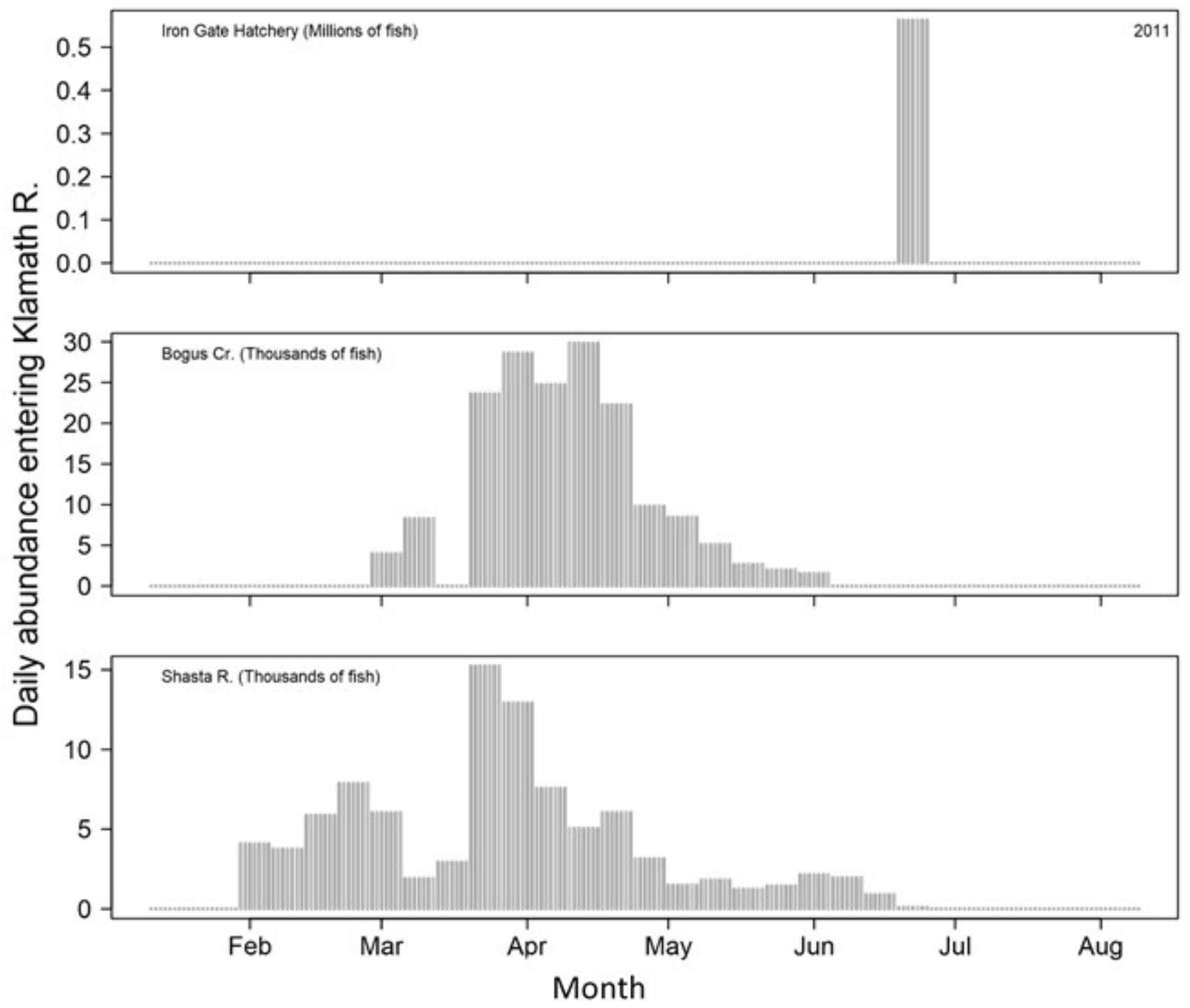

Figure 6.6. Graphs showing temporal distribution of fall Chinook salmon entering from each of the major tributaries that were used as inputs to the Stream Salmonid Simulator model for the Klamath River, California, migration year 2011. Cr., Creek; R., River. 


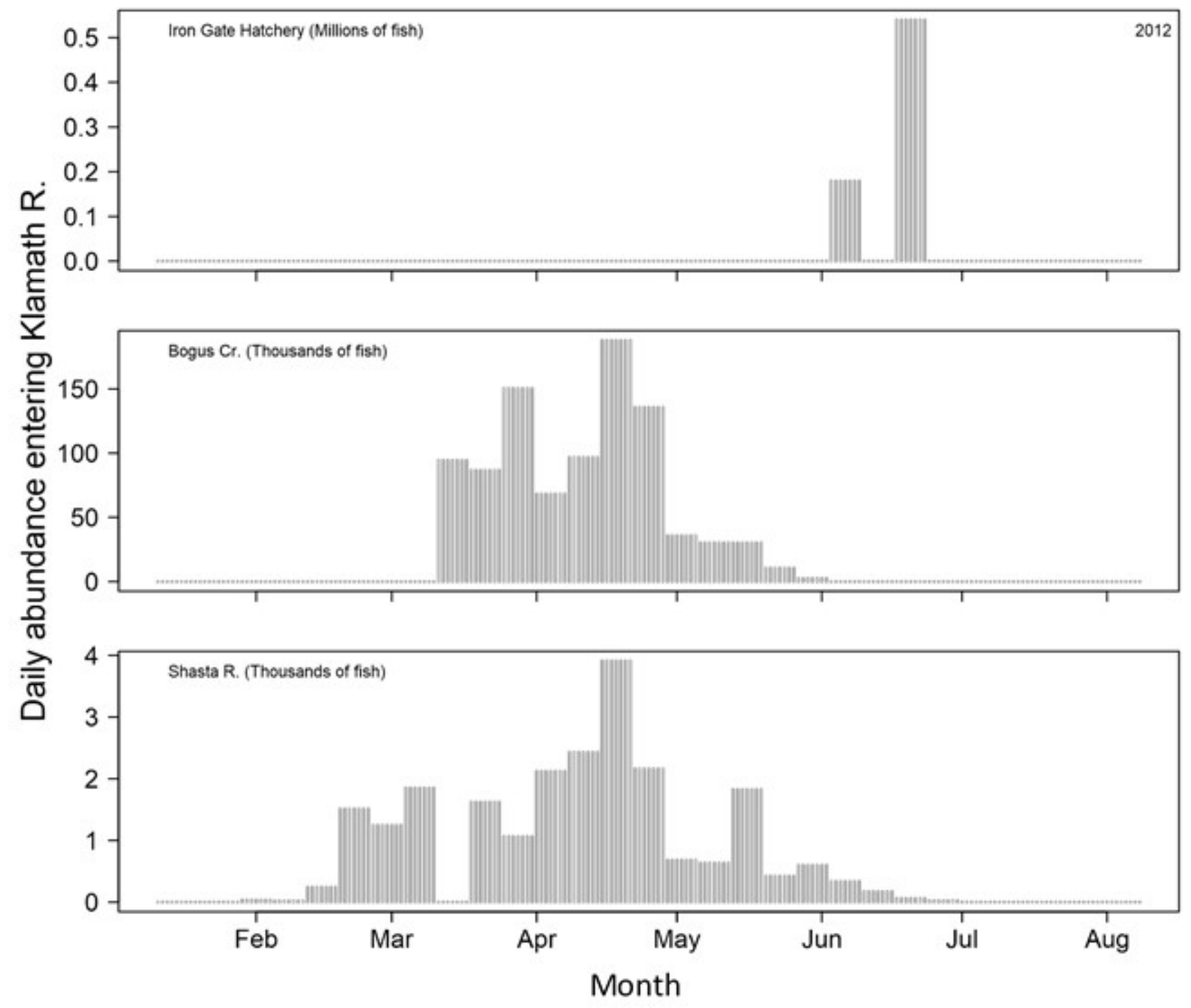

Figure 6.7. Graphs showing temporal distribution of fall Chinook salmon entering from each of the major tributaries that were used as inputs to the Stream Salmonid Simulator model for the Klamath River, California, migration year 2012. Cr., Creek; R., River. 


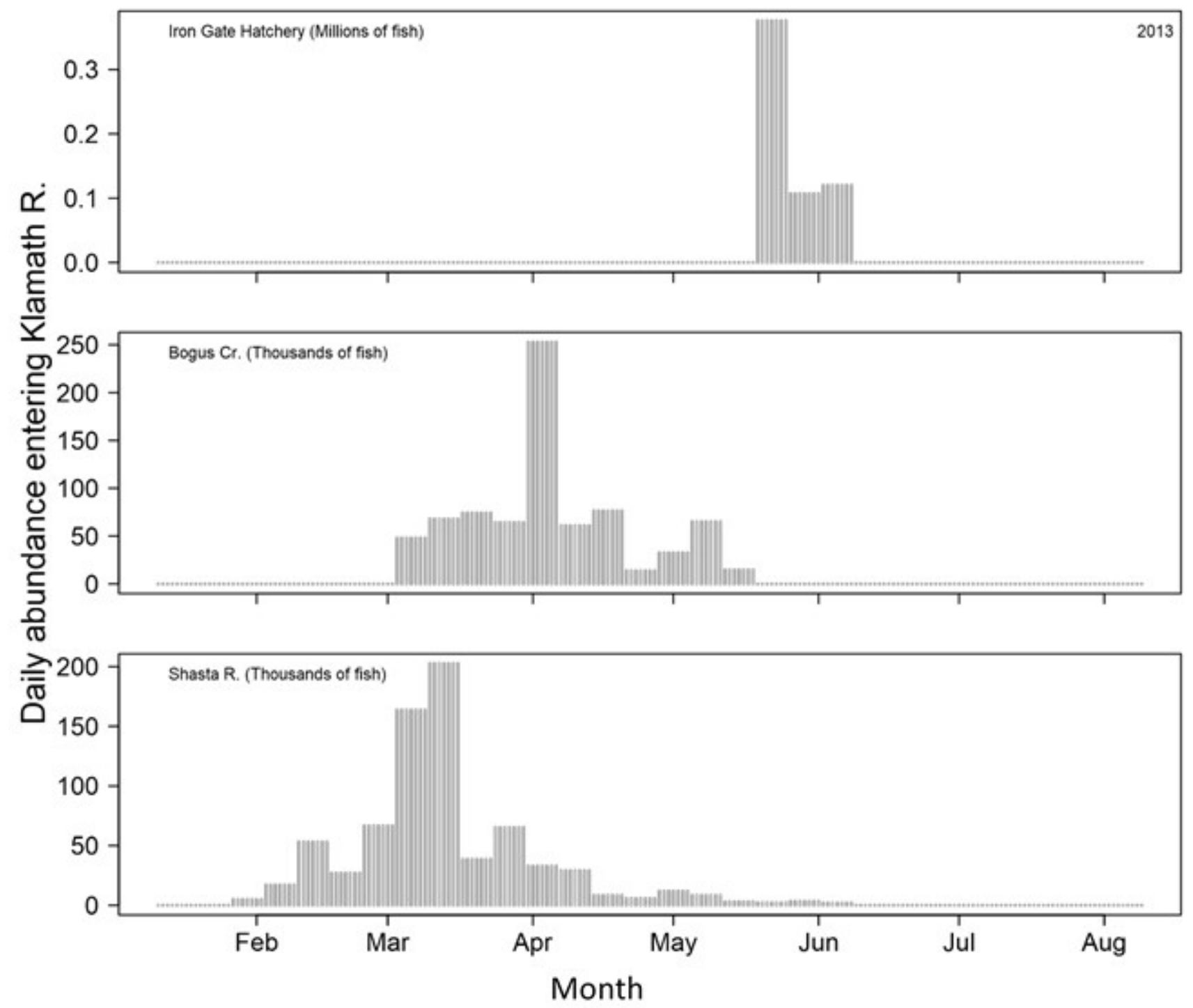

Figure 6.8. Graphs showing temporal distribution of fall Chinook salmon entering from each of the major tributaries that were used as inputs to the Stream Salmonid Simulator model for the Klamath River, California, migration year 2013. Cr., Creek; R., River. 


\section{Appendix 7. Temporal Emergence Distributions}
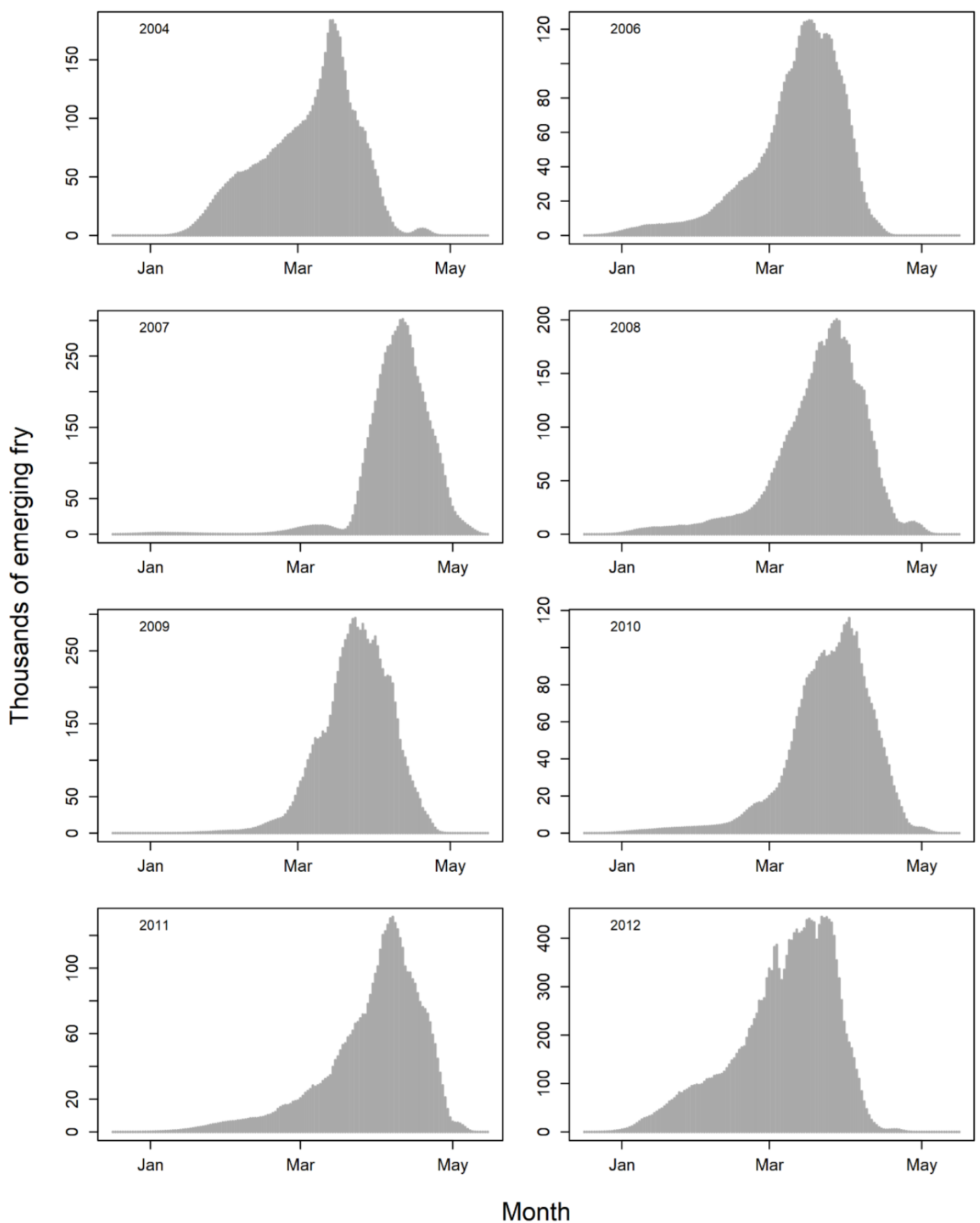

Figure 7.1. Graphs showing temporal distribution, by brood year, of fall Chinook salmon emerging in the mainstem Klamath River, California, 2004 and 2006-12. 

Publishing support provided by the U.S. Geological Survey Science Publishing Network, Tacoma Publishing Service Center

For more information concerning the research in this report, contact the Director, Western Fisheries Research Center

U.S. Geological Survey 6505 NE 65th Street

Seattle, Washington 98115-5016

https://www.usgs.gov/centers/wfrc 


\section{$\frac{2}{2}$}

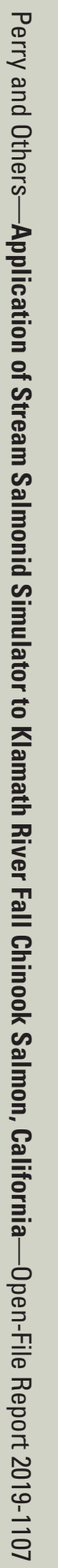

